\title{
ALTERNATIVE INVESTMENTS: A PRIMER FOR INVESTMENT PROFESSIONALS
}

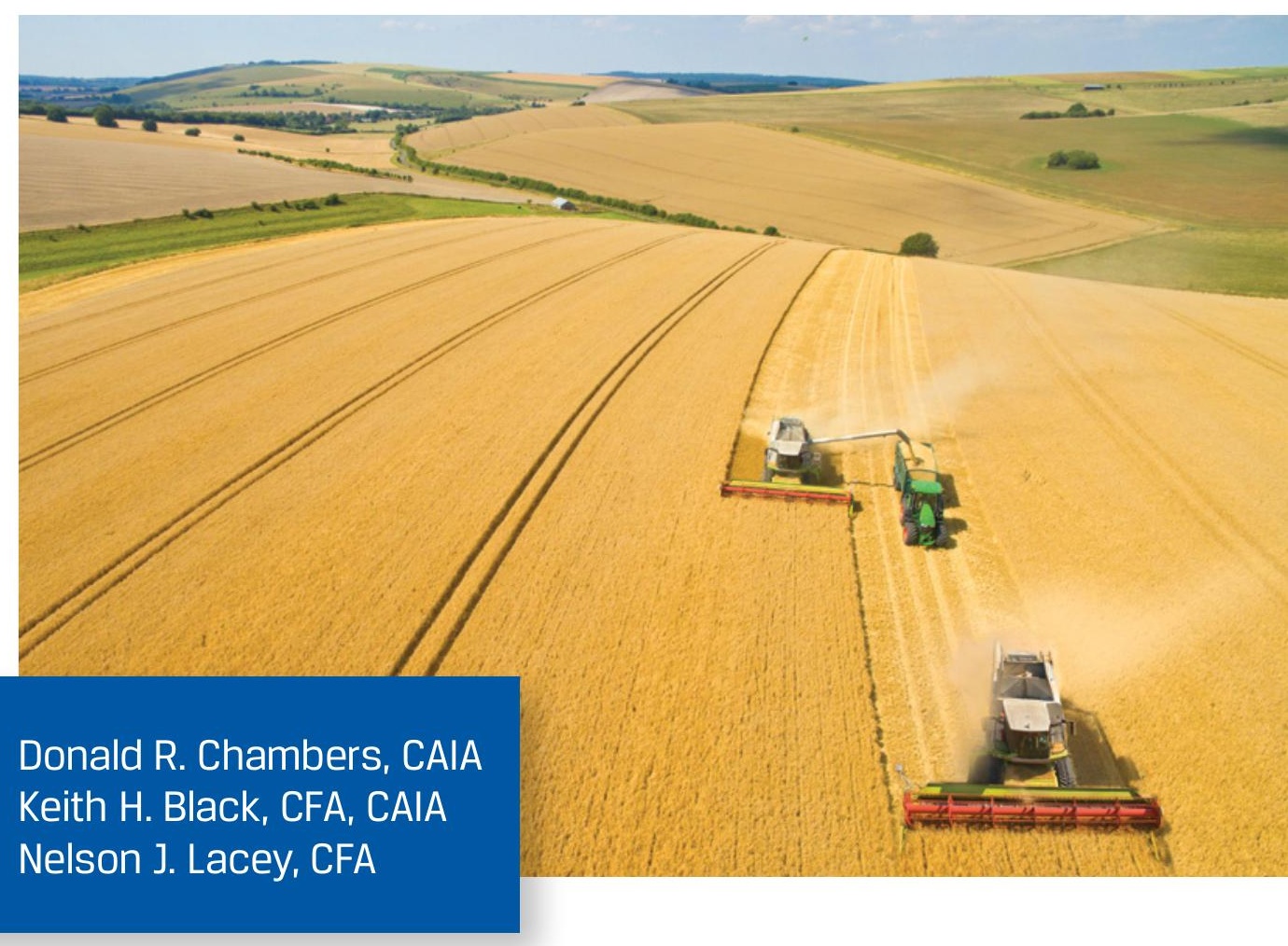




\section{ALTERNATIVE INVESTMENTS: A PRIMER FOR INVESTMENT PROFESSIONALS}

Donald R. Chambers, CAIA Keith H. Black, CFA, CAIA Nelson J. Lacey, CFA 


\section{Statement of Purpose}

\section{CFA Institute Research Foundation is a not-for-profit organization established to promote the development and dissemination of relevant research for investment practitioners worldwide.}

Neither CFA Institute Research Foundation, CFA Institute, nor the publication's editorial staff is responsible for facts and opinions presented in this publication. This publication reflects the views of the author(s) and does not represent the official views of CFA Institute Research Foundation.

$\mathrm{CFA}^{\circledR}$, Chartered Financial Analyst ${ }^{\circledR}$, and GIPS ${ }^{\circledR}$ are just a few of the trademarks owned by CFA Institute. To view a list of CFA Institute trademarks and the Guide for the Use of CFA Institute Marks, please visit our website at www.cfainstitute.org.

(C) 2018 CAIA Association. All rights reserved.

No part of this publication may be reproduced, stored in a retrieval system, or transmitted, in any form or by any means, electronic, mechanical, photocopying, recording, or otherwise, without the prior written permission of the copyright holder.

This publication is designed to provide accurate and authoritative information in regard to the subject matter covered. It is sold with the understanding that the publisher is not engaged in rendering legal, accounting, or other professional service. If legal advice or other expert assistance is required, the services of a competent professional should be sought.

Cover Image Photo Credit: Juice Images/Getty Images

ISBN 978-1-944960-37-7

\section{Editorial Staff}

Mary-Kate Hines Assistant Editor
Tracy Dinning Senior Publishing Technology Specialist 


\section{Contents}

1. Introduction to Alternative Investing.

1.1. Purpose and Scope of the Book........................................... 1

1.2. An Overview of Alternative Assets ...................................... 1

1.3. The History of Alternative Investing ....................................... 4

1.4. Distinguishing Characteristics and Methods of Alternative Investing............................................................. 5

1.5. Two Pillars of Portfolio Oversight ......................................... 6

1.6. Informational Market Efficiency and "Efficient Inefficiency".... $\quad 8$

1.7. An Overview of the Purposes of Investing in Alternative Investments..................................................... 10

1.8. Organization of the Book ..................................................... 11

2. The Ecology of Alternative Investments ......................................... 12

2.1. Key Contributors ........................................................... 12

2.2. Key Elements ................................................................. 13

2.3. Key Regulations .............................................................. 15

2.4. Other Key Terms .................................................................. 17

3. Introduction to Hedge Funds ........................................................ 20

3.1. Overview of Hedge Funds ............................................... 20

3.2. Hedge Fund Structures ..................................................... 21

3.3. Hedge Fund Liquidity...................................................... 22

3.4. Terms of Hedge Fund Investments.................................... 24

3.5. The Option-Like Nature and Moral Hazard of

3.6. Hedge Fund Governance ............................................... 27

3.7. Conclusion ..................................................................... 27

4. Hedge Fund Strategies ................................................................ 28

4.1. Classifying Hedge Fund Strategies ................................... 28

4.2. Macro and Managed Futures Funds ................................. $\quad 29$

4.3. Event-Driven Hedge Funds .............................................. $\quad 31$

4.4. Relative-Value Funds ........................................................ 33

4.5. Equity Hedge Funds ...................................................... $\quad 36$

4.6. Conclusion........................................................................ 37

5. Accessing Multiple Hedge Fund Strategies .................................... 39

5.1. Diversifying across Managers and Strategies...................... $\quad 39$

5.2. Due Diligence on Numerous Single Hedge Funds .............. 40

5.3. Direct Investment Program ............................................... 41

5.4. Netting of Incentive Fees.................................................... 42 
5.5. Funds of Funds ............................................................. 42

5.6. Multistrategy Funds.......................................................... 44

5.7. Hedge Fund Indexes ....................................................... 45

5.8. Conclusion....................................................................... 47

6. Introduction to Real Assets.............................................................. 48

6.1. The Key Attributes of Real Assets....................................... 48

6.2. Accessing Real Assets.................................................... $\quad 50$

6.3. Valuation of Real Assets and Smoothed Returns................. $\quad 52$

6.4. Raw Land ....................................................................... 52

6.5. Farmland ................................................................... 53

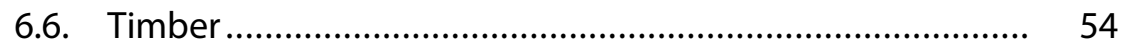

6.7. Infrastructure ........................................................... 55

6.8. Intellectual Property........................................................ 56

6.9. Conclusion ....................................................................... 57

7. Real Assets: Commodities ............................................................ 59

7.1. Overview of Commodity Investing .................................... 59

7.2. Potential Benefits of Commodities ...................................... 62

7.3. Economic Reasoning regarding Expected Commodity

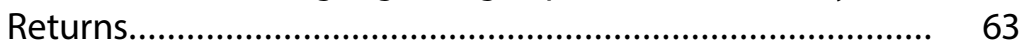

7.4. Empirical Evidence regarding Commodity Returns............. 65

7.5. Access to Commodities with Futures Contracts .................. 66

7.6. Commodity Returns and Sources of Returns....................... 68

8. Private Real Estate and Illiquidity................................................. $\quad 70$

8.1. Types of Private Real Estate................................................ $\quad 70$

8.2. The Challenges of Illiquidity ............................................. $\quad 71$

8.3. Real Estate Valuation Approaches ...................................... $\quad 72$

8.4. Relying on Appraisals and Market Values.......................... $\quad 72$

8.5. Economic Reasoning and the Illiquidity of Private Investments...................................................................... 74

8.6. Internal Rate of Return as a Measure of Performance ......... $\quad 75$

8.7. Aspects That Discourage Allocations to Private Real Estate ... 77

8.8. Pooled Access to Direct Real Estate.................................... 78

8.9. Conclusion........................................................................ 79

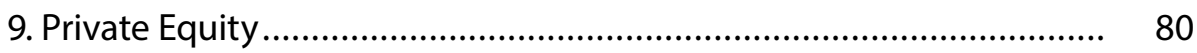

9.1. Types of Private Equity ...................................................... 80

9.2. Equity Types of Private Equity: Venture Capital and

9.3. Debt Securities as Private Equity ...................................... 82

9.4. Access to Private Equity .................................................... 82

9.5. Private Equity Fund Fees ................................................. 86 
9.6. Challenges of Internal Rate of Return ................................ 87

9.7. The J-Curve ..................................................................... 88

9.8. Key Sources of Returns from Private Equity........................ 90

9.9. Conclusion .................................................................... 91

10. Financial Derivatives .................................................................... 92

10.1. Motivations for Using Derivatives ................................... 92

10.2. Options, Futures, Forwards, and Swaps........................... 94

10.3. Structured Products ..................................................... 95

10.4. Volatility Products........................................................... 96

10.5. The Greeks.................................................................. 100

10.6. Aggregation of Risks to the Portfolio Level ..................... 101

10.7. Conclusion .................................................................... 102

11. Structured Products: Collateralized Debt Obligations .................... 103

11.1. Overview ...................................................................... 103

11.2. How the Market for CDOs Developed.............................. 103

11.3. The Creation of Tranches ................................................. 105

11.4. Example of the Waterfall of Cash Flows ............................ 108

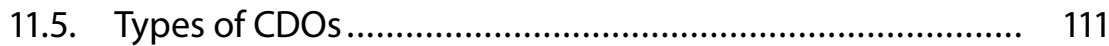

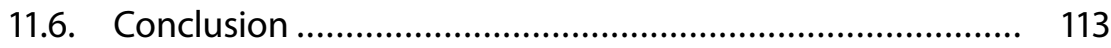

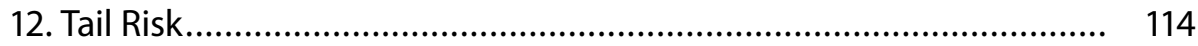

12.1. Tail Risk from Investment Strategy ..................................... 114

12.2. Tail Risk from Investment Strategy Drift .......................... 115

12.3. Tail Risk from Rogue Traders .......................................... 118

12.4. Tail Risk from Operational Failure .................................... 119

12.5. Tail Risk from Fraud.................................................... 120

12.6. Conclusion..................................................................... 121

13. Investment Process, Operations, and Due Diligence ...................... 122

13.1. The Investment Process .................................................... 122

13.2. Noninvestment Operations ............................................ 123

13.3. Due Diligence ............................................................... 124

13.4. Risk Alert and Due Diligence Regulations regarding Alternative Investments................................................. 127

13.5. Industry Trends in Due Diligence..................................... 128

13.6. Warning Indicators or Awareness Signals ......................... 131

13.7. Compliance Programs and the Code of Ethics ................... 132

13.8. Conclusion ...................................................................... 134

14. Measurement and Management of Returns and Risk ..................... 135

14.1. Measurement of Return and Return Distributions .............. 135

14.2. Measures of Risk ........................................................... 140

14.3. Measures of Return vs. Risk............................................ 143 
14.4. Investment Monitoring and Gaming ............................... 145

14.5. Conclusion ................................................................... 146

15. Benchmarking, Return Expectations, and Performance Attribution ... 147

15.1. Alpha, Beta, and Models of Expected Return.................... 147

15.2. Benchmarking Absolute Return Investments.................... 150

15.3. Benchmarking and Performance Attribution .................... 151

15.4. Single-Factor Asset Pricing and Performance Attribution.. 152

15.5. Multifactor Asset Pricing and Performance Attribution ..... 153

15.6. Benchmarking Relative Return Assets with Peer Groups.... 156

15.7. Conclusion ................................................................... 156

16. Portfolio Construction and Management..................................... 157

16.1. The 60/40 and Liability-Driven Asset Allocation Models .... 157

16.2. Naive or $1 / N$ Diversification ............................................. 158

16.3. Risk Budgeting Portfolio Selection Models ...................... 159

16.4. Risk Parity .................................................................. 161

16.5. Moment Optimization Approaches.................................. 163

16.6. Conclusion ...................................................................... 165

17. The Case for Investing in Alternatives ............................................ 166

17.1. Valuation Levels of Traditional Assets............................... 166

17.2. The Endowment Model ................................................. 167

17.3. Enhanced Efficient Frontiers: Broader Beta Coverage......... 168

17.4. Enhanced Efficient Frontiers: Alpha, Illiquidity, and Skill-Based Premiums.................................................... 169

17.5. Conclusion ..................................................................... 170 


\section{Introduction to Alternative Investing}

This chapter describes the purpose and scope of this book and provides an overview of institutional-quality alternative investing.

\subsection{Purpose and Scope of the Book}

This book provides an overview of alternative investments for an institutional asset allocator or overseer of a portfolio containing both traditional and alternative assets. The reader is assumed to have broad knowledge of investing in general and of traditional asset allocation in particular. The book is designed to build on the reader's existing knowledge by providing essential information about the characteristics, challenges, and purposes of alternative assets in the context of a well-diversified institutional portfolio.

This book does not emphasize legal or fiduciary responsibilities of trustees and asset allocators. A Primer for Investment Trustees by Jeffrey V. Bailey, CFA, and Thomas M. Richards, CFA, provides an excellent treatment of those issues. ${ }^{1}$ This book emphasizes the financial economics of alternative assets in a well-diversified institutional portfolio.

Asset allocation decisions are the dominant determinant of long-term portfolio returns. Thus, the decisions of an institutional asset allocator regarding how much, if any, of the portfolio to allocate to alternative assets and how to weight the various types of alternative assets are among the most important determinants of portfolio return. Such decisions should be based on careful analysis and regular monitoring.

\subsection{An Overview of Alternative Assets}

There is no uniform definition of alternative investments or definitive list of alternative assets. This book examines the four broadest and largest categories of alternative investments: hedge funds, private equity, real assets, and structured products.

Hedge Funds. Hedge funds are investment pools that are typically privately organized and invest principally in publicly traded assets, such as stocks, bonds, currencies, commodities, and derivatives. Unlike traditional investment pools, such as mutual funds, they can use leverage and sell short. They are typically available only to qualified institutional and wealthy individual investors. Their essential characteristic is that the fund implements

Jeffrey V. Bailey and Thomas M. Richards, A Primer for Investment Trustees, 2nd ed. (CFA Institute Research Foundation, October 2017): www.cfapubs.org/doi/pdf/10.2470/rf.v2017.n3.1. 
skill-based trading strategies that generate returns with substantially different risk and return exposures than those found in traditional investment pools. The hedge fund category includes managed futures funds. Separately managed accounts with hedge fund-like characteristics are also classified into the hedge fund category.

Private Equity. Private equity includes the common stock, preferred stock, and (in some cases) debt securities of firms that are not publicly traded and that have equity-like risk exposures. The category includes venture capital (nascent enterprises) and leveraged buyouts (established publicly traded firms being taken private) as well as risky debt (including mezzanine debt and distressed debt).

Real Assets. Real assets such as real estate, infrastructure, commodities, and natural resources have value as a direct claim on productivity, in contrast to financial assets that are claims on cash flows. Real assets also include such tangible assets as land, farmland, and timber. Not all real assets are tangible. A large and growing sector of real assets is intellectual property, such as patents and copyrights.

Structured Products. Structured products are created using financial engineering and generate return, risk, taxation, or other opportunities that are not directly available from static long-only positions in traditional investments. Structured products include various types of collateralized debt obligations and other derivatives.

The lines between traditional and alternative assets are not distinct and universal. Exhibit 1.1 depicts the four categories of alternative investments (in the left column), assets that are sometimes listed as alternative and sometimes as traditional (in the middle column), and assets viewed only as traditional (in the right column). Exhibit 1.1 illustrates the lack of clear lines between alternative and traditional assets. This book will focus on those assets that are most universally described as alternative.

Note in Exhibit 1.1 that hedge fund-like returns are now available in publicly traded "liquid alternative" mutual funds. Not all hedge fund strategies are available through these public mutual funds-that is, the US Investment Company Act of 1940 (the '40 Act) or undertakings for collective investment in transferable securities (UCITS) funds-because of regulatory limits on leverage and illiquidity. ${ }^{2}$ Some alternative strategies are available through closed-end fund structures.

${ }^{2}$ So-called '40 Act (1940 Act) funds are those regulated under the US Investment Company Act of 1940 . 
Exhibit 1.1. The Blurred Lines between Traditional and Alternative Assets

\begin{tabular}{lcc}
\hline Alternative Investments & $\begin{array}{c}\text { Assets Often Characterized as } \\
\text { Traditional or Alternative }\end{array}$ & Analogous Traditional Assets \\
\hline Hedge funds & $\begin{array}{c}\text { Liquid alternative mutual funds } \\
\text { Private equity }\end{array}$ & Ordinary mutual funds \\
Real assets & $\begin{array}{c}\text { Poldings } \\
\text { Public real estate and public } \\
\text { equities of corporations with } \\
\text { performance dominated by stable } \\
\text { positions in real assets }\end{array}$ & $\begin{array}{c}\text { Public equities with performance } \\
\text { dominated by managerial } \\
\text { decisions }\end{array}$ \\
$\begin{array}{c}\text { Complex structured } \\
\text { products }\end{array}$ & $\begin{array}{c}\text { Simple structured products offer- } \\
\text { ing relatively stable and common } \\
\text { risk and return characteristics }\end{array}$ & $\begin{array}{c}\text { Simple derivatives used as part } \\
\text { of a strategy with stable risk }\end{array}$ \\
\hline
\end{tabular}

Private equity is inherently illiquid and generally is not available via '40 Act funds or other public investment pools, although several closed-end structures, such as business development corporations, hold private equity as their underlying investments. Closed-end fund structures can use modest amounts of leverage and illiquid underlying assets because the investment companies are not generally required to redeem investor shares on demand.

Among the category of real assets, real estate is most often characterized as both traditional and alternative, especially when the real estate is accessed through publicly traded investment pools, such as REITs. Some publicly traded common stocks with value primarily derived from holdings of natural resources, such as oil reserves, mineral rights, or land, are often classified as real assets. However, to the extent that a stock's value is driven by such managerial expertise as marketing, trading of assets, or technology, the returns will not be dominated by the values of underlying real assets and the stocks are more appropriately viewed as traditional operating firms.

Finally, the category of structured products varies from rather simple financial derivatives that are often classified as traditional investments (e.g., credit default swaps) to more complex derivatives, such as collateralized loan obligations, that are usually classified as alternative. Furthermore, some financial derivatives, such as futures contracts and forward contracts, can be used to replicate traditional asset exposures and thus clearly fall within the realm of traditional investing. For example, a portfolio of cash plus a long position in a forward contract on an equity index synthetically replicates a long position in the equities underlying the index. The decision of whether to 
classify a structured product as an alternative investment should be based on the extent to which the product offers nontraditional risk and return exposures and requires investment management methods that differ markedly from traditional investment management methods.

\subsection{The History of Alternative Investing}

Exhibit 1.2 provides a general overview of the investments typically held by institutional investors, such as banks, pension funds, endowments, and insurance companies. Throughout much of the 20th century, each institutionalquality investment was evaluated primarily on the safety of its income and principal and tended to be evaluated on a standalone basis.

Beginning in the 1950s and 1960s, modern portfolio theory established the mechanics and advantages of diversification. Modern portfolio theory evaluates risk on a portfolio basis - formalizing the idea that much risk can be diversified away by holding a broad mix of available investments. In the 1980s and 1990s, the appropriateness of investments for institutions increasingly began to be evaluated on a portfolio basis.

The change in law and investment practices from evaluating risk on a standalone basis to a portfolio-as-a-whole basis is evidenced in Exhibit 1.2. Beginning in the 1980s, inclusion of such assets as small-company stocks, low-quality corporate bonds, and alternative assets became more common among financial institutions, such as banks, pension funds, endowment funds, and insurance companies. Evaluated on a standalone basis, many of these assets had little or no reliable income and were at risk for loss of the original investment. But when held in a portfolio, these relatively high-risk investments could lower the total risk of the portfolio because of their ability to provide improved diversification.

Exhibit 1.2 indicates that institutions usually did not hold common stocks prior to 1920. Most institutional-quality investments more than 100 years ago were those secured by tangible assets, such as real estate.

\section{Exhibit 1.2. Popular Institutional-Quality Assets, 1890-Present}

$1890-1920$

$1920-1950$

$1950-1980$

1980-Present
Government debt, real estate, mortgages, preferred stock

Add high-quality corporate bonds, domestic equities, agricultural debt

Add average-quality corporate bonds, international equities

Add high-yield debt, small stocks, structured products, private equity, hedge funds, real assets 
The underlying determinants of economic performance are changing with increasing speed. Take, for instance, the composition of the major stocks in the United States. In early 1901, the Dow Jones Industrial Average included 12 stocks: 10 common stocks and 2 preferred stocks. Almost every 1 of the 12 stocks was a commodity producer (copper, sugar, tobacco, paper, lead, coal, leather, rubber, and steel).

By 1960, the top seven Fortune 500 firms in the United States were General Motors Company, Standard Oil Company of New Jersey, Ford Motor Company, General Electric, US Steel, Mobil, and Gulf Oil. The list included three oil companies and one steel company as well as two automobile manufacturers and one electrical equipment manufacturer.

Now, top firms are dominated by services and technology. The top five US firms in terms of market capitalization in 2017 were Apple Inc., Alphabet Inc., Microsoft Corporation, Amazon.com Inc., and Berkshire Hathaway Inc. Facebook, Inc., was seventh in mid-2017 with a market capitalization of more than $\$ 500$ billion, no inventory, and fixed assets of only about $\$ 10$ billion. Clearly, it is inappropriate to view traditional assets as solid and alternative assets as speculative.

Investments closely tied to commodity prices are now viewed as alternative investments, yet they constituted most of the industrial investment opportunities in 1900. With such dramatic and increasingly rapid changes in the components of an economy, it is difficult to conclude that conservative and traditional investment principles consist of maintaining unchanging investment practices. In effect, sticking with traditional investment practices moves the risk and diversification of a portfolio through time as the economy underlying the investment opportunities shifts. It is only through a dynamic approach to asset allocation (one that adjusts to new industries, securities, and other economic changes) that a portfolio can maintain good principles of diversification.

\subsection{Distinguishing Characteristics and Methods of Alternative Investing}

To distinguish the characteristics and methods of alternative investment, we first define traditional investments. All other forms of investing are then considered alternatives.

In the 21st-century economic environment, traditional investments include equities (corporate stocks) and investment-grade bonds (debt issued by corporations and governments) anywhere in the world. Alternatives, then, have three primary attributes, any one of which can cause an asset to be classified as an alternative asset: 
1. The investment's returns are driven by exposures to underlying assets with nontraditional cash flows-that is, cash flows that are not highly correlated with those that underlie traditional stocks and bonds. Although traditional investments are funded by cash flows from traditional operating firms, many alternative investments are funded by cash flows from nontraditional sources, such as venture capital, life insurance contracts, art, and farmland, which causes their returns to be less correlated with the returns of the overall stock market.

2. The investment's returns are driven by complex trading strategies involving leverage, short sales, and financial derivatives, causing unusual risk exposures, even though the underlying asset might be traditional securities.

3. The investment's returns are structured to generate nontraditional payouts, such as those found in collateralized debt obligations.

In all three cases, the returns of the investment do not mimic the returns of traditional asset classes (stocks and bonds), and therefore, they require specialized methods of analysis. Notably, traditional investments are analyzed and managed using established methods that are commonly found in investment textbooks but that are not sufficient for managing and analyzing alternative investments.

Some alternative assets offer absolute returns. Absolute returns have little or no correlation with the returns of major asset classes. Examples of absolute return strategies include market-neutral strategies and arbitrage strategies. Virtually all traditional assets and strategies are relative return products that feature returns that are substantially correlated with those of traditional equities and bonds.

Alternative assets have risk characteristics, or exposures, that differ from those experienced with a relatively stable portfolio of long-only positions in ordinary stocks and bonds. Alternative investments include strategies that offer unusual risk and return characteristics even when the securities underlying the strategy are traditional stocks and bonds. The unusual risk-and-return characteristics of the strategy may be generated from trading that causes large shifts in risk through time and from positions, such as short sales, that generate these nontraditional risk exposures.

\subsection{Two Pillars of Portfolio Oversight}

For well over a century, the set of assets deemed to be traditional institutional assets has changed dramatically. Institutional asset allocators must decide which new asset classes to include in their portfolio and when to include those 
assets. Conservatism in allocating to "new" institutional investment classes runs the risk of missing out on improved diversification and perhaps missing stellar early first-mover returns (i.e., high returns resulting from institutions pouring new money into an asset class that is increasingly viewed as appropriate for them to hold). Boldly venturing into asset classes not previously included in institutional portfolios, however, also exposes institutions to the risk of underperforming their more conservative peers.

The challenge for an asset allocator is to decide, as skillfully as possible, which new types of assets to include in a portfolio and which to exclude. How does an asset allocator make such difficult decisions? This section advocates relying on two pillars: empirical analysis and economic reasoning.

Empirical Analysis. Investment literature abounds with the warning that "future investment performance" should not "be inferred from or predicted based on past investment performance." This overstated warning is taken from Rule 156 of the Securities Act of 1933. In practice, much-if not most - investment analysis and decision making is ultimately based on historical risk-adjusted performance. For example, it is primarily through historical observation that investment managers have developed opinions on the extent to which investing in equities differs from investing in bonds.

Conversely, the empirical methods used to explain the performance of alternative investments tend not to be as reliable and developed as the methods used to evaluate the performance of traditional investments. Investment professionals seek investments that can enhance the risk-adjusted performance of portfolios. But with huge numbers of potential strategies and powerful tools to backtest performance, it is risky to select opportunities based on empirical analysis alone.

Economic Reasoning. Historical analysis alone is insufficient for determining asset allocations. For example, in the late 1990s the performance of US growth stocks was consistently and strongly positive. The outstanding performance of this sector generated historic returns with extremely attractive statistics: high mean returns, very low variances, and virtually no major drawdowns. The empirical results were so uniformly positive that they led one major investment research firm specializing in mutual funds to assign attractively low risk ratings to many US equity growth funds - then came the dot-com crash of 2000, plummeting values of growth stock funds resulting in huge losses for their investors.

Asset allocators should be especially skeptical of empirical analyses that sound too good to be true. Economic reasoning can serve as a reliable reality check. Does solid theory support the contention that a particular asset 
will enhance risk-adjusted return? The addition of any new type of alternative investment into a well-diversified portfolio should be supported to the greatest extent possible by both empirics and theory.

Philosophers debate the two major approaches to the acquisition of knowledge (i.e., theory and empirics). Rationalists argue that most or all knowledge is ultimately understood through reasoning. Empiricists argue that reasoning is derived from observation. We would argue that both are needed.

The crux of the matter is that best practices in asset allocation include striving to make decisions that are supported both by sound analysis of past performance data and careful economic reasoning. The goal throughout this book is to provide reliable information for asset allocators overseeing portfolios with both traditional and alternative assets. This goal is executed with a balance of the two pillars of portfolio oversight: (1) evidence based on objective analysis of empirical data and (2) evidence based on an unbiased assessment of theories based on economic reasoning.

\subsection{Informational Market Efficiency and "Efficient Inefficiency"}

Informational market efficiency is the state in which available information regarding an asset is quickly reflected in the market price of that asset. For example, when does the market price of an equity, such as Tesla Inc., reflect the value of a new technology developed by the firm? Does the stock price rise when the idea for the technology is created, when the idea is made public, when the firm announces an investment to deploy the technology, when the technology is proved reliable, or when the firm begins receiving cash flows from sales based on the technology? In an informationally efficient market, the answer is that the stock price reflects all the potential cash flows (with their attendant probabilities) the moment the information regarding those cash flows is revealed to the marketplace. In such a market, no investor is able to consistently earn superior risk-adjusted returns based on available information because the information is instantaneously reflected in market prices when it becomes publicly available.

A clear understanding of the implications of informational market efficiency is vital to being an effective overseer of assets. Informational market efficiency is a theoretical idea rather than a precise description of actual markets. No asset market is perfectly efficient. Actual markets should be viewed as exhibiting different degrees of market efficiency. But perfect informational market efficiency is an important ideal. By way of analogy, consider a plumb line. A plumb line is a vertical line usually approximated using a suspended 
string with a weight attached at the bottom. A plumb line can be an important method of ensuring that a building's framework is well constructed. In practice, however, no building has perfect beams or walls. Similarly, the concept of perfect informational market efficiency creates a reference point against which market inefficiencies can be identified and convergence of prices to the theoretically correct price can be forecast. In other words, perfect market efficiency is how financial analysts predict how prices should behave-allowing traders to identify mispriced assets and estimate their expected return and risk. Skill-based traders base their trades on perceived departures of actual asset prices from their informationally efficient prices.

How do empirics and economic reasoning inform asset allocators and their overseers about the extent to which various asset markets are informationally efficient? Markets tend to be more informationally efficient to the extent that they (1) are being traded by large numbers of well-informed and financially sound traders competing for profits, (2) contain securities for which substantial amounts of reliable information are made broadly and quickly available, and (3) are subject to minimal transactions costs, taxes, and other impediments to trade. Large markets in modern economies with institutions that support free trade tend to exhibit high degrees of informational market efficiency.

The proposition that markets are perfectly efficient, however, is inconsistent with rational investing. If markets were perfectly efficient, no trader could earn a superior profit by performing analyses using available information. Traders performing analysis would be wasting their valuable time processing information and would lose wealth relative to buy-and-hold investors because of higher trading levels and increased transaction costs. In the long run, it is only the existence of market inefficiencies that incentivizes analysts to use available information to drive markets toward efficiency.

Markets become more efficient through the efforts of speculators and other traders to identify mispriced assets and then to buy those perceived as being underpriced and to sell those perceived as being overpriced. The best traders are successful; they gain wealth, and they exert increasing influence on the pricing of assets.

The enigma as to how markets can become efficient when efficiency destroys the incentives to process information has led to the proposition that markets tend toward being efficiently inefficient. ${ }^{3}$ The idea is that each market tends toward its own equilibrium degree of informational inefficiency, where that amount of inefficiency balances the marginal costs of additional skillbased trading with the marginal revenues from the skill-based trades.

\footnotetext{
${ }^{3}$ See, for example, Lasse Heje Pedersen, Efficiently Inefficient (Princeton, NJ: Princeton University Press, 2015).
} 
Empirical studies of market efficiency reveal varying degrees of it in different markets and tend to indicate that opportunities to exploit particular inefficiencies decay through time as each successful trading strategy attracts additional capital. The empirical and theoretical evidence together suggest that skill-based trading strategies are more likely to be successful when (1) executed by the most skilled traders in any market and (2) executed in relatively new markets or with relatively new securities that have less competition among skill-based traders.

\subsection{An Overview of the Purposes of Investing in Alternative Investments}

Chapter 17 summarizes the case for investing in alternative assets based on the foundations provided in the first 16 chapters. This section briefly introduces the three key reasons for adding alternative investments to a well-diversified portfolio.

Reduced Risk through Diversification. A primary goal of alternative investing is to reduce risk through diversification. One of the distinguishing features of most alternative investments is their lack of correlation with the major traditional asset classes of public equities and public fixed-income assets. A portfolio containing a variety of alternative assets may offer reduced risk without a proportionate reduction in expected return.

Enhanced Return through Alpha. A second major goal of alternative investing is to enhance the expected return of a portfolio by acquiring alternative assets that offer reasonable expectations of alpha-that is, superior risk-adjusted returns. Alternative investing has a track record of offering opportunities, including hedge funds and private equity, that can enhance the risk-adjusted returns of well-diversified portfolios through alpha.

Avoiding Obsolescence. As evidenced by Exhibit 1.1, the asset classes viewed as appropriate for institutional investing have changed dramatically over time. Surely the asset classes used in the future for institutional investing will continue to change. Institutional investors who are the last adopters of institutional-quality asset classes will find that prices have adjusted such that the greatest opportunities have been missed. In Chapter 9, Private Equity, we will discuss the first mover advantage, whereby the first institutions to find attractive investment opportunities will derive the greatest benefits. In a similar vein, those asset allocators who are last to embrace change are likely to yield disappointing performance. In other words, those who wait to invest in alternative assets until they have become so mainstream as to be considered to be traditional may suffer from a "last-mover disadvantage." 


\subsection{Organization of the Book}

Chapter 2 provides a brief overview of the alternative investing environment. Chapters 3 through 11 describe the four broad categories of alternative investments in greater detail in the following order: hedge funds, real assets, private equity, and financial derivatives and structured products. Chapters 12 through 16 cover topics related to risk measurement, risk management, portfolio benchmarking, and portfolio construction. Chapter 17 details the case for including alternative assets in institutional portfolios. 


\section{The Ecology of Alternative Investments}

Alternative investments are supported by a host of service providers and governed by regulations, which differ by location. This chapter includes a glossary of terms defining the facets and complexities that make up the alternative investment space. Traditional investments are generally long-only, publicly traded, and highly regulated assets. As a result, traditional asset overseers often have less need for knowledge regarding underlying such issues as the safekeeping of assets. Alternative assets are often less regulated, more complex, and private. As a result, overseers of alternative assets often need to be familiar with such issues as safekeeping of assets, borrowing facilities, and third-party service providers.

The terms that follow provide the foundation for the knowledge needed to oversee a diverse portfolio of alternative investments. Readers should review this chapter before proceeding to subsequent chapters and may refer to it as needed throughout the remainder of this primer.

\subsection{Key Contributors}

Depositories and Custodians. Depositories and custodians hold customer securities for safekeeping and may perform additional activities, such as settlement, tax withholding, and proxy voting. Asset allocators need to consider depositories and custodians not only in the context of the securities that they hold but also with regard to understanding the safekeeping of assets underlying the investment pools in which they invest.

Fund Administrators. Fund administrators are specialists that serve numerous roles, including protecting the interest of fund investors by determining the fair pricing of securities and funds. Fund administrators are also responsible for the preparation of annual reports, settlement of securities, payment of fund expenses, and the computation of fund performance measures involved in fund management.

Plan Sponsors. The plan sponsor is the entity that organizes a retirement plan, such as a pension plan, for the benefit of the plan's participants. Other responsibilities of the plan sponsor include determining membership parameters and investment choices. The term plan sponsor is sometimes broadly used to include other asset owners, such as educational endowments, charitable foundations, and sovereign wealth funds.

Prime Brokers. A prime broker is a brokerage firm that provides a suite of services to investment pools, such as hedge funds. The most important 
service is financing the hedge fund's positions and trades (i.e., the broker lends to the hedge fund). Other services provided include access to complex securities, technology, and consulting and advisory work. Asset allocators should review the capabilities of the prime brokers that are servicing the hedge funds and other investment pools in which they invest. The complexities of heavy trading, shorting, and leverage make the prime broker an essential component of hedge fund operations.

- Financing. Although traditional investment managers are mostly long-only and often use little or no margin, many hedge funds make frequent use of short positions (which requires borrowing of assets) and margin. The prime broker meets the needs of the fund's trading strategy by arranging a clearing facility so that collateral requirements can be netted across all products simultaneously.

- Complex securities. Prime brokers facilitate access to the diverse array of products used by many hedge funds, including swaps, futures, forwards, and options, which are typically not available through traditional brokers. Prime brokers offer services related to the International Swaps and Derivatives Association (ISDA) Master Agreement, a service agreement for OTC derivatives that sets the terms for both sides of the contract.

Technology. Key information across multiple asset classes is offered through the prime broker platform, which authorizes cash wires, facilitates elections on corporate actions, exercises options, and reconciles individual trades.

- Consulting and advisory. Prime brokers often introduce hedge fund clients to qualified investors (a service called capital introduction), advise new hedge funds on the regulatory requirements in different jurisdictions, and assist in the establishment of risk management platforms.

Risk Managers. Reporting to the chief risk officer (CRO), fund risk managers design systems to identify, quantify, monitor, prioritize, and report aggregate fund risks to investors and counterparties. The main objective of risk systems is to place controls such that the collective risks do not jeopardize the functioning of the business.

\subsection{Key Elements}

Back-Office Operations. The back office, as opposed to the client-facing and revenue-generating front office, is responsible for a variety of services required to keep the company in operation. Primary back-office services include trade settlements, technology infrastructure, and compliance. 
Buy-Side Institutions. The buy side is composed of financial institutions that operate both in the traditional side of investments (e.g., pension funds and insurance companies) and in the alternative investment space (e.g., foundations, sovereign wealth funds, and private investment pools, such as hedge funds and master limited partnerships). Buy-side analysts build portfolios for their clients that meet specific needs, such as the duration matching of assets to liabilities and alpha generation.

Family Offices. Offering guidance and financial services for high-networth individuals, the family office operates either for a single family or in the service of multiple families. In essence, family offices are investment management firms organized for individuals with wealth so substantial that professional investment managers are retained "in house." In addition to executing detailed financial plans, family offices deliver financial education and philanthropy planning for current and future generations.

Front-Office Operations. As opposed to the operational support of the back office, the front office is outward facing and responsible for revenue generation. Front-office roles include sales, portfolio analysis and management, trading, and business development.

Management Company Operating Agreements. Private investments, such as most hedge funds and private equity funds, involve legal documents that are not used for positions in public securities. Similar to corporate bylaws, operating agreements are legal documents that govern the business structure of the limited liability corporation (LLC) and define the rights and duties of the LLC's constituents. The operating agreement specifies the separation between the company and its owners as well as the rules and regulations for the smooth operation of the business.

Partnership Agreements. Private investments, such as most hedge funds and private equity funds, involve legal documents that are not used for positions in public securities. Partnership agreements are complex legal documents that outline all terms between the fund's limited partners (the investors) and the fund's general partner (the manager). The partnership agreement spells out the precise fees and expenses paid to the general partner, the allocation and distribution of profits to the general and limited partners, withdrawal provisions, lockups, and any imposed gates.

Private Placement Memoranda. Private investments, such as most hedge funds and private equity funds, involve legal documents that are not used for positions in public securities. Similar to a prospectus, private placement memorandums (PPMs), also called offering memorandums, give investors 
much of the information necessary to make informed investment decisions. The PPM provides the background of the management team and describes the business plan, the pro forma financials, and the legal details with respect to the liabilities of the company and the rights of the investor.

Sell-Side Institutions. The sell side, as the name suggests, consists of institutions that engage in the sale of securities to investors. Research analysts guide sell-side activities by building performance models, preparing earnings forecasts, and making investment recommendations. The sell side is dominated in terms of activity by large dealer banks, such as Deutsche Bank AG; Goldman Sachs Group, Inc.; Bank of America Merrill Lynch; and Credit Suisse Group.

Sovereign Wealth Funds. Sovereign wealth funds (SWFs) are stateowned investment pools structured to stabilize national budgets and secure wealth for future generations. SWFs are most prevalent in countries with large natural resources or a volatile balance of trade and foreign currency reserves. With the objective of increasing savings for future generations, SWFs have long-term investment horizons and typically operate with the goal of achieving a total return that is greater than that earned on foreign currency reserves. For example, Norway uses its large SWF to finance rising public pension expenditures and to contribute to intergenerational equity. Given Norway's enormous balance of payments surplus, the SWF portfolio tilts toward global equities and real estate to diversify away from investment factors that underlie oil revenues.

Subscription Agreements. Investors joining limited partnerships must file applications known as subscription agreements. In addition to documenting the investor's suitability to invest in the partnership, the agreement will specify terms with respect to liquidation and termination. Once filed, the general partners must decide to approve the application.

\subsection{Key Regulations}

Investment Company Act of 1940. Commonly referred to as the '40 Act, this key act defines how investment companies are regulated in the United States. Funds compliant with the '40 Act (i.e., '40 Act funds or liquid alternative funds) offer regular liquidity, redemptions within seven days, disclosure of fund holdings on a regular basis, and $300 \%$ asset coverage (i.e., borrowing is limited to $33 \%$ of assets). Diversification regulations apply to the fund's portfolio whereby assets invested in one issuer cannot exceed $5 \%$ of the portfolio, assets invested in one industry cannot exceed $25 \%$ of the portfolio, 
and the fund cannot hold more than $10 \%$ of the shares outstanding of a single company. No more than $15 \%$ of a fund registered under the ' 40 Act can be invested in illiquid assets. Performance fees, rarely applied in '40 Act funds, are required to be symmetric so that fees on investment profits are matched by the givebacks on investment losses.

In the alternative investment space, managers rely on specific exemptions to the ' 40 Act that create flexibility with respect to illiquidity, transparency, concentration, leverage, and fees. Section 3(c)1 of the ' 40 Act provides a safe harbor exemption based on offering securities to only a limited number of accredited investors, defined as having a minimum net worth in excess of $\$ 1$ million or income in each of the past two years of $\$ 200,000$ (or $\$ 300,000$ for a married couple) with the expectation of earning at least that amount in the current year. For example, a qualified exemption allows for the fund to charge asymmetric performance fees, earning the incentive fee on profits while not requiring givebacks on losses.

Regulation T Margin. Many alternative investment strategies, such as hedge funds, use substantial leverage or margin. Under the authority of the US Federal Reserve, Regulation $\mathrm{T}$ is a collection of provisions that governs the amount of credit that securities brokers and dealers can extend to the purchase of securities by investors. Margin requirements define the amount that investors must deposit for each dollar of securities purchased (i.e., limits on the use of leverage).

Markets in Financial Instruments Directive. The formal attempt to unify financial market regulations across the European Union (EU) is codified under the Markets in Financial Instruments Directive (MiFID). This set of regulations is designed to enhance consumer protection throughout all 31 member states of the EU. MiFID covers the full range of financial securities, including derivatives (e.g., options and futures), with the goal of harmonizing regulations instead of imposing multiple regulations by individual member states.

\section{Undertakings for Collective Investment in Transferable Securities} (UCITS) Funds. Similar to the '40 Act, which regulates investment funds in the United States, regulations set forth in the UCITS Directives apply to products sold throughout the various member states of the EU. UCITScompliant funds are subject to strict restrictions with respect to liquidity, transparency, leverage, and diversification. Since the original UCITS Directive of 1985, additional directives have been put in place and are known as UCITS II through UCITS V with such aims as facilitating cross-border offerings, broadening investment vehicles that are allowed under the regulations, and tightening duties and responsibilities of fund managers. 
Most prominently, UCITS funds must conform to a minimum size based on the fund's age, are subject to annual audits, and must meet standards concerning its promoters, its management, and the distribution of products and services. Regulators in the home EU country must authorize a UCITS fund.

\subsection{Other Key Terms}

Capital Calls. Also known as capital commitments or drawdowns, capital calls in the private equity space represent the legal right of the private equity firm to procure funds from investors who have committed capital to the fund. Committed capital typically is not invested immediately but rather is "taken down" (obtained from the investor) as opportunities are presented. The vintage year is defined as the first year that capital is called.

Dark Pools. Dark pools are private securities exchanges that allow for anonymous trading. Non-exchange trading enables large institutional investors to escape identification, thus removing identity and intention-signals that could hamper price execution of subsequent trading.

Gates and Lockups. Gates are restrictions placed by hedge funds and some other investment pools on the amount of withdrawals allowed over a specified period of time. Typically, gates are imposed on pools with illiquid investments and protect the operations of the business as well as remaining investors who could be harmed by capital flight. Lockup provisions state a minimum holding period for a fund, which may be 1 year for hedge funds and 10 years for private equity.

Liquid Alternative Investments. Liquid alternative investments are a relatively new asset class that seeks to deliver the investment characteristics associated with alternative investments to retail investors. This approach contrasts with private investment pools that provide access to alternative strategies to accredited investors (who are assumed to possess the requisite knowledge and experience to be exposed to full spectrums of risk). Liquid alternatives create a retail wrapper to house trading strategies usually associated with hedge funds (e.g., equity long-short strategies) so that they remain compliant with major regulatory acts, such as the ' 40 Act and UCITS. Regulatory limits regarding illiquid securities, incentive fees, and leverage within public funds discourage or prevent liquid alternatives from replicating some of the strategies implemented by hedge funds (that are not subject to these limitations).

Limited Partnerships. Limited partnerships are the legal structure commonly used in hedge funds and private equities. The basic limited partnership 
is a legal structure in which at least one general partner (GP, or management) and at least one limited partner (LP, or investor) join together to start and share a business. The partnership does not have employees, and the general partner is responsible for all operational activities. LPs are pass-through entities for tax purposes, which means that the LP is not subject to corporate income tax and avoids the potential for double taxation of income.

Master Limited Partnerships. The main distinction of the master limited partnership (MLP) relative to LPs is that interests in MLPs trade on an exchange. In the United States, the pass-through tax status of MLPs is offered only in such industries as the energy sector and other classes of real assets, such as timber. In addition to its public trading, the MLP structure has a tax advantage. Investors are taxed on profits, not on distributions. Generous tax deductions in such industries as energy (e.g., depletion allowances) mean that partnerships with high positive cash flows may have little or no taxable income. Distributions to the LPs are treated as distributions of capital and are not taxed when made. However, the distributions reduce the tax basis of the investors, which increases taxation when the position is liquidated. As a disadvantage, the LPs receive Form K-1, a partnership tax return known for its complexity. $\mathrm{K}-1 \mathrm{~s}$ are often distributed on a delayed basis relative to other investment-related tax documents, such as 1099s. Investing in MLPs can lead to income tax liability for qualified funds and other tax-exempt entities, such as not-for-profits, because of the potential for the MLPs to generate unrelated business taxable income (UBTI). Also, substantial investments in MLPs can lead to the need to file income tax returns in multiple states.

Portable Alpha. Alpha is the abnormal return (i.e., risk-adjusted return in excess of the benchmark's return) tied to managerial skill. Portable alpha refers to the idea that the alpha earned in one asset class can be transported from that asset class and inserted into a different one where it is more desired by the investor. For example, consider an investor with a mandate to track the performance of the S\&P 500 Index and who wishes to pursue an alpha opportunity in Japanese equities. The alpha sought in a portfolio of Japanese equities can be ported to add alpha relative to the S\&P 500 by entering into financial derivative contracts that hedge the systematic risk exposure of the portfolio to Japanese equities and create the desired risk exposure to the performance of US equities.

Proprietary Trading. Also known as prop trading, proprietary trading occurs through a desk within a financial institution that seeks to earn total returns rather than commissions from processing trades. These trades are usually speculative in nature, include leverage, and make use of derivative 
products. The substantial proprietary trading desk losses suffered during the US financial crisis led to the enactment of the Volcker Rule, which provides for heavy regulation and restrictions on proprietary trading by US banks.

Separately Managed Accounts. In the most general sense, a separately managed account (SMA) is any portfolio of securities managed on behalf of a specific client by a professional. In the context of investment pools, SMAs can be used by a fund manager to provide access to the performance of the pool without investing in it by providing the same positions and trades to an investor on an individual basis. Unlike having an interest in an investment pool, an investor in an SMA directly owns the underlying assets. The SMA is thus flexible, transparent, and uniquely customized with respect to tax planning and liquidity needs. Furthermore, SMA investors avoid the potential problems (e.g., higher transaction costs and excess cash) inherent in investment pools when other investors disrupt the pool through large contributions or withdrawals.

Systemic Risk. Systemic risk is the potential for the interconnectedness of a financial system or economy to trigger concerns over the health of the financial system that lead to cascading losses within the economy. For example, in the absence of a healthy bank deposit insurance system, the closing of one bank may lead to a run on bank deposits throughout the banking system as concerns rise over the health of all banks. Systemic risk is different from systematic risk. Systematic risk is a shared correlation by securities within a market that is not directly tied to the viability of the actual financial system. 


\section{Introduction to Hedge Funds}

Hedge funds form one of the largest categories of alternative investments as measured by assets under management (AUM). These vehicles tend to offer returns between those of stocks and those of bonds and with less risk than a long-only investment in stocks. Ideally, the correlation of returns between hedge funds and stocks or bonds is low, but the risk mitigation ability of hedge funds varies by strategy. Hedge funds are most diversifying to a stock and bond portfolio when they have both low volatility and a low correlation with the stocks, bonds, and other assets held in the portfolio.

\subsection{Overview of Hedge Funds}

Hedge funds are investment pools that offer greater flexibility than traditional pools in offering such features as large short positions, high degrees of leverage, and rapidly changing risk exposures. Hedge funds are often structured as private placement vehicles, where the funds are not publicly listed on a securities exchange.

Rationale for Hedge Fund Investing. The purpose of adding hedge funds to an investment portfolio is to access return streams that are different from those available in the stock and bond markets, ideally by hiring general partners (managers) with significant investment skill. Hedge fund managers use their skill to invest in areas and ways that are less popular among other investors. For example, the portfolios of most active managers are dominated by long positions in securities that may have been purchased because they are believed to be undervalued. Hedge fund managers may find that overvalued securities are easier to identify because fewer than $10 \%$ of shares in most securities are held short. If there are at least 10 times the number of long positions than short positions, there is less competition to find overvalued securities, and thus, hedge funds may find more inefficiencies on the short side of their portfolio.

Rationale for Adding Hedge Funds to Portfolios with Traditional Investments. When hedge fund returns have lower volatility than and a low level of correlation with returns in other parts of the investor's portfolio, the addition of hedge funds will reduce portfolio volatility. In most cases, increasing the allocation to hedge funds by reducing equity exposure will lead to both lower risk and lower expected return at the portfolio level. To the extent that alternative investments, such as hedge funds, are funded by reducing the amount allocated to bonds-in industry jargon, "used as a bond 
substitute"- they can lead to higher risk and higher expected returns at the portfolio level.

Risks. Hedge fund managers approach risk taking and trading quite differently than their long-only counterparts. Hedge funds are more likely to accept complexity risk, illiquidity risk, and event risk than long-only investors. If the market offers compensation for accepting these risks, then hedge fund managers may be more likely to earn excess returns. Hedge funds that invest in convertible bonds or collateralized debt obligations are allocating assets to more complex securities and are often rewarded for the efforts they take to understand these complex securities.

For example, in the aftermath of the global financial crisis, some convertible bonds traded at lower prices and higher yields than option-free bonds of the same firm, even though the convertible bonds were clearly worth more. Convertible bonds have valuable embedded options that can potentially be converted into shares of stock in the underlying firm. Another example is that hedge funds may take illiquidity risk by investing in shares of small-cap or unlisted stocks or by holding distressed or defaulted securities that have been sold by other investors who may have regulatory restrictions keeping them from holding those bonds. Finally, hedge fund managers may assume event risk, where they can earn excess returns only if an anticipated event, such as the consummation of a merger agreement, occurs.

Unlocking Value. Most hedge fund managers are not passive holders of securities. A traditional buy-and-hold investor may buy a stock and hold that position until the company releases information that benefits the investor's position. However, some hedge funds actively work to influence the operations or capital structure of the company, serving as an active catalyst to unlock value within a firm. Activist hedge fund managers take a large position in a company and then lobby management to enact changes in the governance of the firm that are intended to increase the stock price. Similarly, distressed debt managers may lobby the bankruptcy court to expedite a settlement of obligations that can lead to larger or quicker payouts to bondholders. Some hedge fund managers, then, earn returns through their own efforts to bring change to a company rather than waiting for the company to enact a change and for the market to revalue the securities to reflect the value of those changes.

\subsection{Hedge Fund Structures}

Hedge funds may be offered to investors in a variety of structures. More recently, growth has been strong in an area called liquid alternative investments, 
which can be structured as open-end mutual funds or as exchange-traded vehicles similar to mutual funds but implementing hedge fund-like strategies. Because these vehicles are publicly available to all types of investors, they are subject to local regulations, such as the Undertakings for Collective Investments in Transferrable Securities rules in Europe or the Investment Company Act of 1940 in the United States. These regulations limit the amount of risk taken in the funds as measured by leverage, net market position, or degree of illiquid investments.

Traditionally, hedge funds have been available primarily as private placement vehicles, where the investments are not publicly available, for example, by being listed on a securities exchange. Private placement hedge funds (e.g., limited partnerships) have greater investment flexibility than other funds. In a private placement vehicle, the fund management company may face less regulation regarding disclosures and limits on portfolio risks than is required for exchange-traded vehicles. In exchange for less regulation, hedge funds may be limited in their marketing reach or the type of investors they serve. For example, in the United States, hedge funds have a safe harbor from some aspects of the Investment Company Act of 1940 if they offer investments only to individuals and institutions termed accredited investors or qualified purchasers, meaning that the investors meet specific net worth requirements. As a result of these regulations, and the high-net-worth nature of the investors, the median hedge fund has a minimum investment size of $\$ 500,000$.

In this private placement structure, investors are called limited partners and fund managers are called general partners. When investment funds contain leverage or derivatives, the losses of the fund could exceed the capital contributed by investors. Hedge funds can be structured in a way that limited partners cannot lose more than the capital they contributed to the investment vehicle, thus the name limited partners. A limited partnership is a specific legal structure that limits the degree of active decision making that investors can have regarding the fund and its investments. The general partners, also known as fund managers, make all investment decisions in the fund and may be liable for losses in excess of the capital contributed by the fund's limited partners.

\subsection{Hedge Fund Liquidity}

Asset allocators investing in hedge funds must understand and manage the potential illiquidity of many private hedge fund products.

Although liquid alternative investments and exchange-traded vehicles typically have daily or weekly liquidity, hedge funds are less liquid because they are priced and traded less frequently. Most hedge funds only post a net asset value (NAV) at the end of each month, meaning that no money can be added to or 
withdrawn from the fund except at the end of each calendar month. Hedge funds may have specific calendar requirements for subscriptions (additions to the fund) and redemptions (withdrawals from the fund), and they require advance notice before redemptions. For example, some funds may have monthly subscriptions and quarterly redemptions with 30 days' notice required before redemption. That is, an investment can be redeemed at the end of March only if the redemption notice is received before the end of February. This advance notice before redemption gives the hedge fund manager time to liquidate positions to fund the investor's withdrawal without creating a significant market impact or trading cost to the fund (and to the fund's other investors).

Approximately half of global hedge fund assets are managed using the equity hedge, macro, or managed futures strategies that will be discussed in Chapter 4. Because these funds invest in liquid assets (e.g., stocks or futures), other than the advance notice of withdrawal before the next NAV date, as discussed earlier, these funds typically do not restrict withdrawals. Some hedge fund styles, however, especially those in the relative-value and event-driven categories, may hold highly levered, highly concentrated, or illiquid underlying investments, which may require investors to commit to a longer holding period. Hedge funds holding distressed debt, other illiquid fixed-income securities, unlisted equity securities, or highly levered or illiquid investments may require investors to accept a lockup period. This lockup period may require investors to keep their assets in the hedge fund for a stated initial period of one to three years. In a hard lockup period, investors are not allowed to redeem their fund interests during the lockup period for any reason. In a soft lockup period, investors can redeem their investments before the end of the lockup period by paying a fee of $1 \%-3 \%$ of the withdrawal amount to compensate the other investors in the fund for the trading costs incurred to facilitate the early redemption. Once the lockup period has been satisfied, investors can redeem from the hedge fund according to requirements for advance notice and the specified redemption dates.

Some hedge funds may erect gates that will delay redemption requests even after investors have satisfied the lockup period. These gates are meant to protect investor capital during times of extraordinary and illiquid market conditions. For example, many debt issues traded at enormous credit spreads and extremely low prices in 2008-2009. Rather than allow hedge fund investors to redeem their interests, which would force hedge fund managers to sell these bonds at distressed prices, many credit-oriented hedge funds enacted gates to delay the redemption requests of their investors. For example, a redemption request that was submitted in the first quarter of 2009 may not have been fulfilled until 2010, when credit market conditions had stabilized 
and prices had recovered to the point at which the impact of the redemptions on remaining partners was limited.

\subsection{Terms of Hedge Fund Investments}

Privately organized hedge funds have widely varying terms regarding the size and timing of fees collected by the hedge fund managers (i.e., general partners).

Overview of Hedge Fund Fees. To be compensated for their specialized skills in managing funds with broad investment flexibility, hedge fund managers typically earn both a management fee and an incentive fee. The management fee, often in the annual range of $1 \%-2 \%$ of assets per year, may be charged each quarter on all assets regardless of performance. The incentive fee, or performance fee, is typically paid annually in the amount of $10 \%-20 \%$ of all new profits earned in the fund. Traditionally, hedge funds charged fees of " 2 and 20," meaning a $2 \%$ management fee and a 20\% incentive fee. With the growth of the hedge fund industry and declining returns since 2008, fees have been falling toward the level of $1.5 \%$ and $15 \%$ for large institutional allocations. Smaller investors may still be charged fees closer to $2 \%$ and $20 \%$ because many hedge fund managers have fee schedules that charge different fees for different investors, rewarding investors who write larger checks or accept more stringent liquidity terms with lower fees. For example, an investor who allocates $\$ 1$ million to a hedge fund with a one-year hard lockup period might be charged 2 and 20, whereas an allocator who invests $\$ 25$ million for a minimum period of two years might be charged 1.5 and 15.

Hurdle Rates. Hedge funds charge incentive fees on both realized and unrealized gains. In a hurdle rate structure, a hedge fund's incentive fee is charged only after returns to the investor exceed some predetermined levelsay, $8 \%$ per year. After accounting for investment profits net of management fees, the general partner will not earn any incentive fees until the investor's compounded annual return exceeds, in this example, the $8 \%$ hurdle rate (also called preferred return). Once the investor's annualized return exceeds this level, the fund manager will often be allowed by the terms of the contract to "catch up" by earning all profits greater than the $8 \%$ hurdle until the general partner has earned the $20 \%$ carried interest on the $8 \%$ hurdle rate. After that point, all fund profits are split 20\% to the general partner and $80 \%$ to the limited partner.

Preferred Returns and Comparison of Hedge Fund and Private Equity Fees. Many private equity funds offer fee structures that may be more favorable to investors than the fee structures typically charged by hedge funds. Hedge funds charge incentive fees on both realized and unrealized 
gains, whereas private equity funds charge carried interest (their version of incentive fees) only on the realized gains from exited deals. Private equity funds are more likely (66\%) than hedge funds (33\%) to include hurdle rates in their fee structure. In private equity, preferred returns range from $6 \%$ to $12 \%$, with $8 \%$ being most common. If a fund is earning carried interest on a dealby-deal basis - that is, immediately after each deal is exited-a scenario could arise in which the remaining investments are later written off and the general partner has earned too much in carried interest relative to the return of the fund as a whole. In that case, the incentive fees earned by the general partner are typically subject to a clawback provision, where previously paid fees are refunded to the limited partner to ensure that the investor has paid the proper amount of fees at the end of the life of the fund.

High-Water Marks and Incentive Fees. Most hedge funds calculate incentive fees using a high-water-mark provision, which ensures that each unit of profit is charged an incentive fee only once. To illustrate, consider a hedge fund with an NAV of $€ 80$, which rises to $€ 100$ over the course of one year, net of the management fee and other expenses. At the end of the year, the $€ 20$ profit incurs a $20 \%$ incentive fee (i.e., $€ 4$ ), which is retained by the general partner; the limited partner keeps the other $€ 16$ in gains inside the fund (i.e., the NAV is now €96). In the following year, the NAV declines from $€ 96$ to $€ 86.4$, a drawdown (loss from a peak valuation to a later valuation) of $10 \%$. In any year in which the fund experiences losses, the general partner earns no incentive fees. Finally, in the third year, the NAV rises from $€ 86.4$ to $€ 116$. From the first year, the high-water mark (i.e., the highest previous NAV on which the limited partner paid incentive fees) was €96. In the third year, no incentive fees are paid on the gains from $€ 86.4$ to $€ 96$ because the incentive fee on those profits was paid in year one, when the fund first reached the high-water mark of $€ 96$. The part of the gain realized in the third year-from $€ 96$ to $€ 116$ - is new, however, so the general partner will earn an incentive fee in the amount of $20 \%$ of $€ 20$, or $€ 4$.

\subsection{The Option-Like Nature and Moral Hazard of Incentive Fees}

Hedge fund fees differ from mutual fund fees in that mutual funds only charge a flat (fixed-percentage) management fee regardless of the value added by the fund manager. Most hedge funds pay the fund manager an incentive fee that increases with the returns generated by the fund. The purpose of incentive fees is to attract top managers to the fund and to provide them with an incentive to do a great job of managing the fund. 
Some investors are concerned that this incentive fee charged by hedge fund managers (or the carried interest charged by private equity fund managers) can have a downside in terms of risk taking. If the general partner earns an asymmetric incentive fee of $20 \%$ of profits while not sharing in the losses, the fund manager may have perverse incentives to invest in highly volatile strategies. In this case, the manager wins if the investments pay off but only the investors lose if the investments decline in value.

Incentive fees can be viewed as call options held by fund managers on the performance of the fund. Just like having an explicit call option on the fund's assets, the incentive fee has the option-like feature of providing large positive returns when the fund's assets rise without having exposure to losses if the fund's assets decline in value.

This call option can be extremely valuable to the hedge fund manager because incentive fees potentially can reach levels of $30 \%$ or more of the investor's initial capital over a successful 10-year period. The value of the fund manager's call option rises with the size of the fund and the length of time the assets remain invested, as well as with increased volatility of the fund's assets.

When viewing incentive fees as an option, we can theorize how managers may be tempted to act. Once returns have been strong and the fund is far above the high-water mark, managers may consider reducing risk to lock in the gains that already have been earned until the next incentive fee payment date. This risk-averse behavior occurs when the fund is well above its highwater mark and the risk to the manager becomes symmetrical. Specifically, the manager's incentive fees due at the end of the period rise when performance improves, and the fees decline as performance deteriorates. Conversely, consider a manager in the midst of a large drawdown, when the fund is far below the high-water mark. In this scenario, the manager may be tempted to substantially increase risk because a large gain could lead to a significant incentive fee, whereas further losses may lock in the investors' decisions to redeem from the fund. Because the manager believes that he has little to lose, the temptation to increase risk can be high.

This incentive for a manager to take very high levels of risk can be offset by managers investing their personal capital in the fund. By investing alongside limited partners, the general partner maintains the incentive fee structure to encourage large potential gains, while the manager's investment exposes her to personal losses, a condition that hopefully offsets the moral hazard and discourages potentially reckless investment behavior. Some limited partners include the degree of manager coinvestment in their due diligence process, going so far as to decline investing in a fund if less than $30 \%$ of the manager's personal assets are invested in the fund alongside the limited partners. 
The downside of managers having a large share of their personal assets in the hedge funds they manage is that, to protect their financial security, they may not take enough risk. Limited partners, who typically invest only a small portion of their assets in a given hedge fund, do not share this concern and want managers to take risk commensurate with their investment skill.

\subsection{Hedge Fund Governance}

The previous section on incentive fees raises the issue of perverse incentives for fund managers and the importance of selecting high-quality managers. Investors should perform comprehensive due diligence on each fund manager before committing an allocation to a fund. In addition to having managers invest in their own funds, limited partners are interested in determining the investment experience and skill of the manager's team, the care of the risk management and clearing process, and the ethics and incentives of the general partner, as discussed.

When considering investment experience and skill, investors can evaluate both qualitative and quantitative characteristics of a hedge fund. The qualitative aspects of the due diligence process are discussed in Chapter 13. Quantitatively, investors are looking for low volatility and low correlation with other assets in their portfolio, as well as the manager's ability to earn alpha, or risk-adjusted excess returns. Investors should ensure that they understand various aspects of performance by taking such measures as evaluating the track record of a long-short equity manager by separating the returns on the long positions from the short positions. Finally, investors should perform operational due diligence, detailed in Chapter 13, before making any commitment to a hedge fund.

\subsection{Conclusion}

Hedge funds allow investors to access skill-based managers to improve a portfolio's combination of risk and returns. With trillions of dollars of AUM in the hedge fund industry, hedge fund managers are competing with each other as well as the broader world of investors to generate attractive returns. Investors experienced only with traditional investments should familiarize themselves with the unique sources of returns, risks, liquidity issues, fees, and potential conflicts of interest in hedge funds. Chapter 4 provides an overview of the tremendously broad and diverse investment strategies implemented by hedge fund managers. Chapter 5 discusses the various approaches that an institution can use to access hedge fund opportunities with diversification, including multistrategy funds, funds of funds, and in-house hedge fund investment programs. 


\section{Hedge Fund Strategies}

Chapter 3 discusses how hedge funds can be used to diversify a portfolio of stocks and bonds. Such diversification is best achieved when the hedge funds have both a low volatility of returns and a low correlation of returns with other assets held in the portfolio. Investing in single-manager hedge funds typically gives investors access to a specific strategy subject to the hedge fund manager's investment and risk management skills. Investors should be well diversified in their selection of these hedge fund strategies. Chapter 5 discusses three methods to achieve this diversification: multistrategy funds, funds of hedge funds, and direct investing in a number of single-manager hedge funds.

\subsection{Classifying Hedge Fund Strategies}

There are over 8,000 single-manager hedge funds. Most of these funds focus on a strategy that fits into 1 of about 15 categories. Investors are encouraged to understand the category to which a fund manager's offering likely belongs as well as how the specific hedge fund under consideration is similar to or different from most of the other funds in the stated category.

This chapter discusses the four key categories of hedge funds:

1. Macro and managed futures funds

2. Event-driven hedge funds

3. Relative-value funds

4. Equity hedge funds

These four major categories have different general tendencies. Macro and managed futures funds may be highly diversifying to a stock and bond portfolio, whereas event-driven and relative-value hedge funds may experience the greatest losses during a time of significant drawdowns in the investor's stock and bond portfolios. Equity hedge funds, especially long-short funds that maintain a positive exposure to equity markets, are expected to have less risk than equity markets but maintain a high correlation with stock market indexes because of their net long stock market exposure. Within each category are several subtypes that further differ in terms of their risk, return, and trading focus.

In addition to selecting funds based on investment strategies, investors must perform both investment due diligence and operational due diligence as discussed in Chapter 13. Some investors will screen by the age or assets under 
management (AUM) of a hedge fund. Hedge Fund Research (HFR) notes that the largest $27 \%$ of hedge fund management firms (i.e., those with more than $\$ 500$ million in assets under management) now control nearly $95 \%$ of industry assets.

\subsection{Macro and Managed Futures Funds}

Macro and managed futures funds invest at the macro, or "big picture," level. They typically maintain long or short positions throughout the global equity, fixed-income, currency, and commodity markets using derivative products, including futures, forwards, and swaps. Because of their focus on the derivatives markets, macro and managed futures funds typically have highly liquid holdings, allowing for a quick liquidation of positions, even in volatile and crisis markets. The leverage in macro and managed futures funds comes from the derivatives markets, which differ from the short-term borrowings that facilitate leverage in event-driven and relative-value funds and that may incur counterparty risk. Consider the counterparty risk that may be embedded in an interest rate swap in the over-the-counter market executed by a relativevalue hedge fund. A hedge fund that designed a swap to receive the return of sovereign debt and pay the return of subprime mortgage debt may not have received its profits on the 2008 mortgage collapse if its swap counterparty was Lehman Brothers or another failed bank. Such counterparty risk does not exist on futures and options exchanges. Instead, the clearing corporation is designed to pay all gains and collect all losses, even when some market participants are unable to do so.

Investors allocating across hedge fund strategies should consider liquidity as well as typical performance during crisis markets. Macro and managed futures funds have tended to preserve or increase in value during crisis time periods, whereas other hedge fund strategies tend to experience losses at the same time as the investor's equity portfolio. Should these characteristics persist in future periods of market stress, macro and managed futures funds may be the most diversifying strategies relative to an investor's equity and bond portfolio.

Managed futures funds and macro funds tend to be similar in that they take positions in derivatives markets at the macro level. Macro funds are often discretionary, anticipatory, and concentrated, and they tend to employ fundamental analysis. Managed futures funds, often called trend followers or commodity trading advisers (CTAs), tend to be more systematic, reactive, and diversified, and they tend to use technical analysis.

Macro Funds. Both macro and managed futures funds often attempt to benefit from anticipating global money flows across asset classes that may 
cause markets to make large directional moves. Global macro funds tend to anticipate these moves through fundamental analysis of market conditions. Global macro managers often have a background in macroeconomics and thus have been trained to analyze how the actions of central banks may affect currency and sovereign debt markets.

In many cases, macro managers seek to find trades that may exhibit large potential gains with reduced potential losses. One favorite trade of discretionary macro managers is to short a currency that is pegged to a rate that the managers believe is too high relative to another currency and is likely to be devalued. Macro managers earned large profits on the devaluation of the Thai, Malaysian, and Indonesian currencies in 1997 and the British pound in 1992. Today, global macro managers may establish positions based on the anticipation of the likelihood of a breakup in the eurozone and its effects on the sovereign debt of weaker southern nations, such as Spain, Portugal, Italy, and Greece.

Macro funds, of course, are not without risks. Because macro funds tend to trade in a discretionary way, it can be difficult to predict what the positions of a given hedge fund may be. That is, macro managers may have positions that are quite similar to or different from each other. Some macro funds may have concentrated or highly leveraged trades. However, if an investor is concerned that issues surrounding the currency or sovereign debt markets are a key risk to their current stock and bond portfolio, macro funds may be a great fit to reduce the total risk of the portfolio to the extent that the funds offer high returns in periods of stress.

Managed Futures Funds. Managed futures funds often follow trends, seeking to take long positions when the manager forecasts prices as trending higher and short positions when lower prices are predicted. The decisions regarding which trades to implement are often based on so-called black box trading systems that use proprietary methods of technical analysis to forecast which markets are trending. These trading systems are built using historical data, perhaps to take advantage of the human emotions of fear and greed, which may influence markets. In an unemotional way, the system determines which markets to buy and sell based on how closely a current market price pattern matches a profitable historical pattern.

Although these funds are often called CTAs, most managed futures funds typically invest around two-thirds of their assets in equity index, fixedincome, interest rate, and currency derivatives, with about one-third invested in metals, energy, and agricultural commodity derivatives. Because these funds are opportunistically long or short, managed futures funds tend not to 
have a persistent long exposure to the underlying markets. Historically, managed futures funds have experienced gains in crisis markets, such as the $18 \%$ profit net of fees earned by some managed futures indexes in 2008 .

The greatest risk to managed futures funds is that markets don't trend or don't behave the way that they did in the past. If the computer models are continuously taking positions in search of a trending market that persistently reverses after the position is taken, the fund will be whipsawed and will experience a large number of relatively small losses. Another risk of computerbased funds is that many funds may be using similar systems; crowded trades can distort market prices. Finally, errors in the computer code may cause the strategy to be implemented in unexpected ways that can generate quick losses.

\subsection{Event-Driven Hedge Funds}

Event-driven hedge funds place trades in the securities of specific companies that are anticipated to undergo dramatic changes in the coming months. These funds may focus on mergers, spinoffs, distressed debt situations, or other changes in the equity or debt composition of a firm. Typically, an eventdriven fund invests in a way that profits when the anticipated event occurs as planned. This is similar to selling insurance on the successful completion of specific corporate actions and is designed to earn an insurance-like premium for accepting the event risk.

Merger Arbitrage. Consider the case of merger arbitrage funds, which typically take a long position in the target firm and a short position in the acquiring firm after an acquisition is announced. For example, a firm is trading at $€ 20$ per share. Another firm makes an acquisition bid at €33. Upon the announcement of the deal, the share price of the target firm immediately jumps to $€ 30$. Many shareholders in the target firm may immediately sell their shares after a 50\% overnight gain (from €20 to €30). The hedge fund seeks to profit $10 \%$ by buying the target firm at $€ 30$ and waiting for the merger to consummate at the eventual price of $€ 33$. More sophisticated strategies tend to be used when the bidding firm offers its stock rather than cash to finance the proposed acquisition.

The largest risk to traditional merger arbitrage occurs when an announced merger is not completed, which can result when shareholders, managers, or regulators reject the merger. Traditional merger arbitrage (i.e., taking long positions in the target firm) may be viewed as being analogous to writing insurance. The shareholders who sell their shares of the target firm on the day the merger is announced are effectively buying insurance-like protection from the merger arbitrage fund against the risk of a failed deal. The hedge 
fund seeks to profit by $10 \%$ but risks a potentially huge decline if the merger fails because failed mergers typically lead to a sharp decline in the price of the stock of the target firm. The performance of a merger arbitrage manager depends on the manager's success in predicting each merger's likelihood. Additionally, merger arbitrage funds typically perform well in healthy economies that tend to stimulate higher levels of merger activity.

Activists. Although many investors buy and hold a stock, waiting for corporate management to add value to their investment, activists seek to influence corporate decisions by exerting their shareholder rights. Activists can promote an agenda that brings about a variety of changes in the way the firm is managed, including composition of the board or capital structure of the firm. Activists can be friendly, seeking to work with corporate management behind the scenes to enact the desired changes. Other activists tend to be more hostile, laying out their agenda in public and criticizing the board for the way the company has been managed.

In some cases, activists will start a proxy fight, wherein they campaign to get shareholder votes on a proposal that is contrary to the goals of corporate management. Some activists may perceive too much cash building up in a corporation and seek to distribute that cash to shareholders in the form of buybacks or dividends. Other activists may seek to reorganize or break up the company to increase shareholder wealth by spinning off the fast-growing areas from the mature areas of the business or by separating a retail company from its underlying real estate holdings.

Activists tend to hold highly concentrated portfolios, often unhedged against market risk. As such, some investors consider activists not to be hedge funds and allocate assets to these managers out of the equity portion of their asset allocation strategy. The largest risks to investing in activist funds are declining equity markets and the failure of the activist to enact positive change at a targeted firm.

Distressed. Distressed hedge funds invest in securities of a firm that has declared bankruptcy or is likely to do so because of declining financial performance. Securities of a distressed firm may be undervalued as a result of a clientele effect, in which some investors, such as insurance companies, may be legally required to divest some or all of their holdings in non-investmentgrade or defaulted securities.

Investing in the securities of distressed firms can be highly complex and illiquid. Depending on the jurisdiction, a corporation may enter the legal proceedings of bankruptcy designed to either liquidate or reorganize the firm. The bankruptcy court oversees the process and will generally enforce 
a priority of claims such that senior and collateralized debt holders are often paid in full and junior or subordinated debt holders either are impaired or recover new equity. Those holding equity before the bankruptcy of the firm typically lose their entire investment.

Skilled managers of distressed hedge funds may have a financial background that allows them to better value the assets of the firm and estimate the recovery value that may be distributed to holders of various classes of securities. Others may have a legal background that allows them to participate in the legal process, attempting to either speed up the proceedings or influence how the value of the firm is distributed across creditors. Some distressed hedge funds invest only in long positions in various debt securities, whereas others may engage in capital structure arbitrage in which they purchase one security and sell short another security of the same firm.

Investing in distressed hedge funds poses a number of risks, the most obvious of which are the illiquid and complex nature of the securities of defaulting firms as well as the credit risk and declining asset values of the issuing firms. When distressed funds are long only, investors have the risks of a deterioration of credit conditions in the overall market, a lengthening time period to settle the affairs of the bankrupt firm, or poor fund managerial skill in estimating recovery values.

Event-Driven Multistrategy. Some event-driven managers focus on just one investment strategy, but others combine these strategies into a single fund. Perhaps the best reason to combine these strategies is that many of the event-driven opportunities are countercyclical relative to each other. Merger arbitrage activity tends to be at its greatest in strong equity markets with a large number of proposed mergers and acquisitions. In contrast, opportunities for distressed fund managers are greater during a market downturn, when more companies are not able to service their debt because of a decline in economic conditions. By allowing a fund manager to invest across the full event-driven space, an investor is likely to receive reduced volatility of returns through greater deal diversification and a more consistent level of activity across the business cycle.

\subsection{Relative-Value Funds}

Relative-value hedge funds focus on convergence in the prices of related or similar securities. Like event-driven funds, relative-value funds can make money slowly and lose money quickly. Convergence strategies typically profit in stable market conditions, especially with declining volatility or tightening credit spreads. Relative value funds, however, can experience extreme losses, especially during 
times of market turbulence. Losses can be especially severe when levered funds have credit line reductions by their prime brokers. Absent crisis market conditions, relative-value funds can post solid profits with quite low volatility.

Convertible Arbitrage. Convertible bonds are hybrid securities. They are corporate bonds that contain an embedded equity call option. For example, a convertible bond may offer its holder the option to receive interest and principal payments or to convert the bond to shares of stock $T$ at, say, $\$ 20$ per share. If the stock price stays below $\$ 20$ per share, investors receive their coupons and principal payments (absent bankruptcy). If the stock price exceeds $\$ 20$ at maturity, investors elect to receive the shares rather than the face value of the debt. Investors pay for this valuable option by accepting a lower coupon (bond yield) when investing in convertible bonds.

Convertible bonds are illiquid and complex securities, particularly when the bond is callable, is puttable, or has forced conversion features. Given the more complex and less liquid nature of these convertible bonds, opportunities for mispricing are greater. Convertible arbitrage hedge funds typically perceive cases in which the embedded equity option appears to be underpriced. Given this perception, the hedge fund buys the convertible bond and simultaneously sells short an amount of the underlying stock designed to precisely hedge the risk of changes in the price of the underlying stock. As a result, the extent to which the subsequent volatility in the underlying stock exceeds the volatility implied by the convertible bond's option price drives the performance of the combined position of the long bond and short stock.

One risk to investing in convertible arbitrage strategies is model risk, where the valuation and hedging models deployed by the fund manager do not accurately reflect the valuation or the risk of the strategy and the underlying securities. Like other relative value strategies, convertible bond hedge funds tend to use leverage, which must be managed carefully to avoid a forced liquidation during a market crisis or time of constrained liquidity.

Volatility Arbitrage. Although most investors think in terms of stocks and bonds, some hedge funds focus on options trading and volatility trading. Volatility-based strategies focus on changes in and the difference between anticipated and realized volatilities-especially equity price volatilities. Futures contracts and exchange-traded products on implied volatility are increasingly popular products. Many volatility arbitrage hedge funds seek to profit when options may be mispriced relative to each other or when options may be mispriced relative to movement in the underlying security.

Many hedge fund managers strive to buy underpriced options, sell overpriced options, and earn superior returns. At the same time, they seek to 
dynamically hedge the option positions with offsetting positions in the assets underlying the options. Other hedge funds may trade one set of options relative to another. One common trade is a dispersion trade, which offsets a position in equity index options with positions in options on the individual stocks within the index. Often termed correlation trading, hedge funds that feature long options on individual stocks and short index options can profit when correlation declines.

Some funds, such as tail risk funds, may be net buyers of volatility (i.e., options). These funds are designed to post large gains during crisis market scenarios, but they tend to have low returns, or even losses, during times of quiet markets when many of the purchased options will expire out of the money.

Fixed-Income Arbitrage. In fixed-income arbitrage, hedge fund managers take offsetting long and short positions in sovereign debt or credit securities in an attempt to profit from changes in yield relationships over time. Any type of fixed-income or security or derivative can be involved, including sovereign debt, investment-grade and high-yield corporate bonds, asset-backed securities, mortgage-backed securities (MBS), and credit default swaps. Most trades are designed to be duration neutral, in which a small change in overall interest rate levels has little effect on the value of a trade.

Some fixed-income arbitrage trades are relatively simple, perhaps predicting that a sovereign yield curve will flatten or steepen over time. For example, a trader who anticipates that a flat curve will steepen (i.e., shortterm rates will fall faster than long-term rates) will purchase the longerdated (more price sensitive) security and sell short the shorter-dated security. If the fund manager's prediction is correct, the longer-dated security's longer duration will generate profits that exceed the losses on the shorter-dated security. A more risky example of fixed-income arbitrage is a carry trade, in which investors buy high-yielding securities on leverage and use derivatives or sovereign debt to hedge the interest rate risk. In normal market conditions when credit spreads are stable or declining, levered carry trades can post substantial profits for extended periods of time. This strategy has been compared with picking up nickels in front of a steamroller. If credit spreads increase quickly, the losses can be large because of leverage and the increased costs of financing.

Relative-Value Multistrategy. Relative-value multistrategy funds can invest in a wide variety of relative-value trades, including fixed-income arbitrage (using various types of bonds, such as MBS), convertible bond arbitrage, and volatility arbitrage. Most relative-value hedge funds trade in a multistrategy manner rather than focusing on a more specific underlying strategy. 


\subsection{Equity Hedge Funds}

Equity hedge funds are the simplest type of hedge fund to understand: Fund managers seek to take long positions in stocks they believe are undervalued and short positions in stocks regarded as overvalued. The main difference between the subtypes of equity hedge funds is the amount of net market exposure. Long-short funds are typically net long, market-neutral funds are generally fully hedged against market moves, and short-selling funds are generally net short (or only short) and thus perform relatively well in declining stock markets. When investing in equity funds, investors should consider the beta risk to the underlying equity market retained in each strategy, which has a high correlation with the equity investments held elsewhere in an investor's portfolio.

Equity hedge fund managers often implement either a fundamental or quantitative stock selection method. Fundamental managers focus on the bottom-up characteristics of companies, performing deep research on the company, its assets, and its prospects for profitability. Fundamental managers may have concentrated portfolios with relatively few positions. Quantitative managers will have more diversified portfolios with a larger number of positions, because their methods do not consider company-specific fundamentals beyond what can be found in financial statements. Quantitative managers often focus on factor exposures.

Long-Short Equity Funds. Most long-short equity funds hold a long market bias, meaning that their long positions are larger than their short positions. A typical fund exposure would have 100\% long positions and 50\% short positions. The net exposure of $+50 \%$ would lead the fund to have much less volatility than the underlying market, with the expectation of that fund having half of the upside potential and half of the downside risk of the underlying stock market. The gross exposure of the fund, $150 \%$, is the sum of the long and short positions and represents the amount of investor capital that is exposed to the stock selection skill of the fund manager. Ideally, a long-short equity hedge fund manager would be able to add alpha (added return) from both his long and short stock selections, perhaps targeting $80 \%$ of the upside in an equity market with only $50 \%$ of the risk.

When evaluating long-short equity funds, investors should inquire about the manager's process and demonstrated skill on both her long and short security selections. The goals, process, and mechanics of selling short are inherently different from simply buying or taking long positions in stocks. Long positions can be held for very long periods of time, and the potential gain can be much larger than the potential losses, which are limited to a $100 \%$ loss. Short positions are the opposite: The maximum possible gain is the proceeds 
of the short sales, or $100 \%$ of the current stock price; potential losses, in contrast, are unlimited. Short positions require the borrowing of shares that must be returned upon the demand by the lender. Although fund managers typically control the timing of the closing of their long stock positions, they may be unable to control when the short stock positions must be closed.

Market-Neutral Equity Funds. Market-neutral equity funds simply balance the size and the risk of the long stock positions with the size and the risk of the short stock positions, seeking to have a zero beta, or zero directional exposure, relative to the underlying stock market. The expected performance of the strategy relies fully on the manager's stock selection skill. The expected return to a zero beta position is simply the risk-free rate plus the alpha (positive or negative) created from the manager's investment activity.

Short-Selling Equity Funds. Some short-selling funds may focus exclusively on short selling, whereas others may be the inverse of a longshort fund-with funds that mix long and short stock positions having perhaps $50 \%$ long positions and $100 \%$ short positions, for a net short position of $50 \%$. It can be challenging to manage a fund that is persistently $50 \%-$ $100 \%$ net short, because most equity markets rise over time and managers with large positive alpha from stock selection may have negative or zero returns in large bull markets. Investors should focus on the alpha, and not on the total return, of short selling equity funds. The funds can be used in a portfolio context to hedge long stock positions that may have a lower alpha than the short-selling fund manager.

A potential advantage to short selling equity funds emanates from the asymmetry of competition between the long and short sides of a trade. Only a small portion, perhaps less than $10 \%$, of shares is typically held short. A large number of investors seek long positions in undervalued stocks, but fewer investors are looking to sell short overvalued names. This reduced competition could provide short sellers with a higher likelihood of producing alpha.

\subsection{Conclusion}

Hedge fund strategies vary widely, from lower to higher risk and from more defensive to more bullish postures. Macro and managed futures funds tend to retain their value or even profit in times of equity market stress, whereas the majority of equity hedge funds tend to perform better in times of rising equity markets because of their net long equity market exposure. Event-driven and relative-value funds focus on security-specific characteristics, hoping to realize superior returns from market inefficiencies. These funds tend to perform 
best in normal market environments, in which credit spreads are stable to declining and equity market prices are driven by stable economic growth. Event-driven and relative-value funds tend to suffer in periods of market crisis. Knowledge of these characteristics can enable asset allocators to build portfolios with high levels of diversification and attractive expected returns. 


\section{Accessing Multiple Hedge Fund Strategies}

Chapter 4 discussed a variety of hedge fund strategies, including macro and managed futures, equity strategies, and event-driven and relative-value funds. Each of these strategies has its own risk and return profile and preferred market environment. Investing in a single hedge fund subjects investors to manager risk as well as to the risk of investing in a single strategy. Most investors seek to diversify both manager risk and strategy risk by allocating to a number of managers or strategies. Because returns across managers and strategies have correlations less than 1 , combining multiple strategies in a portfolio can substantially reduce risk through diversification. This chapter discusses the three primary methods for achieving this diversification: (1) investing directly in a portfolio of single-manager hedge funds, (2) using one or more multimanager or fund-of-funds ( $\mathrm{FoF}$ ) products, or (3) investing in one or more multistrategy funds. Before discussing the three methods of diversifying in detail, the next section presents the case for diversification.

\subsection{Diversifying across Managers and Strategies}

Investing in a single hedge fund is like investing in a single stock. Owning just a single stock leaves an investor with a large amount of idiosyncratic or stockspecific risk. Most publicly traded companies operate in a single industry with a given management team. This focus on a given industry subjects the investor to a specific business cycle, which may differ from that of other industries in the economy. For example, investors have long known that technology and commodity stocks may have unique and extreme cyclicality, whereas other industries, such as consumer staples, are more stable over the course of a business cycle. Investors in a single firm also place their trust in a single management team that builds a company around a specific set of products or services. If the company incurs a crisis or the company's products or services fall out of favor, then investors may experience huge losses relative to the overall market.

The same principle applies when investing in hedge funds. Investing in a single hedge fund gives investors a specific risk/return profile. For example, investing in a relative-value fund may give a low-risk, steady-return profile during times of low volatility and stable credit spreads while also being prone to surprisingly large losses during a credit crisis. Just as consumer staple stocks diversify the commodity stock risk in a portfolio, managed futures funds may offer gains in a crisis market that offset the losses from the relative-value fund. 
Investing in a single hedge fund also concentrates the investor's risk into a single management team. Should that fund manager have a highly concentrated or leveraged position at the wrong time, significant losses can result.

Fothergill and Coke (2001) and Amo, Harasty, and Hillion (2007) discussed the diversification benefits of investing in multiple hedge funds. ${ }^{4}$ These authors have suggested that portfolios of 15-20 hedge funds offer substantial risk reduction over investments in a single hedge fund. Portfolios of this size have less than half the standard deviation risk of a single hedge fund and may approach the risk of a portfolio of fixed-income securities. Studies indicate that beyond 20 hedge funds, manager risk and style risk are well diversified and additional hedge fund investments provide minimal additional diversification benefits.

\subsection{Due Diligence on Numerous Single Hedge Funds}

Investors need to make substantial efforts to perform due diligence on a universe of funds to build a diversified portfolio of hedge funds through a direct investment program. A database compiled by Hedge Fund Research (HFR) tracks more than 8,000 single hedge funds and nearly 1,500 fundof-funds products. Using a hedge fund database, an investor may be able to quickly narrow the universe of funds eligible for investment down to fewer than 1,000 funds based on such criteria as the length of track record, assets under management (AUM), or returns or risk better than the average fund in a strategy. For instance, many institutional investors prefer to invest in funds with more than $\$ 100$ million in AUM and a three-year track record. A large number of eligible funds typically remain, however. Performing analysis on these funds can be expensive and time consuming.

Funds with larger AUM may be easier to evaluate, because they often make large investments in institutional-quality infrastructure designed to make investors comfortable with the investment and operational processes of the fund management company. Fewer than $30 \%$ of hedge funds, however, have more than $\$ 500$ million in assets, so there are thousands of relatively small funds to research, not all of which have made these infrastructure investments or reported their track record to one or more hedge fund databases.

Once these candidate funds are identified, the investor needs to contact each fund for more information and to schedule an initial interview. Funds

${ }^{4}$ Martin Fothergill and Carolyn Coke, "Funds of Hedge Funds: An Introduction to MultiManager Funds," Journal of Alternative Investments 4, no. 2 (Fall 2001): 7-16; Anne-Valere Amo, Helene Harasty, and Pierre Hillion, "Diversification Benefits of Funds of Hedge Funds: Identifying the Optimal Number of Hedge Funds," Journal of Alternative Investments 10, no. 2 (Fall 2007): 10-21. 
that are selected in this informational stage move to the due diligence phase. Chapter 13 discusses the extensive due diligence that is recommended for hedge funds investing, including onsite visits, operational due diligence (ODD), and investment due diligence (IDD). No matter how impressive the historic returns may be, investors need to examine critical issues in the ODD process, including the potential lack of risk controls or conflicts of interest in the cash management process. In the IDD process, investors should carefully evaluate the skills, experience, and teamwork of the fund's investment management personnel. Investors should evaluate the alpha earned by the fund management team, assess how the investment strategy is similar to or different from other funds trading the same strategy, and understand the expected risk and return of the strategy and how they are expected to vary over the business cycle and across market conditions.

\subsection{Direct Investment Program}

Before embarking on a program to build a portfolio of direct investments in hedge funds, investors need to consider the scale and the cost of the resources necessary to build this program. If the median hedge fund has a minimum required investment of $\$ 500,000$ and it takes 20 hedge funds to be fully diversified, investors need to allocate at least $\$ 10$ million to their hedge fund investments for a direct investment program to make economic sense. If the hedge fund portfolio is designed to be $10 \%$ of the investor's assets, then only those investors with portfolios exceeding $\$ 100$ million should consider direct investments in hedge funds.

In addition to the scale of the investment program, investors need to consider the cost. To build a hedge fund portfolio, investors need to allocate staff time to select and monitor the hedge fund investments, buy one or more hedge fund databases, work with a consultant or a manager research firm, travel to visit each candidate hedge fund on site, and incur legal fees to ensure that each hedge fund investment contract has been structured correctly. If these costs are $\$ 500,000$ per year, investors can perform a buy-versus-build analysis relative to investing in a fund of hedge funds (i.e., FoF). If the FoF charges a $1 \%$ management fee and no incentive fee, then investors with a hedge fund portfolio of less than $\$ 50$ million ( $\$ 500,000$ divided by $1 \%$ ) may wish to invest in funds of funds or multistrategy funds rather than performing their own due diligence process. If the FoF charges incentive fees or higher management fees, the breakeven asset size would be lower.

Some investors may wish to directly invest in hedge funds, even if the economics don't match those laid out here, because the direct approach gives investors much more control over how their hedge fund portfolio is allocated 
and managed. That is, although some investors may prefer to tactically change their hedge fund investments to fit their forecasted view of future market conditions, other investors may make a strategic decision to overweight macro and managed futures funds to offset risks in other areas of their investment portfolio. The downside, however, is the cost of initial and ongoing due diligence as well as the fees charged by the underlying hedge funds. Some hedge funds are willing to negotiate lower fees with investors, but investors with the largest investments are often best able to negotiate these fees.

\subsection{Netting of Incentive Fees}

As discussed in Chapter 3, many single-manager hedge funds charge fees of 2 and 20, whereas FoFs may charge up to 1 and 10 in addition to the 2 and 20 . Investors need to fully understand how incentive fees work, especially when multiple hedge funds are involved because the fees for multiple hedge funds may be higher than if all of the hedge funds' positions were held in a single portfolio. The issue is the netting of incentive fees.

Assume the unfortunate outcome that your hedge fund portfolio has a gross-of-fee return of $2 \%$, with half of your funds earning $8 \%$ and half returning $-4 \%$ before management fees. We might be tempted to calculate the portfolio return as zero net of fees, thinking that the $2 \%$ management fee offsets the $2 \%$ gross return and that no incentive fees are payable because the portfolio earned $0 \%$ net of management fees. Only the funds that lost $4 \%$ have zero incentive fees, however; the funds that returned $8 \%$ before management fees and $6 \%$ after management fees still earned the incentive fees. The $20 \%$ incentive fee on the half of the portfolio with a $6 \%$ return net of management fees is $1.2 \%$, putting the investor's total portfolio return at $-1.2 \%$. When investing in a portfolio of hedge funds, either directly or through a fund of funds, the incentive fees are not netted, meaning that incentive fees are due to funds that earned positive new investment gains, while the hedge funds that posted negative performance in the most recent period do not provide any incentive fee rebates.

\subsection{Funds of Funds}

FoFs or multimanager funds are structures that contain multiple hedge fund managers. This section discusses the implications on diversification, fees, and costs associated with these structures rather than a direct hedge fund program.

Previously, we compared single hedge funds with single stocks and noted that each single investment contains idiosyncratic risk from its management team, industry sector, or trading style. We now extend that analogy and compare FoFs (or multimanager funds) with mutual funds. In both FoFs and 
mutual funds, investors pay a fee to hire professional managers to select and monitor investments. FoFs and mutual funds provide access for small investors who don't have the time, knowledge, or minimum investment required to build a fully diversified portfolio of hedge funds or stocks.

There are many benefits to investing in FoFs and just a few disadvantages. The primary disadvantage of investing in FoFs is the cost, including the fees (often 1 and 10 on top of the individual fund fees of 2 and 20) as well as the lack of netting of incentive fees, a condition that is also present when investing directly in a portfolio of hedge funds. After subtracting the FoF's fees, FoF investments tend to underperform direct hedge fund investments as well as investments in a single hedge fund that invests in multiple strategies with a single layer of fees (often 2 and 20). Many investors regard ceding control of manager and strategy selection as a key advantage of investing in FoFs, but sophisticated investors who wish to maintain this control would view that as a disadvantage of investing in FoFs.

For their fees, FoFs provide investors with many valuable services. The most notable value added of FoFs is that these multimanager fund structures assume the cost and responsibility of performing the hedge fund selection and manager research process, including the time-consuming and costly task of due diligence. Some investors prefer FoFs for the lower minimum investment required. Although it may take a single investor $\$ 10$ million to build a portfolio of hedge funds at their required minimum investment, investors can achieve the same level of diversification by investing in a fund of funds with a minimum investment of $\$ 1$ million.

The FoF also adds value through its relationship with the hedge fund managers held in its portfolio. Some of these underlying hedge funds may be closed to new investors after reaching capacity, but the FoF may still be able to add assets to a closed fund, allowing its investors to participate in a closed fund that they otherwise would not be able to invest in. Because of the larger scale that comes from commingling the assets of many investors, FoFs may have superior negotiating ability with hedge fund managers, perhaps being able to secure lower fees or better liquidity terms than investors on their own. To the extent that the FoF is able to negotiate lower fees with the underlying managers, the fee the FoF manager charges investors is effectively reduced by the lower fees on the portfolio funds. That is, although the hedge fund and FoF fees may be 2 and 20 and 1 and 10, respectively, the total fees could be much less than 3 and 30 if the FoF successfully reduces fees on the underlying hedge fund investments to a level below 2 and 20 .

The FoF can add value through strategic and tactical allocation across managers and strategies. The portfolio construction process requires 
knowledge of the return characteristics of each style and each manager as well as an ability to see how the hedge fund investments may work together through time. In strategic asset allocation, the FoF will have a relatively static mix of strategies over time, perhaps equally weighted across event-driven, relative-value, and equity funds as well as macro and managed futures funds. A fund of funds may add value through tactical decisions, perhaps overweighting equity and relative-value strategies when assuming that equity and credit bull markets will continue or overweighting macro and managed futures funds when markets are expected to decline and experience rising volatility. The opportunity to add value may be even greater through manager selection than through strategy selection, because the return spread between top and bottom hedge funds in a given strategy tends to be larger than the return spread across various hedge fund strategies.

Most hedge fund investments are made through commingled accounts, where investors send their money to a hedge fund manager who commingles their assets with those of other investors and provides periodic, often monthly, reports on the performance of the fund. Investors in commingled funds need to comply with fund terms, such as lockup and redemption periods, and the security holdings within these hedge fund investments often are not transparent. Some FoFs seek to reduce risk and increase transparency through the use of separate accounts, managed accounts, or funds of one (described in the next paragraph).

In a separate account, also called a managed account, each investor keeps custody of his assets and allows the hedge fund manager to trade in his account. The investor can monitor all holdings in real time, which can allow him to implement a risk management strategy for all of the combined holdings across managers. Because managed accounts do not automatically offer the limited liability features of an investment in a fund vehicle, some FoFs have been investing in funds of one. That is, if a manager engages in leveraged or derivatives trades in a managed account, the investor potentially could lose more than the amount of assets originally allocated to the strategy. In a fund of one, the assets are held in the hedge fund manager's custody without being commingled with other investors' assets. This structure retains the limited liability feature for the investor with the added benefit of negotiating the degree of transparency to the fund's underlying positions.

\subsection{Multistrategy Funds}

In a multistrategy fund, a single hedge fund manager invests in multiple hedge fund strategies in a single fund vehicle. In one fund, for example, the manager mixes relative-value, event-driven, equity, macro, and managed 
futures strategies. In many cases, the multistrategy fund has a structure in which a single fund has multiple investment teams. Each strategy team operates relatively independently, but a senior fund manager or allocation committee chooses how best to allocate capital across each of the internal trading teams. Those tactical reallocations can be due to the outperformance or underperformance of one of the investment teams or a prediction that the coming market environment will favor one specific strategy over another. Because all of the trading teams are typically housed within one fund or one bank, the multistrategy fund as a whole has transparency into the underlying portfolio, which can facilitate risk management and tactical reallocations at the fund level. Because of lockup and notice periods, this type of tactical reallocation is much more difficult for FoFs than for multistrategy managers.

Some investors may invest in one or more multistrategy funds rather than in FoFs. Historically, multistrategy funds have outperformed FoFs because multistrategy funds lack the additional layer of fees (1 and 10). Multistrategy fund investors can benefit from the netting of incentive fees, charging a single fee-perhaps 2 and 20, which is lower than that charged in a portfolio of hedge funds because, in the latter, the investors do not benefit from the netting of incentive fees. Multistrategy funds pose one key disadvantage, however, which stems from the fact that just one bank or one fund manager ultimately manages this fund. Relative to a fund of funds, which might invest across 20 different fund management companies, thereby providing a highly diversified portfolio of investment and operational risks, the multistrategy fund concentrates all of the investment and operational risks within the structure of a single fund manager.

\subsection{Hedge Fund Indexes}

Whether investing directly in hedge funds, in a fund a funds, or in a multistrategy fund, a key decision is how to diversify assets across hedge fund strategy types. Many investors will quantitatively model their asset allocation decision using hedge fund databases and indexes as a guide to the risk and return of each strategy as well as the correlation of returns of each strategy with each other and the likely behavior of each strategy given various bull and bear market scenarios.

A hedge fund index fund that gives investors a way to passively invest in every hedge fund at a low cost does not exist. Some hedge funds are closed, some aren't disclosed to investors, and the sum of the minimum investments 
across funds would be prohibitively high. Indexes typically are calculated net of fees with no netting of incentive fees. ${ }^{5}$

Investors are cautioned, however, that the historical returns of a hedge fund index or a hedge fund database may be quite different from those experienced when investing in a single fund or even a portfolio of funds. For example, let's consider a hedge fund index tracking long-short equity hedge funds, which may contain more than 1,000 individual hedge funds. The hedge fund index may be constructed by equally weighting returns across the funds or by asset weighting, in which the largest funds have the largest weights in the index. It would be difficult to invest any large amount of money in an equally weighted index (because the smallest funds would not be able to accept their share of the index investment) and effectively impossible to rebalance. Asset-weighted indexes can be highly concentrated; because the largest 20\% of funds (those with more than $\$ 1$ billion AUM) manage $90 \%$ of all assets, the index is unrepresentative of the experience of investors who are not in the largest funds. Thus, there is no ideal index.

Note that the return to the index is some type of average of all of the funds tracked by the index, funds that may have positive or negative alpha, or fund that may have $20 \%$ net long or $80 \%$ net long equity market exposure. Single managers typically have a higher standard deviation of returns than the index, because the index is averaging returns across all managers, whereas single funds may have returns far from their category average.

Hedge fund indexes are carefully calculated to minimize biases in return calculations. Hedge fund databases may have significant biases, however, many of which appear to increase the return or decrease the risk of investing in hedge funds. Because it is voluntary for hedge funds to report their returns to a hedge fund database, we need to consider selection bias. Selection bias refers to the situation wherein managers with strong returns are more likely to report their returns than managers with weaker track records.

This problem is closely related to instant history or backfill bias. Consider a manager with a strong two-year track record who decides to report to a hedge

\footnotetext{
${ }^{5}$ See the large body of literature on hedge fund indexes; readers are referred to Greg Gregoriou, Georges Hubner, Nicolas Papageorgiou, and Fabrice Rouah, "Survival of Commodity Trading Advisors: 1990-2003," Journal of Futures Markets 25, no. 8 (2005): 795-815; Jenke ter Horst and Marno Verbeek, "Fund Liquidation, Self-Selection, and Look-Ahead Bias in the Hedge Fund Industry," Review of Finance 11, no. 4 (2007): 605-32; William Fung and David Hsieh, "Empirical Characteristics of Dynamic Trading Strategies: The Case of Hedge Funds," Review of Financial Studies 10, no. 2 (1997): 275-302; William Fung and David Hsieh, "Performance Characteristics of Hedge Funds and Commodity Funds: Natural versus Spurious Biases," Journal of Financial and Quantitative Analysis 25 (2000): 291-307; Bing Liang, "Hedge Funds: The Living and the Dead," Journal of Financial and Quantitative Analysis 35, no. 3 (2000): 309-26.
} 
fund database for the first time. When returns are reported to the database, the first two years (or however long the hedge fund was managed before returns were reported to the database) will be added all at once, whereas the later track record will be added in real time - a single month at a time. For many funds, the live track record isn't as impressive as the initial returns- the good initial returns being the reason why the hedge fund began to report in the first place. Therefore, the returns that have been backfilled may be assumed to be higher, with less risk, than the returns that are later reported in real time.

Hedge fund databases also experience issues with survivorship bias. Hedge funds that have liquidated are assumed to have lower returns and higher risks than hedge funds that continue to be managed and report returns to databases. With many hedge funds opening and closing in periods as short as three to five years, survivorship bias can be a significant issue. This problem may arise if an analyst seeks to understand the risk and return of the hedge funds using the returns of all hedge funds being managed today without compensating for the hedge funds that have been liquidated since the start of the study.

Although these biases can be significant when studying returns in hedge fund databases, investors have much less need to be concerned regarding these biases when working with hedge fund index return data. Index providers are aware of these issues and carefully construct indexes to overcome them. Consider a hedge fund that reported to a hedge fund database at the end of its second year and liquidated at the end of its fourth year. The database includes all four years of its track record, including the two years of backfilled returns, and moves the fund from its live database to its defunct or graveyard database at the end of the fund's life. In contrast, the hedge fund index would include the fund's returns only in years three and four and would not restate the returns reported live by that fund when it subsequently liquidated.

\subsection{Conclusion}

Hedge funds are a popular alternative investment strategy, recently topping $\$ 3$ trillion in global investment. Investors are cautioned, however, not to invest in just one hedge fund or one hedge fund strategy because doing so needlessly concentrates idiosyncratic risk. Investors, then, should diversify across both hedge fund styles and hedge fund managers to reduce this idiosyncratic risk and have a more balanced return pattern across the business cycle. Depending on the sophistication, size, and goals of the investor, this diversification may be achieved through direct fund investment, funds of funds, or multistrategy funds. 


\section{Introduction to Real Assets}

This chapter provides an introduction to the main categories of real assets, both tangible (e.g., land) and intangible (e.g., intellectual property). The chapter examines some of the unique features of real assets and surveys some historical evidence regarding performance. This chapter discusses five important categories: vacant land, farmland, timber, infrastructure, and intellectual property. Chapters 7 and 8 discuss two other major categories of investable real assets: commodities and private real estate. The distinction between the land-related assets covered in this chapter and the real estate covered in Chapter 8 is that the latter category has been improved with buildings for use in housing and businesses.

\subsection{The Key Attributes of Real Assets}

This chapter examines institutional-quality real assets—that is, alternatives that financial institutions commonly elect to include in their investment portfolios (as opposed to real assets, such as collectibles). Real assets are defined as any economic resource (other than human capital) directly used to create value.

The Range of Real Assets. Two interesting aspects of real assets are their unfamiliarity to many investors and their diversity. Take, for example, infrastructure and motion pictures-two subclasses not commonly held by institutions that in previous decades have exhibited vastly different features. The typical infrastructure investment, such as a toll road, generates predictable streams of cash flows similar to coupons on highly rated bonds. In direct contrast are film production and distribution, which are considered to be high-risk investments with features similar to private equity. A large percentage of motion pictures fail to recover their initial investment, followed by a small percentage that earn high rates of return, and even fewer that go on to build a powerful franchise of offspring with superior rates of return.

Real Assets as Diversifiers. Although the key attributes of real asset investments can be quite different, they are similar in their role as diversifiers. Consider commercial real estate, farmland, and timberland. All three include land investments, but the economic forces that drive the performance of each category are not the same. The economics driving the performance of an investment in an office building are different from those of a working farm and of a forest of timber. All three have weak correlations with equity markets. This performance is illustrated in Table 6.1, which reports return correlation coefficients of these three real assets and an equity index provided 
Table 6.1. Correlations of Returns on Three Categories of Real Estate and US Equities, 1991-2015

\begin{tabular}{l|cccc}
\hline & Equities & Real Estate & Farmland & Timberland \\
\hline Equities & 1.00 & 0.23 & 0.02 & 0.17 \\
Real estate & $\mathbf{0 . 2 3}$ & 1.00 & 0.40 & -0.06 \\
Farmland & $\mathbf{0 . 0 2}$ & $\mathbf{0 . 4 0}$ & 1.00 & 0.18 \\
Timberland & $\mathbf{0 . 1 7}$ & $\mathbf{- 0 . 0 6}$ & $\mathbf{0 . 1 8}$ & 1.00 \\
\hline
\end{tabular}

Source: TIAA, "Private Real Assets: Improving Portfolio Diversification with Uncorrelated Market Exposure" (Winter 2016).

for comparison purposes. The three real asset classes are represented by the National Council of Real Estate Investment Fiduciaries (NCREIF) indexes (privately held commercial real estate, privately held US farmland, and privately held timberland), and the Russell 3000 stock index represents equities. Six key correlation coefficients are bolded in the table.

Reduction in Portfolio Risk from Diversifiers. Table 6.2 indicates the percentage risk reduction achieved by having two or more asset classes in a portfolio (relative to having only one asset class) assuming all asset classes are equally weighted and have identical volatilities and that all correlations among the asset classes are equal. Note that lower correlations and additional assets both have strong diversification effects. Tables 6.1 and 6.2 viewed together indicate the potential for alternatives to provide diversification when added to an equity portfolio. For example, Table 6.2 demonstrates that going from one asset class to four asset classes reduces total risk by between $26 \%$ and $50 \%$ when correlation coefficients are 0.4 or less.

Table 6.2. Reduction in Portfolio Risk Relative to a One-Asset Portfolio*

\begin{tabular}{lccccc}
\hline & \multicolumn{5}{c}{ Number of Assets in Portfolio (Equally Weighted) } \\
\cline { 2 - 6 } Corr. Coeff. & \multicolumn{1}{c}{2} & 4 & 7 & 10 & 15 \\
\hline 1.0 & $0 \%$ & $0 \%$ & $0 \%$ & $0 \%$ & $0 \%$ \\
0.8 & $-5 \%$ & $-8 \%$ & $-9 \%$ & $-9 \%$ & $-10 \%$ \\
0.6 & $-11 \%$ & $-16 \%$ & $-19 \%$ & $-20 \%$ & $-21 \%$ \\
0.4 & $-16 \%$ & $-26 \%$ & $-30 \%$ & $-32 \%$ & $-34 \%$ \\
0.2 & $-23 \%$ & $-37 \%$ & $-44 \%$ & $-47 \%$ & $-50 \%$ \\
0.0 & $-29 \%$ & $-50 \%$ & $-62 \%$ & $-68 \%$ & $-74 \%$ \\
\hline
\end{tabular}

*Assumes equal volatilities, weights, and correlation coefficients. 
Caution should be taken, however, in accepting these results as indicating true reductions in risk. In particular, the NCREIF indexes are based primarily on appraisals, which are notorious for underestimating risk, as discussed later in this chapter. Correlations of 0.4 or less among asset class returns would be considered low to very low, values near zero indicate no relationship between the two asset categories, and negative values indicate two investment types that tend to move in opposite directions.

Historical Performance of Alternative Assets. Table 6.3 provides a long-term summary of the returns of the assets depicted in Table 6.1. The real asset subclasses of commercial real estate, farmland, and timberland performed well in a time period that has been mostly favorable for equities and that includes both broad economic expansion and major retrenchments. With annual returns on par with or exceeding equities and with reported volatilities at roughly onehalf those of equities, the resulting Sharpe ratios (i.e., return-to-risk ratios) for these real assets are high. The takeaway from the data in these tables is that real assets not only are effective diversifiers but also have performed relatively well as standalone assets. Caution, however, should be exercised because the volatilities of the three alternative assets may be understated as a result of the use of appraised values in constructing the underlying returns.

\subsection{Accessing Real Assets}

Institutional investor access to real assets involves a spectrum of opportunities. This section discusses four of these opportunities: direct investment, investment through funds, partnership interests, and derivatives.

Direct Investment. Direct investment involves direct ownership of the real assets by a single entity, such as ownership of a real estate project by a single institution. Management of the properties or other assets is typically subcontracted to a management firm. Access through direct investment tends to be illiquid and lumpy (investment size is dictated by the size of the asset).

Table 6.3. Average Returns and Volatilities of Three Categories of Real Estate, plus US Equities, 1991-2015

\begin{tabular}{lcccc}
\hline & Equities & Real Estate & Farmland & Timberland \\
\hline Average annual return & $9.26 \%$ & $8.44 \%$ & $12.10 \%$ & $10.81 \%$ \\
Std. dev. (volatility) & $17.38 \%$ & $8.67 \%$ & $7.01 \%$ & $10.06 \%$ \\
Sharpe ratio & 0.53 & 0.97 & 1.73 & 1.07 \\
\hline
\end{tabular}

Source: TIAA, "Private Real Assets: Improving Portfolio Diversification with Uncorrelated Market Exposure” (Winter 2016). 
Advantages of direct investment by large institutions include full control of the properties, managers, and choice of exit strategy.

Fund Investment. Access to funds holding real assets can alleviate some of the need to be involved with managerial issues; however, these funds can increase potential conflicts of interest and decrease the institution's control relative to direct investment. Private fund structures, including commingled funds, syndications, and joint ventures, vary by the number of investors and their relationship with the managers. Private fund investments are illiquid. Publicly traded funds, such as publicly traded REITs, provide liquidity. Although publicly traded funds provide the convenience of quick exits, they come with a potential downside.

Some research indicates that market values of REITs not only respond to their core factors (e.g., underlying real estate) but also take on additional systematic risk by trading alongside equity investments. Under this interpretation, publicly traded fund returns contain artificially high amounts of risk because they pick up the risk of equity market turmoil. Other research suggests that the publicly traded fund returns are more accurate indicators of the true performance of the underlying assets and that the returns based on appraised values understate volatility because of the smoothing effects of basing returns on subjective valuations.

Limited Partnerships. As with hedge funds, some real asset investments are structured as limited partnerships. Especially in the area of energy production and distribution (mostly natural gas and oil), assets can be accessed through master limited partnerships (MLPs) and are made liquid by trading on an exchange. The MLP structure has a number of advantages. First, an MLP listed in the United States qualifies for pass-through status as long as at least $90 \%$ of its income is related to its core business. This means that the MLP is not subject to corporate income tax, avoiding the potential for double taxation of income. Another tax advantage is that the distributions to the limited partners are not considered as income but rather as return on capital, allowing depreciation and depletion to defer income subject to taxation. As a disadvantage, the limited partners receive K- 1 tax forms, and they may need to file and pay income taxes in multiple states.

Access through Derivatives. Other avenues of access to real assets include derivative contracts (e.g., options, futures, forwards, and swaps). Although publicly traded derivatives markets are a key method of investing in commodities and real estate, the derivatives market for other real assets is still developing. Real assets that are heterogeneous and illiquid are less conducive to derivatives trading than are real assets, such as commodities. 


\subsection{Valuation of Real Assets and Smoothed Returns}

The valuation of many real assets is accomplished through appraisal-that is, by an expert's opinion of value. Appraisals are performed with a variety of methods, including comparative sales, analysis of net assets, and discounted cash flows (or income). Real asset appraisals, such as those of land, timberland, farmland, and other real estate, can be especially subjective because of the heterogeneity of the assets and the resulting ambiguities in comparative analyses.

A key issue in appraised valuation is the tendency of appraisals to generate a smoothed series of prices that stray from market-based indicators of values and changes in values. The raw data behind an index based on appraisals are subjective estimates that could come from analyses of old transactions and other old information. Furthermore, appraisers may form muted estimates of changes in valuations as a result of behavioral phenomena (e.g., anchoring) that inhibit timely recognition of the effects of changes in market conditions, such as rental rates; changes in macroeconomic conditions, such as discount rates; and the most recent sales agreements. Smoothing has been shown to reduce, perhaps substantially, the estimates of volatility and correlation. Note that smoothing has a minimal impact on estimated long-term average rates of return. With this in mind, the data reported in Tables 6.1 and 6.3 regarding volatility and correlations may overstate the key advantages of holding real assets.

The potential for managerial discretion to smooth or otherwise distort reported performance is related to valuation distortions caused by appraisals. In some cases, the properties managers select for updated appraisals are not random but rather are selected carefully to manage apparent returns-delaying bad news and sometimes saving some of the good news for a future time. In addition, returns can be managed through model manipulation, defined as inflated or deflated model inputs to generate particular values. One example of this practice is the use of an unrealistically low discount rate that has the effect of elevating the property's value. Finally, a favorable mark (i.e., a biased indication of value that is provided by a third party) can be used to inflate the reported value of a portfolio of real assets.

\subsection{Raw Land}

Raw land is any undeveloped surface or lot. Investments in raw land range from vacant lots to lots primed for construction, and they are usually preceded by government approval to build (or mine) in the future. Raw land purchased for building in the future is called land banking - that is, purchasing land without any specific plans for development. Most land is purchased for surface development, but land ownership in the United States may also 
include mineral rights. Investors who purchase land with the intent to extract minerals must determine whether the rights to the surface extend to resources below the surface.

A useful way to view raw land investment is as a call option on future development. This framework emphasizes the prospective value of the land should one or more future paths present themselves. The higher the number of uses for the raw land (i.e., the more potential paths), the higher the value of the call option. The greater the volatility around the payoffs connected to these paths, the greater the value of the option. This may sound counterintuitive, given that an increase in volatility is typically associated with a fall in the present value of future cash flows. But for raw land options, the downside loss associated with any particular path is limited to the amount of the investment, whereas the upside gain has no limit.

With respect to raw land as an option, development would be exercised when the value of the land under development exceeds the value of the raw land in waiting. These characteristics make modeling the valuation of raw land particularly challenging because costs and benefits need to be laid out and updated regularly. One type of raw land model that has been shown to have particular promise is real option analysis using tree diagrams that allow for the values of key factors to change through time while also allowing for both project expansion (should conditions change for the better) and project abandonment (should conditions change for the worse).

\subsection{Farmland}

Farmland is a land investment that generates crop or livestock income. Farmland combines the investment characteristics of land ownership with a steady source of income and, therefore, combines two risk components: (1) exposure related to the rise and fall of commodity prices and (2) exposure related to land speculation. The tendency for these two types of exposure to be uncorrelated benefits the farmland investor in the form of risk reduction.

Farmland investors typically transfer day-to-day management and supervision to tenant farmers. In the typical case, the tenant farmer and the owner of the farmland will enter an agreement over many years that specifies the amount of rent that the tenant farmer will pay. The annual income to the farmland investor from row crops (e.g., soybeans and corn), permanent crops (e.g., fruits and citrus), and livestock has been historically stable and relatively low, in the 3\%-6\% range as estimated by the US Department of Agriculture. Therefore, volatility in short-term farmland investment returns is driven mostly by potential changes in the value of the land. 
Farmland investment has been shown to offer a valuable opportunity to hedge inflation risk. Because farmland income is tied to commodity price levels, the historical relationship between the inflation rate and the nominal rate of return on farmland has been shown to be positive. Note that this positive relationship, sometimes referred to as positive inflation beta, is generally not the case for financial assets (the counterpart to real assets) that typically exhibit negative inflation betas.

\subsection{Timber}

Similar to farmland, timber is an investment in both land and an underlying commodity-in this case, the cultivation and long-term management of trees. Continued strong global demand for timber products along with moderate volatility and low correlation with a variety of asset classes has energized this market in recent years.

The access gate into the timber market has gone through a fundamental shift over the past few decades. What was once a market dominated by integrated lumber companies (e.g., Weyerhaeuser) that both owned and harvested the land has transitioned into a market in which the timber assets are controlled by timber investment management organizations (TIMOs). The role of the TIMO is to provide skills and expertise in managing the timber assets. Timber investors take an ownership position in the timberland and at the same time turn over the day-to-day operations to the TIMO, which then charges fees of about $1 \%$ of assets under management.

Investors can examine prices of liquid access to timber markets to measure risk and return. A number of exchange-traded funds (ETFs) have surfaced to facilitate easy access to publicly traded corporations with substantial timber exposure. One example is the Global Timber and Forestry ETF (WOOD) that has been trading for more than five years and represents an index of publicly traded companies that own or supply forests and timberlands. Table 6.4 compares the performance of this ETF to that of the S\&P 500 Index.

Table 6.4. Timber Liquid Alternatives Performance, August 2012-August 2017

\begin{tabular}{lcc}
\hline & Timber ETF & S\&P 500 Index \\
\hline Average annual return & $4.63 \%$ & $5.05 \%$ \\
Annual volatility & $15.5 \%$ & $12.2 \%$ \\
Correlation with S\&P 500 & 0.791 & \\
\hline
\end{tabular}

Source: CAIA Association. 
Note that the volatility of timber returns and the correlation of timber with equity returns are much higher in Table 6.4 than is reported for timber in Tables 6.1 and 6.3. These results highlight the issue of appraisals, market values, and smoothing. Investors in the ETF can enjoy the daily liquidity and low minimum investment of the ETF, but they give up the relatively low reported volatility and low correlation based on appraisals that comes with direct investment in timber. The debate remains: Does liquid access to real assets create additional risk or reveal true risk relative to illiquid access? Perhaps the answer is a combination of the two possibilities.

One interesting aspect of timber is that harvests can be timed to manage realized returns. The growth rates for various tree types are mathematically modeled. When combined with expected revenues and costs per cubic foot, investors can precisely model the optimal harvesting time of trees as economic conditions change. Indeed, these models can become quite complex when extended over multiple periods and multiple rotations (rotation refers to the timing of the harvest and is usually defined as the point at which profit peaks). The decision of when to harvest can be changed based on new information about timber prices, such as delaying harvest when lumber prices are depressed, which is a time during which the trees continue to grow and become more valuable. This option has value and is in contrast to more typical harvests, such as corn or wheat, that are on a strict schedule because of potential spoilage.

\subsection{Infrastructure}

Infrastructure is a large and increasing class of investable assets. Infrastructure is a hybrid asset class, with characteristics of both fixed-income securities and private equity. An infrastructure investment is represented by facilities providing the services necessary for a society to function. Examples include utility projects (e.g., power plants and water treatment facilities), transportation projects (e.g., toll roads, airports, terminals, and ports), and social projects (e.g., schools, hospitals, courts, and correction facilities). The Preqin Quarterly Update: Infrastructure Q2 2017 ranks the top five infrastructure types as follows: renewable energy, transport, utilities, other energy, and social. The Preqin Quarterly Update lists Europe as the largest investment region, followed closely by North America and Asia.

Infrastructure projects are often divided into greenfield (yet to be started) and brownfield (existing). For example, in 2008, India opened a greenfield airport in Hyderabad, built using a public-private partnership model from the ground up on undeveloped land, and it instantly became the country's most modern airport. This is in contrast to India's simultaneous brownfield renovation of existing airports in Mumbai and Delhi. 
Infrastructure investments tend to be distinguished by the following five features:

1. Large physical assets

2. Long duration

3. Stable, predictable, long-term cash flows

4. Regulated pricing

5. Uncorrelated returns

These five features are suggestive of a business that operates as a monopoly. For example, the aforementioned Hyderabad airport has no direct competitor. In the area of public utilities, the market position of power plants is such that governments often play an assertive role in the operation of the business, setting prices through a rate-making process. Other areas of possible regulatory interference in the operation of an infrastructure project include overseeing services; setting caps on profit margins; and perhaps most important, creating the potential to revoke operational licenses. Political risk, defined as the potential for the actions of governments to reduce the value of an investment, must be considered when investing in infrastructure.

Historical performance of unlisted infrastructure funds indicates an average annual return near that of equities, volatility at less than half that of equities, and near-zero correlation with equities. As with timber, however, infrastructure investors seeking liquid access, such as that provided by iShares Global Infrastructure ETF (IGF), should expect returns with a high correlation with equities and high levels of volatility, as indicated in Table 6.5.

\subsection{Intellectual Property}

The last type of real asset highlighted in this chapter is intellectual property (IP). In the context of institutional-quality investing, IP is an intangible and valuable creation of the mind that is investable. Investors have long recognized

Table 6.5. Infrastructure Liquid Alternatives Performance, August 2012-August 2017

\begin{tabular}{lcc}
\hline & Infrastructure ETF & S\&P 500 Index \\
\hline Average annual return & $2.71 \%$ & $5.05 \%$ \\
Annual volatility & $13.1 \%$ & $12.2 \%$ \\
Correlation with S\&P & 0.738 & \\
\hline
\end{tabular}

Source: CAIA Association. 
the worth and importance of intellectual capital as a driver of firm value. For example, the high market value of many high-tech companies, relative to the balance sheet values of their tangible assets, indicates the critical role played by IP in creating value for the firm. Traditional investing can capture exposure to IP through investments in public equities whose assets include substantial IP.

Investors can access exposures to a broader range of IP through IP assets that exist outside publicly traded corporations. These include copyrights on video (e.g., films), copyrights on audio (e.g., music), patents, trademarks, service marks, and trade secrets. These investments can be accessed through private funds or can be purchased on secondary markets. For example, most of the 8 or 10 largest film producers in the United States are subsidiaries of massive publicly traded conglomerates whose assets cover diverse industries. One of the more common ways to gain pure exposure to films is through coinvesting deals arranged by financial intermediaries that invest in a slate (a set) of films.

Within each category of IP are subclasses that offer diverse risk exposures. For example, the risk exposures of film production differ by genre and budget. Diversifying the film investment by type and other characteristics is considered to be a good strategy because profits on films have been shown to be highly positively skewed, similar to venture capital. Diversification increases the chances of attaining what most motivates investors to consider film investing: the prospect of being an investor in the select few films that go on to create a franchise of stackable sequels that take on the enviable characteristics of low risk and very high returns. Thus, the life cycle of the most successful film investment begins with greenfield characteristics resembling a venture deal and ends with a mature IP investment that generates reliable licensing, royalty, and patent-based income.

\subsection{Conclusion}

Real assets directly produce or assist in the production of economic benefits. Examples include tangible assets, such as land or buildings, and intangible assets, such as patents and copyrights. Combining tangible real assets with labor, financial capital, and intangible assets is the formula for the creation and enhancement of wealth through the positive net present values of successful firms. This chapter has provided an overview of the characteristics of real assets and the major real asset subclasses other than commodities (covered in Chapter 7) and improved real estate (covered in Chapter 8).

Investors in real assets primarily seek these investments for their contribution as portfolio diversifiers. Previous research based on appraised values has shown that institutional-quality classes of real assets, such as raw land, farmland, timberland, and infrastructure have near zero correlation 
with traditional equities and minimal correlations with each other. To the extent that the appraised values accurately indicate opportunities to exit (i.e., potential transaction prices), adding one or more of these classes of real assets to a portfolio of traditional assets can build more efficient portfolios by diversifying nonsystematic risk. Valuation by appraisal, however, often results in smoothed returns and underestimated risk parameters relative to those revealed by prices in financial markets. A serious consequence of using appraisals that smooth returns is underestimation of risk and overestimation of diversification benefits. 


\section{Real Assets: Commodities}

Chapter 4 discussed managed futures funds, some of which actively trade both long and short positions in commodities. This chapter exclusively details long-only investing in commodities, typically obtained through long positions in swaps or futures contracts. Commodities represent a substantial portion of invested assets among institutions. For example, the CAIA Alternative Index allocates a $10 \%$ weight to commodities as a representative allocation within the entire category of institutional alternatives.

\subsection{Overview of Commodity Investing}

The primary method by which institutions gain exposure to long-only commodity returns is through swaps or futures contracts on commodities, which are held either directly or through commodity managers. For this overview of asset allocation-related issues, we use the term futures contracts to include both futures contracts and forward contracts.

A futures contract is an agreement, not an option, to exchange a specified underlying asset on a specified settlement or delivery date. A long position in the contract is an agreement to buy, and a short position is an agreement to sell. Most futures contracts do not end with delivery; they end with both sides of the contract closing their positions prior to the delivery date. Usually participants do not engage in futures contracts to take or make delivery; rather, they do so to take on or lay off the price risk of the underlying asset. If market participants wish to maintain exposure to a commodity, they roll over their positions periodically from a contract close to delivery to contracts with later delivery dates, such as by selling the expiring March contract and buying the June futures contract.

In the United States, major commodities are usually divided into categories because so many commodities are traded in cash markets and futures markets. Exhibit 7.1 provides a summary of popular categories of commodity futures

\section{Exhibit 7.1. Popular Commodities with Futures Contracts}

\begin{tabular}{ll}
\hline Agricultural and Food & Meats, grains, coffee, sugar, orange juice \\
Energy & Crude oil, natural gas, gasoline \\
Metals & $\begin{array}{l}\text { Precious metals, such as gold and silver; industrial metals, such as } \\
\text { aluminum and copper }\end{array}$ \\
Others & Commodity indexes, lumber
\end{tabular}


as well as representative examples. Note that tremendously important financial futures contracts, such as equity indexes, interest rates, and currencies, are not part of this discussion because the underlying assets in these cases are financial securities rather than real assets. Many managed futures funds emphasize financial futures contracts rather than physical commodities, so managed futures or commodity trading advisers are not generally appropriate vehicles to maintain persistent long exposure to commodity markets.

Many commodities play large roles in the world economy, so it is natural that numerous commodity indexes have emerged to indicate the tendencies of these commodity prices as a whole. A handful of especially popular indexes in the United States are summarized in Exhibit 7.2. The construction methods for commodity indexes vary widely and raise serious issues regarding the extent to which commodity investing can be accurately indexed. Which commodities should be included and how they should be weighted are key issues. Popular indexes have large differences.

One issue when constructing commodity indexes is to determine how many and which commodities to include, given the substantial variation among indexes. The biggest challenge with constructing these commodity indexes, however, is knowing how to weight each category. Energy products, including oil and natural gas, dominate the markets for physical commodities; these products provide about half the physical commodity futures trading volume and open interest in recent years. Well over half the weight of Standard \& Poor's (S\&P) GSCI is in energy commodities, the BCOM caps all weights at $33 \%$, and the CRB's exposure to energy products is capped at $33 \%$. A challenge with institutional commodity investing, therefore, is

\section{Exhibit 7.2. Major US Commodity Price Indexes}

Bloomberg Commodity Index (BCOM):

Formerly Dow Jones UBS

Uses physical commodities weighted by trading activity

Limits the weight on each commodity sector to $33 \%$

Standard and Poor's GSCI:

Is subdivided into numerous subindexes

Weights based on the value of production

Dominated by the weight on energy commodities

Thomson Reuters/Core Commodity CRB Index (CRB):

Originally created by the Commodity Research Bureau

Weighted in tiers designed to reflect economic importance 
that the performance of most physical commodity indexes is dominated by changes in energy prices-especially during periods of large changes in the price of crude oil.

If the traditional index construction approach toward market-value weighting (or approaches that make relatively modest modifications to market weighting) is applied to commodity index weighting, the result will be return exposures that are dominated by energy price movements during many time intervals. In addition, what is meant by "market value" is less clear in commodities than in equities or bonds, so production weighting and other schemes believed to approximate market value are used. Thus, unlike traditional investments, the weighting methods for indexes become a huge factor. Solutions include using a popular index or making the weights an important part of the investment process.

An issue that arises in performance measurement for commodities is that no universally accepted standard is used to calculate the return of a specific commodity. In the case of equities, the returns are often clear: For example, the daily return of the stock of IBM would typically be the price change for that day, plus any dividends received, divided by the closing price on the previous day using the NYSE prices. The problem with performing the same calculation on a commodity, such as corn, is that such commodities do not have a universal cash-market price or a unique futures market price because commodity futures are traded with numerous delivery dates.

Even when a futures contract month is specified (e.g., December 2018 corn), when that month arrives, the position will need to be rolled over into a month with a more distant settlement date to maintain a steady exposure. The crux is that the computation of long-term performance for a commodity using futures contracts depends on the procedures by which the contracts are rolled over prior to settlement. The procedures can differ by how near the delivery date the old contract is exited and how far out the new contract is entered in terms of its delivery date.

It has become customary to define the total return on a commodity investment as the sum of (1) the change in the cash price over a period, (2) the "roll yield" from the futures contract rolling procedure described earlier, and (3) the return on any cash collateral deposited to support the futures contracts. This total represents the return on a fully cash-collateralized, unleveraged position in the commodity. As described earlier, however, there are multiple ways to calculate this return.

The performance of long-only commodity investing using collateralized futures contracts is driven primarily by the selection and weighting of the commodities. Unlike traditional long-only strategies, which are usually 
analyzed relative to a market-weighted portfolio of securities, no clear benchmark for performance exists for commodities. If exposure to individual commodities is closely related to the size or economic importance of the commodities, then the resulting portfolio will be dominated by energy commodities. The challenge of long-only commodity investing, therefore, is to identify a weighting scheme and a benchmark that best provide the benefits soughtin particular, diversification.

\subsection{Potential Benefits of Commodities}

Commodity investing by institutions soared in the years before the 2007-09 global financial crisis. Gresham Investment Management reports that institutional investment in commodities increased fourfold to $\$ 175$ billion in the years leading up to $2007 .{ }^{6}$

What motivated institutions to allocate so strongly to commodities? The primary attractions to long-only commodity investing include inflation protection, diversification, and the potential for attractive expected returns. Let's take a close look at each of those potential benefits.

Inflation Protection. Nominal commodity prices tend to rise when the value of money falls (i.e., inflation occurs). The economic linkage is clear because commodity prices are an important component of broad price indexes and thus a positive correlation should exist between the prices of the component (commodity price levels) and the changes in the price index (inflation). Energy prices are a key driver of general commodity price levels, which in turn are a driver of wholesale and consumer prices. Clearly, commodities provide at least moderate protection against inflation.

Diversification. What causes the general price levels of commodities to change? Like the prices of all assets, commodity prices are driven by supply and demand. So commodity prices should be expected to rise when demand rises or supplies fall. Increases in demand for most commodities coincide with increases in general economic activity. The consequence is that general physical commodity price levels are positively correlated with economic activity. Thus, economic reasoning suggests that the price level of a broad commodity index (and the prices of many individual commodities) should have a positive beta. Statistical analysis of past data generally finds positive betas (computed relative to an equity market index) for most commodities.

Take, for instance, the huge impact of energy prices on overall physical commodity price levels. During periods of oil price volatility, a clear

${ }^{6}$ Gresham Investment Management, "Strategic Commodities Funds 2007 Annual Review" (2007). 
correlation often exists between oil price changes and forecasts of worldwide demand, with the worldwide demand forecasted to rise whenever global economic growth is expected to rise.

Investments in general commodity price levels are not absolute return products; commodity returns tend to have positive betas relative to equity markets, yet they tend to offer moderate diversification benefits.

Potential for Attractive Expected Returns. There are two potential reasons for enhanced return from commodity exposures: (1) higher expected returns from bearing nontraditional beta risk (i.e., alternative betas) and (2) higher expected returns from alpha.

The first explanation for potentially attractive returns is the belief that commodity exposures diversify into alternative systematic risks and away from traditional risks in the search for risk premiums. Note that diversification is often used exclusively to describe the process of reducing nonsystematic (unique) risks. Here the term is being used to describe the process of taking more distinct bets, causing a portfolio's systematic risk exposure to be less concentrated in traditional systematic risk factors (equity market risk, interest rate risk, and credit risk) and more exposed to alternative risk factors. The goal is to invest in a broader set of systematic risk factors and, in so doing, achieve a better combination of risk and return.

The second reason for potentially attractive returns is the belief that commodity prices are underpriced on sufficient occasions to justify exposure to that asset class. To the extent that commodity markets are informationally inefficient, alpha may result from using superior managers.

\subsection{Economic Reasoning regarding Expected Commodity Returns}

The theoretical arguments regarding long-term returns on commodity futures date back to seminal work by Keynes, Working, and Black. ${ }^{7}$ A major use of commodity futures is to allow commodity producers to lock in the sales prices of their products into the future by "selling" their production by establishing short positions in futures contracts. These producers are natural hedgers attempting to reduce their risks. Conversely, users of commodities are less concerned about long-term commodity prices and tend to use cash markets and inventories to meet their short-term needs for commodities. It is argued

7.M. Keynes, A Treatise on Money (London: Macmillan 1930); H. Working, "The Theory of the Price of Storage," American Economic Review 39, no. 6 (1949): 1254-62; Fischer Black, "The Pricing of Commodity Contracts," Journal of Financial Economics 3, no. 1-2 (January/ March 1976): 167-79. 
that the result creates downward pressure on futures prices relative to prices in the cash market for commodities ("spot" prices).

Figure 7.1 illustrates the hypothesized relationship between futures prices and cash prices in commodities when natural hedgers drive down long-term futures prices. The illustrated relationship is termed backwardation (when the curve slopes upward, it is termed contango).

In a backwardated market, if spot prices remain stable, then forward prices tend to rise through time because forward prices converge to spot prices at delivery. Thus, it can be argued that backwardated markets indicate high expected returns on futures-based long-only commodity strategies. It is also possible, however, that backwardated prices reflect the anticipation of declines in spot prices that may more than offset the effects of backwardation. Thus, determining expected commodity returns is not easy.

A potentially valuable issue to explore in asset allocation is the source of an asset's expected return. To the extent that natural hedgers fuel high demand for short positions in long-term commodity futures, other market participants will meet that demand by establishing long positions. Arguably, other investors or speculators will meet that need when futures prices decline sufficiently to provide speculators with attractive expected returns on their long futures positions. The key concept is that to the extent that large commodity producers are willing to bear low or negative returns on their short positions in commodity futures, it can be argued that the long positions will consistently generate attractive returns. Alternative investment experts often refer to the economics of this situation using the concept of insurance. Commodity producers are effectively buying insurance protection from

\section{Figure 7.1. Backwardated Forward Curve}

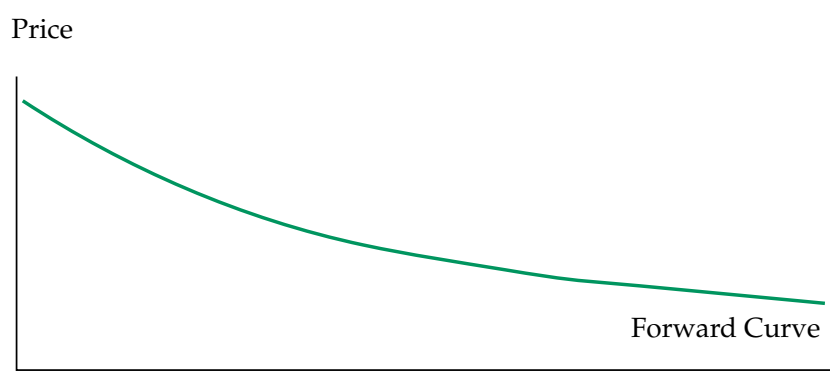

Time to Delivery

Notes: The forward curve represents prices today for delivery of a commodity at various times in the future. A curve in backwardation can increase commodity investment returns when the price of the futures contract rises over time to meet the higher spot price. 
commodity speculators. Commodity speculators are compensated for providing this protection through, on average, receiving trading profits.

A final issue regarding long-term return expectations from commodity investing relates to economic reasoning and the long-term price level of various commodities. On the one hand, commentators argue that natural resources are limited and that the massive growth in the world population is leading to increased scarcity and higher real prices for commodities. This line of reasoning often leads to theories that the supply of certain commodities has "peaked" or is about to peak and that huge price increases are inevitable as commodity production is expected to decline.

On the other hand, many economists note that technology and efficiency have been rapidly increasing for two centuries and that these increases have lowered the real prices of almost all commodities. They point out that a little over a century ago, $50 \%$ of the US workforce was devoted to agriculture-a percentage that has plummeted to $2 \%-3 \%$ in recent years. The idea is that as we become increasingly efficient at producing commodities, the real price of those commodities will tend to fall in the long run. The prevailing trend in commodities for the past two centuries has been a reduction in real prices, although it is the real prices of the output of other sectors (e.g., education and health care) that have been rising.

\subsection{Empirical Evidence regarding Commodity Returns}

In 2006, Gorton and Rouwenhorst reported an important empirical finding regarding long-only commodity returns using an equally weighted average of commodity futures contracts for the July 1959-December 2004 period: "Fully collateralized commodity futures historically have offered the same return and Sharpe ratio as U.S. equities," they wrote. "Although the risk premium on commodity futures is essentially the same as that on equities for the study period, commodity futures returns are negatively correlated with equity returns and bond returns."

This finding implies that investors who included commodities in their asset allocations improved their risk-adjusted returns over the 45-year period. An argument known as the Masters hypotheses, advocated by Michael W.

\footnotetext{
${ }^{8}$ See Gary Gorton and K. Geert Rouwenhorst, "Facts and Fantasies about Commodity Futures," Financial Analysts Journal 62, no. 2 (March/April 2006): 47-68. The returns analyzed were based on fully collateralized positions, which means that cash collateral for the futures contracts was assumed to be invested in interest-bearing money market securities in the same magnitude as the nominal size of the futures contracts. Updated return analysis can be found in Geetesh Bhardwaj, Gary Gorton, and Geert Rouwenhorst, "Facts and Fantasies about Commodity Futures: Ten Years Later," Yale University (25 May 2015).
} 
Masters, ${ }^{9}$ is that institutional enthusiasm for the attractiveness of commodities as an investment led to massive allocations to commodities that in turn caused large commodity price increases in 2007-2008.

Commodity prices soared to a peak in mid-2008 and then fell dramatically in the next seven to eight years. Using the S\&P GSCI as an indicator, from their 2008 highs to the price levels of 2016-2017, commodity prices declined an astounding $80 \%$. Obviously, great caution must be used in basing asset allocations on historical performance alone.

\subsection{Access to Commodities with Futures Contracts}

Although institutions gain access to commodity returns in a variety of ways, positions in commodity futures contracts underlie most of them. This section discusses a key concept underlying futures contract and commodity returns.

To understand the role of futures contracts in providing exposure to commodities, let's begin by considering the case of financial futures, such as a futures contract on the S\&P 500 Index with a settlement date of 15 March. A futures contract enables the party that is long the contract to demand receipt of the underlying asset on the settlement date of the contract from the party that is short the contract at a prespecified price.

Suppose that the S\&P 500 Index is trading at 2400 on the day that an investor establishes a long position in the S\&P 500 futures contract with a delivery price of 2400 on 15 March. The investor sets aside $\$ 2,400$ per contract in money market securities to collateralize the exposure. On the same date, assume that a cash investor purchases an exchange-traded fund (ETF) that mimics the S\&P 500 Index. To simplify this analysis, assume that the dividends that the cash investor receives from the ETF exactly match the interest that the futures investor receives on the collateral. Finally, note that on $15 \mathrm{March}$, the value of the futures contract must converge to the value of the S\&P 500 Index (and the ETF) because, on that date, they all offer the same value at the same time.

Now let's compare the returns of the cash and futures investors. The cash investor pays $\$ 2,400$ and receives the value of the index on 31 March, plus some dividends. The futures investor deposits $\$ 2,400$ and receives the value of the index on $31 \mathrm{March}$, plus some interest. In fact, under our assumption that the interest and dividends are equal, the futures price must at all times be equal to the cash index value. ${ }^{10}$

${ }^{9}$ Izabella Kaminska, "Michael Masters on Speculation, Oil, and Investment," Financial Times Alphaville (3 February 2015).

${ }^{10}$ If the interest rate differs from the dividend yield in this example, then the initial price of the futures contract will differ from the current spot price of the index to ensure that the exposures generate equal returns. Also note that this introductory analysis does not expound on issues, such as marking to market or differences between forward and futures contracts. 
This highly simplified example illustrates a relationship that must be closely approximated in financial markets: The returns to cash investments in a financial asset must equal the returns to a collateralized futures position on that same asset because they offer the same risk

If the previous equation does not hold, shrewd investors will quickly buy the side offering the higher return and sell short the side offering the lower return until the prices are driven into equilibrium. The result in the case of futures on financial assets is that cash markets and futures markets generate nearly identical returns from their equal exposures. In the case of financial securities, investors commonly obtain their exposures to asset classes using cash securities, futures contracts, or both.

The prices of futures contracts on financial assets are governed by a well-known relationship between the price of the financial asset, its anticipated distributions, and short-term interest rates. Arbitrageurs tend to force financial futures prices into a tight relationship with their underlying cash securities.

In the case of physical commodities, however, futures contracts offer some complexities and important advantages to most institutional investors. The pricing of futures contracts on commodities introduces two issues relative to financial futures: storage costs and convenience yield. Storage costs are all of the disadvantages of maintaining a physical inventory through time, such as facility maintenance, insurance costs, and spoilage. Convenience yield is the potential advantage to some operating firms from having physical possession of commodities that they might need to continue to produce the firm's product or service without interruption.

Unlike financial futures pricing, the pricing of futures contracts on commodities involves the complexity of storage cost differentials and convenience yield differentials between market participants. Furthermore, the difficulty of short selling commodities in the cash market can interfere with the ability of arbitrageurs to keep prices in line with a specific model. The task of risk management and asset allocation decisions tends to be much easier when pricing models are highly accurate.

Direct investment in physical inventories of commodities by such institutions as pension funds, banks, insurance companies, and endowments raises serious issues regarding transportation costs, storage costs, and forgone convenience yield. Therefore, commodity futures contracts should be viewed as convenient and cost-effective vehicles with which to establish and maintain long-only exposures to commodity values. Although futures contracts can be traded in a highly speculative manner, fully collateralized, long-only exposures to commodities can be prudent investments. 
There are several common methods of investing in commodity futures. Investors can hold a single futures contract that offers exposure to a set of commodities or can opt for portfolios of individual commodity futures. Institutions may use separately managed accounts managed by a commodity fund manager.

Finally, some securities offer exposure to commodities without direct use of futures contracts, such as ETFs, mutual funds, commodity-linked notes, swaps, and other derivatives.

\subsection{Commodity Returns and Sources of Returns}

How should an asset allocator decide whether to include exposure to commodities (through futures contracts) in a portfolio, and if so, how much of the portfolio should be allocated to commodities? Chapter 1 discussed two pillars of investment analysis: economic reasoning and empirical analysis.

Empirical analysis of commodity returns raises perhaps the most important issue in using historical data to forecast likely future behavior: the decision of how much past data to use to estimate the mean returns and volatility of an asset or an asset class. There are two competing dangers. An observation period that is short (e.g., data over the past 5 or 10 years) runs the risk that the data will reflect only a limited range of economic conditions. A long-term observation period of several decades, however, runs the risk that observations from much of the period reflected economic conditions that differ substantially from what future economic conditions are likely to be.

After a sharp rise in prices, the historical returns of commodities appeared quite attractive in 2007. Reliance on empirical analysis is argued to have led many institutions into new allocations into commodities that drove commodity prices up and led to an eventual collapse. The key concern with using past mean returns to project future expected returns is the potential for returns of assets to revert toward some historical or theoretical mean, punishing investors who "chase" past performance. To the extent that long-term mean reversion of returns exists, then investors should increase allocations to assets that have performed poorly over past years and decrease allocations to assets that have performed well over past years. Conversely, investors allocating assets away from historically well-performing assets toward those asset classes trading at historically low price levels will be punished if market prices are in a long-term rise or decline.

When empirical analysis is not reliable, greater emphasis should be placed on economic reasoning (i.e., theory). Economic reasoning raises two questions: (1) How much expected return should be obtained in a competitive market for bearing the systematic risks of a particular investment (i.e., how much return can be generated from systematic risk premiums), and (2) will 
the expected returns of a particular asset or asset class be different from the expected return that should be received from systematic risk premiums (i.e., is there any alpha)?

Investors should seriously consider the issue of the source of returns.

Section 7.3 discussed the idea that investors with long positions in commodity futures might consistently be able to generate attractive returns because of the strong desire of operating firms to hold short positions in commodity futures to hedge their costs of acquiring the commodities in the future. If operating firms consistently drive down long-term commodity futures contracts prices through their hedging activities, long-only commodity investors might be able to earn attractive returns by holding commodity futures, as the contacts shorten in longevity, especially with a futures market in backwardation. The potential source of returns emanates from establishing long positions in long-dated commodity futures and then "rolling up" the price curve as the contract shortens because of the passage of time. This source of return is called roll yield.

Note, however, that commodity futures prices can drop consistently and dramatically even in backwardated markets. As discussed earlier, some measures indicated $-80 \%$ commodity returns over recent years, primarily because of declining prices in key commodities, such as energy products. 


\section{Private Real Estate and Illiquidity}

This chapter on institutional-quality private real estate focuses on commercial properties. We emphasize allocations to real estate equity rather than mortgages. Mortgage investing, especially residential mortgage investing, offers interesting exposures to prepayment rates, which are discussed in Chapter 11.

The primary issue regarding private real estate in this chapter is its illiquidity. Much of this chapter uses private real estate as a reference point to explore the implications, more generally, of asset illiquidity to asset allocators. Further issues regarding illiquidity are discussed in Chapter 9 in the context of private equity.

Like commodities, institutions invest in private real estate properties for their potential ability to provide diversification, improved risk-adjusted returns, and inflation hedging. Unlike commodities, many real estate holdings can generate substantial and reliable income (i.e., cash flows).

\subsection{Types of Private Real Estate}

At the highest level, equity-like exposure to private commercial real estate is divided into domestic and international properties. Within those categories there are four primary distinctions:

- Type: NCREIF ${ }^{11}$ has established five major categories of commercial real estate properties: (1) apartment, (2) hotel, (3) industrial, (4) office, and (5) retail. Each category is further divided into subtypes in NCREIF's extensive collection of data. Each category offers distinct risk/return exposures.

- Location: Commercial real estate properties are often differentiated into three categories of size or prestige of the geographic area in which they are located. Primary real estate markets tend to have large populations (e.g., perhaps 5 million or more), but the level of real estate investment activity matters as well. Secondary markets have moderate populations or moderate levels of real estate investment activity, and tertiary markets include areas with small populations or limited real estate investment activity.

- Style: NCREIF has established three primary styles of commercial real estate that can be ranked from least risky to most risky: (1) core real estate, which includes fully operational and occupied properties within the major

\footnotetext{
${ }^{11}$ NCREIF (the National Council of Real Estate Investment Fiduciaries) is a not-for-profit US organization focused on collecting and disseminating data and knowledge with regard to private commercial real estate investments.
} 
types of real estate that are located in large or well-known geographic markets, (2) value-added real estate, which includes at least moderately operational and occupied properties within the major types of real estate or other developed properties, and (3) opportunistic real estate, including more speculative or undeveloped properties with little or no occupancy.

- Class: There are several classes or tiers of real estate properties in terms of quality. Class A properties are well-managed, highly desirable properties with premium locations and amenities. Class $\mathrm{B}$ properties tend to be located in areas that are moderately desirable. Class $\mathrm{C}$ properties tend to be outdated and modestly located in nonpremium areas, and Class D properties are older and somewhat poorly maintained.

Asset allocators can use these four classifications to discern general information regarding the reliability of income from each type of real estate and the potential risk exposures that each offers in various economic scenarios. The task of allocating within private real estate categories is to balance the goal of full diversification with the goal of concentrating in those categories for which the allocator has a favorable market view.

\subsection{The Challenges of Illiquidity}

Private real estate is generally quite illiquid. Traditional investing in publicly traded major stocks and bonds offers investors the liquidity of being able to buy or sell with relatively low transaction costs at values determined through a competitive market. Obviously, the illiquidity of many private real estate investment opportunities means that investors wishing to buy or sell real estate face challenges in locating counterparties willing to transact on given properties at appropriate valuations within a desired period of time.

The illiquidity of private real estate raises important issues other than those regarding the execution of purchases and sales of properties. Asset allocators face challenges in selecting, monitoring, and managing illiquid assets. These challenges are not commonly experienced with traditional assets traded in public markets.

Throughout the range of tasks involved in selecting, monitoring, and managing traditional assets, investment professionals rely heavily on observations of market prices. Data on market prices can be used to provide objective measures of past volatility and recent performance; and in the case of options data, they can provide objective measures of anticipated volatility. Highly illiquid assets, such as private real estate, generally cannot be valued and analyzed with traditional methods that require reliable indications of past volatility, recent performance, or anticipated volatility. 


\subsection{Real Estate Valuation Approaches}

Three common valuation approaches apply to commercial real estate-each of which is similar to approaches used in traditional equity valuation.

Cap Rates. A cap rate is a capitalization rate-that is, a percentage rate of return that a real estate investor expects or demands on a commercial property. It is formed by dividing the property's net operating income by the property's total asset value. Net operating income includes rental income and direct costs, but it excludes financing costs. If a $\$ 100$ million property has an annual income of $\$ 9.5$ million, it would have a cap rate of $9.5 \%$. A prospective buyer uses the cap rate relative to cap rates on other properties to evaluate the property's price and may also compare the cap rate with rates of return that are available on competing assets, such as equities or bonds. The cap rate can be viewed as being quite similar to the earnings/price ratio of a common stock. Equity investors use the inverse of the earnings/price ratio, the $\mathrm{P} / \mathrm{E}$ ratio, in much the same way as the cap rate is used in real estate.

Discounted Cash Flow Analysis. Just as traditional equity investors often perform discounted cash flow analysis to estimate the present value of expected future dividends and other cash flows, prospective real estate investors often perform discounted cash flow analysis on properties to assess the attractiveness of a property. In real estate, the discounted cash flow approach is often termed the income approach. In the case of real estate, cash flow can often be projected quite accurately - for example, when properties have substantial long-term leases.

Comparable Sale Approach. Real estate is often valued using the comparable sales approach. The comparable sales approach uses recent transaction prices on similar properties to infer values on unsold properties.

Appraisals tend to be performed using all three of these approaches for properties with reliable income. Prospective real estate buyers often reference appraisal values in their decisions. These appraisal values, in turn, rely on one or more of these three methods.

\subsection{Relying on Appraisals and Market Values}

There are several sources of real estate prices and returns, including appraisals, financial market values, and transaction-based indexes. It is uncertain whether appraisals or financial market values are more reliable measures of the value of real estate properties.

Appraisals are professional estimates of values with several drawbacks in creating a reliable series of performance data. Appraisals are often criticized as being expensive, relatively infrequently performed, delayed, and sometimes 
overly conservative in reflecting large changes. Market prices of real estate pools are often criticized as being unrepresentative of actual real estate transaction prices and of reflecting the volatility of the equity market rather than the volatility of the real estate market.

Consider Table 8.1 and Figure 8.1. The market prices of the NAREIT Index serve as a reasonable proxy for publicly traded US commercial real estate prices. Prices of that index can be observed daily and reflect up-to-the-minute indications from traders with regard to the value of publicly traded real estate held in REITs. According to market data, the financial crisis began driving down real estate prices soon in February 2007. The total decline was $73 \%$ and lasted 25 months.

The preeminent US commercial real estate property index is the NCREIF Property Index (NPI), which is reported quarterly on a delayed basis. The NPI data do not reflect a decline in real estate prices until after the end of the third quarter of 2008-more than 1.5 years later-and indicate that the decline in real estate values lasted only six quarters. As can be seen in Table 8.1, the full decline based on quarterly appraisals was only $24 \%$.

Note that REITs tend to be substantially leveraged, which helps explain the large difference between the reported magnitudes of the declines during the financial crisis.

Finally, there is a third major type of real estate index other than financial market prices and professional appraisals: transaction data. Transaction-based real estate price indexes use recent real estate transaction prices to infer general real estate price levels. Transaction-based price indexes pose two major problems: (1) Transaction data generally are observed with a substantial delay from when the transaction price was agreed on, and (2) the quality and other characteristics of each property are unique-making point-to-point comparisons problematic.

One method used to address the challenges resulting from the heterogeneity of real estate characteristics from transaction to transaction is to use repeat sales (sale of the same property more than once). That approach raises

Table 8.1. Market Prices and Appraisals Spanning the Financial Crisis

\begin{tabular}{lcc}
\hline & Market Data & Appraisal Data \\
\hline Date of pre-crisis high & $2 / 2007$ & $6 / 30 / 2008$ \\
Date of subsequent low & $3 / 2009$ & $12 / 31 / 2009$ \\
Duration of decline & 25 months & 6 quarters \\
Size of decline & $-73 \%$ & $-24 \%$ \\
\hline
\end{tabular}

Sources: Market data based on NAREIT daily closing prices from Bloomberg. Appraisal data from NCREIF Property Index (NPI) quarterly returns. 
Figure 8.1. Public vs. Private Real Estate: Cumulative Wealth, 1 December 19931 September 2017

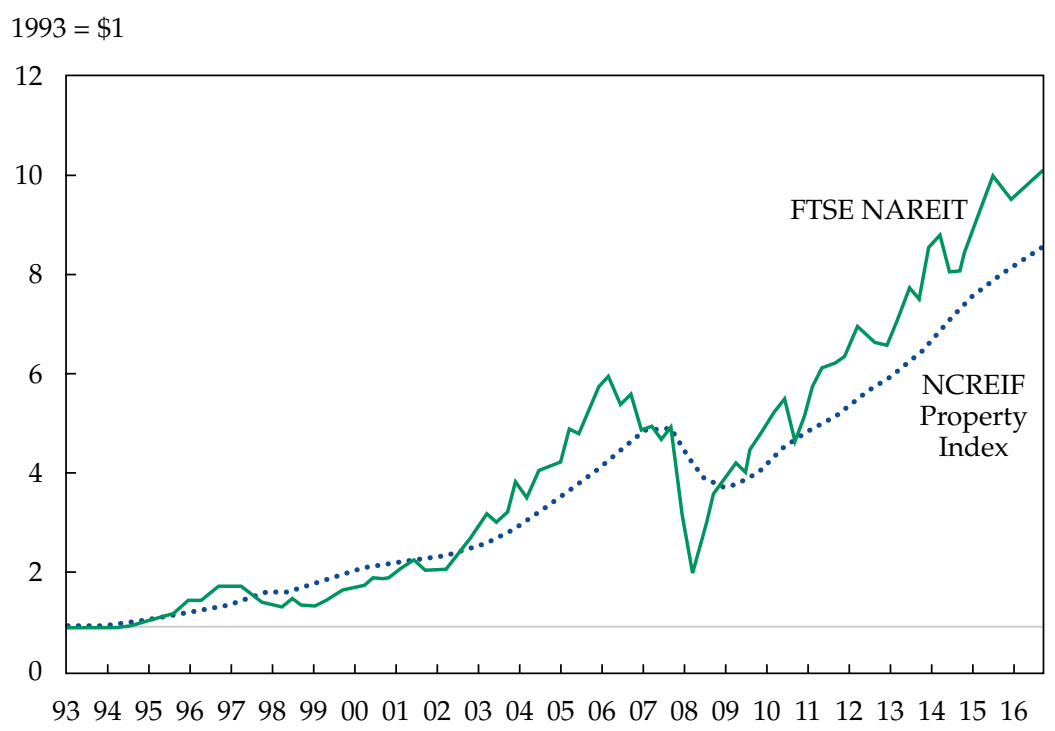

problems, such as limited data, the distorting effects of major changes to a property between sales, and the potential bias among the types of properties that transact in a particular market based on market conditions. For example, in a market with rapidly rising prices, the observed transactions might be overly represented by a particular type of property.

Another way to address these different characteristics of real estate properties is a hedonic approach. Hedonic approaches use statistical analysis of real estate transaction prices and their underlying characteristics to infer the price change of the entire set of real estate properties. For example, properties can be more directly comparable when adjusting for the square footage, number of rooms, or other features.

The primary tools for measuring changes in US commercial real estate values are appraisals and observation of REIT prices.

\subsection{Economic Reasoning and the Illiquidity of Private Investments}

The discussion of the challenges of real estate valuation in the previous section touches on issues relevant to the valuation of all illiquid investments. Real estate provides a long-term and rich set of data for analysis. Asset allocators 
can draw on lessons from the real estate sector to better understand the pricing of other illiquid investment sectors, such as private equity, intellectual property, art, natural resources, and some structured products.

Much has been written about human nature and the potential tendency of appraisers to be overly conservative and reluctant to modify their beliefs regarding valuation levels. Behavioral finance theory cites an anchoring effect in which participants place an inordinate importance on previously accepted beliefs. Appraisers in 2007 had reported virtually continuous quarterly price increases in commercial real estate for 12 years. It is possible that these appraisers were reluctant to conclude that the trend suddenly had reversed until well into the financial crisis when substantial evidence had emerged of a directional change. Note also that transaction prices may be deceptive if real estate sellers are reluctant to sign contracts for sales at a price substantially lower than the previous appraisal. Transaction data in the early stages of an economic slowdown might focus on sales of properties at relatively high prices, whereas the data in the early stages of a recovery might be drawn more from sales of properties at or near the previously observed lowest prices.

Prices based on publicly traded real estate are not without problems. Much has been studied about market prices and behaviors, such as herd behavior, which have been argued to cause extremes in valuation that appear to depart from rational and informationally efficient valuation. The general thesis of the criticism of REIT prices as an indicator of underlying real estate values is that REIT prices are driven by swings in equity markets rather than by true changes in real estate prices that would prevail if those prices could be observed independently.

\subsection{Internal Rate of Return as a Measure of Performance}

Highly liquid publicly traded assets have observable daily (and typically much more frequent) prices. These daily prices allow for the computation of timeweighted returns: returns that directly show the change in the value of an investment each day as a percentage of its value from the close of the previous trading day. Daily returns can be used to construct returns over longer time intervals.

Illiquid assets, such as private real estate, do not have reliable values that can be observed on a daily basis. In many cases, returns are reported only on a monthly or quarterly basis. As a consequence, highly illiquid assets are analyzed with other metrics, primarily the internal rate of return (IRR). An IRR analysis of real estate uses three types of inputs: acquisition costs, cash income, and a final value from an exit or an appraisal.

Let's apply the IRR method to a major publicly traded commercial real estate fund: the Vanguard REIT Index Fund (VNQ). Table 8.2 gives the 
Table 8.2. Performance of Public Real Estate, 2008-2012

\begin{tabular}{lccc}
\hline Date & Price & Dividend & Return \\
\hline Dec/07 & $\$ 61.46$ & & \\
Dec/08 & $\$ 36.45$ & $\$ 3.00$ & $-35.8 \%$ \\
Dec/09 & $\$ 44.74$ & $\$ 1.96$ & $28.1 \%$ \\
Dec/10 & $\$ 55.37$ & $\$ 1.89$ & $28.0 \%$ \\
Dec/11 & $\$ 58.00$ & $\$ 2.05$ & $8.5 \%$ \\
Dec/12 & $\$ 65.80$ & $\$ 2.34$ & $17.5 \%$ \\
\hline
\end{tabular}

annual dividends, year-end prices, and annual returns for VNQ over 20082012, assuming that all dividends were distributed on the last day of the year (i.e., ignoring reinvestment of dividends during the calendar year). To demonstrate the effects of volatility on the analysis, five years of performance, including the period of the financial crisis, are analyzed in Table 8.2.

The IRR from a buy-and-hold strategy for VNQ over the five full years is the rate of return, $r$, that equates the left and right sides of the following equation:

$$
\begin{aligned}
0= & C F_{0}+\left[C F_{1} /(1+r)\right]+\left[C F_{2} /(1+r)^{2}\right]+\left[C F_{3} /(1+r)^{3}\right] \\
& +\left[C F_{4} /(1+r)^{4}\right]+\left[C F_{5} /(1+r)^{5}\right] .
\end{aligned}
$$

The IRR formula may be viewed as the rate, $r$ in Equation 8.1, that equates the present value of an investment's future cash inflows (the righthand side after $\left.C F_{0}\right)$ to its cost $\left(C F_{0}\right.$, a negative number). Inserting the 2007 year-end price as the cost $\left(C F_{0}\right)$, the total annual dividends for years 2008 to 2011 as the cash flows for years 1 to 4, and the sum of the final price of 2012 and the dividends for 2012 as the final cash flow $\left(C F_{5}\right)$ generates an equation that can be solved for $r$ with a financial calculator or spreadsheet using trial and error:

$$
\begin{aligned}
0= & -61.46+[3.00 /(1+r)]+\left[1.96 /(1+r)^{2}\right]+\left[1.89 /(1+r)^{3}\right] \\
& +\left[2.05 /(1+r)^{4}\right]+\left[68.14 /(1+r)^{5}\right] .
\end{aligned}
$$

An investor taking on exposure to commercial real estate by buying VNQ at the end of 2007 and selling it at the end of 2012 would have earned an IRR of $4.96 \%$. This result can be interpreted as one measure of the annual rate of 
return that the investor received over the five years. But this interpretation is useful for an investor with a five-year time horizon only if it is possible for the investor to reinvest the dividends back into the same asset. In the case of a liquid asset, such as VNQ that is a realistic assumption. But in the case of most private investments, ongoing reinvestment in the same asset through time is not possible and thus IRR can be misleading.

As an extreme example, consider an investor who placed $\$ 100$ in an investment that paid back only two cash flows: $\$ 120$ in exactly one year and $\$ 1$ in five years. The IRR for this investment would be slightly more than $20 \%$. The IRR does not indicate the sort of annual average returns an investor could expect over the full five years on the initial investment. Realistically speaking, the investment generated a $20 \%$ profit in year 1 and a very tiny profit in years $2-5$. It would be misleading to claim that this investor enjoyed a five-year $20 \%$ per year return.

Furthermore, the $4.96 \%$ IRR or annual return for VNQ masks the incredible volatility that took place over the financial crisis. Table 8.2 shows that annual returns varied from $-35.8 \%$ to $+28.1 \%$. Only one year generated a return between $-15 \%$ and $+15 \%$. So the IRR of $4.96 \%$ must be viewed as a smoothed value - that is, an average. But several other averages could also be reported based on the annual returns. The average annual arithmetic return was $9.25 \%$, and the average geometric return was $6.05 \%$. Each of these averages has a useful interpretation. ${ }^{12}$ Here is the key point: The usefulness of the IRR is limited. One limitation is that its usefulness rests on the assumption that the investor is able to reinvest cash flows in the investment (or in an investment with identical future returns). Chapter 9 on private equity discusses other potential complications that arise when using IRR as a performance indicator when cash flow streams vary widely between investments.

\subsection{Aspects That Discourage Allocations to Private Real Estate}

Much of this chapter focused on the key disadvantage to private real estate: illiquidity. Of course, private real estate investment may offer illiquidity risk premiums that are attractive to those investors who have a high tolerance for illiquidity. Direct private real estate investment (as opposed to access through investment pools) offers some disadvantages, which are discussed here.

A traditional investment, such as shares of stock in a major corporation, is homogenous across investors: Millions of investors have the same security in

\footnotetext{
${ }^{12}$ The arithmetic mean return can be used to indicate expected short-term returns, whereas the geometric mean is useful for long-term analyses.
} 
their portfolio. This homogeneity not only facilitates liquidity but also facilitates the collection and availability of substantial information on the investment. Private real estate properties are heterogeneous and unique, virtually eliminating the sharing of information on the specific property.

Direct private real estate investments are also lumpy. Lumpiness refers to the difficulty of trading an asset in a desired size or quantity. Outside of fund or partnership investments, an investor either directly invests in an entire property or in none of it (unless the claims to the property are indirect and part of a pool).

Finally, direct private real estate offers income tax advantages that can be wasted by investors who do not face income taxes. Specifically, buildings can be depreciated for tax purposes in the United States and elsewhere, enabling the deferral of income taxes. The deferral of income taxes may be viewed as an interest-free loan from the taxing authority that creates value to the recipient because of the time value of money. Although this tax advantage may be a plus to taxable investors, income tax-free investors may find that real estate prices adjust such that direct real estate investments offer slightly lower expected returns. Pension funds and endowments may find that direct real estate investments (and to a much greater extent, municipal bonds) contain unusable tax advantages and are thus less desirable than fully taxable investments.

\subsection{Pooled Access to Direct Real Estate}

Investment pools vary with regard to the flexibility that they offer investorsby their longevity, by the number of investors in the pool, and by the degree of involvement allowed or required by each investor in the pool.

At one end of the spectrum are public REITs. A REIT is a type of stock that is included in many stock indexes. REITs are a huge and extremely popular method of accessing real estate that otherwise would be private. Public REITs allow exposure to real estate returns by large groups of investors who have no involvement in the ordinary operations of the pool. Although the structures are typically permanent, investors can enter and exit the REIT through liquid public markets. REITs typically focus on either equity investments in properties or on mortgage positions. Real estate operating companies (REOCs) are like REITs except that they reinvest rather than distribute income.

Private REITs, also known as nontraded REITs, are similar to public REITs except that they are not available through public exchanges. They are distributed through investment and financial advisers.

Closed-end funds are appropriate structures for investing in private real estate because-unlike the more common open-end funds-they are not 
required to redeem shares tendered by investors. The investor can exit only by selling the fund shares to another investor. Therefore, closed-end funds do not need to invest in liquid assets.

Private equity real estate funds are private funds that invest in equity exposures to real estate. Numerous types of private equity real estate funds are differentiated by the way that participation of various investors is organized. Popular structures include traditional limited partnerships, funds of funds, commingled funds, syndications, and joint ventures. The joint ventures tend to lie at the opposite end of the spectrum from REITs in the sense that joint ventures are often used by a smaller number of investors who work together and participate in the structure's organization and potentially in its operations.

Numerous structures, especially derivatives, have emerged to offer exposure to indexes of private real estate. These structures include exchange-traded funds; derivatives, such as options on indexes; and structured products, such as structured notes with exposures driven by real estate indexes.

\subsection{Conclusion}

Direct real estate investment was a major component of institutional investing more than a century ago. With the advent of well-organized and highly liquid trading of stocks and bonds, the illiquidity of direct real estate investing has caused this type of investment to recede from prominence in many institutional portfolios. This chapter provided an overview of the issues involved with that illiquidity, including valuation and return measurement. 


\section{Private Equity}

This chapter provides an overview of investing in institutional-quality private equity. Private equity investments are emblematic of the innovative and potentially very high-performing assets that make up the spectrum of alternative investments. The key feature of private equity is its illiquidity. As in the case of private real estate, illiquidity provides higher return potential but requires expanded tool sets to be effectively selected and managed. For example, investing in private equity funds often entails requirements to contribute additional capital to the fund (capital calls), causing net negative cash flows for several years.

\subsection{Types of Private Equity}

Not all private equity is accessible to institutional investors. Many large firms are held by families or founding partners whose shares are simply not available to new investors. Samsung Group (South Korea) is reportedly the largest privately held firm in the world. In the United States, Cargill, Incorporated, and Koch Industries, Inc., are the largest in terms of revenue, and both are among the largest 10 firms globally. Both firms reportedly are owned more than $80 \%$ by family members. There are tens of millions of tiny firms too small for direct institutional investment. Most institutions avoid substantial exposures to firms that have little or no chance of becoming publicly traded in the near to intermediate-term future.

Most institutions focus on private firms with prospects of going public. In other words, institutions allocate to those private firms that have reasonable prospects of offering an exit strategy through public markets. The idea is to purchase exposure to private firms, wait for them to go public, and then sell those positions into the organized equity markets or through mergers and acquisitions.

Private equity is composed of both equity securities and debt securities that offer equity-like exposure and participation. There are two major categories of unambiguous equity participations: venture capital and leveraged buyouts (LBOs). Several categories of debt securities have equity-like exposure, including mezzanine debt, distressed debt, and leveraged loans, such as bank loans.

The next section explores venture capital and buyouts. Section 9.3 discusses debt securities with equity-like characteristics. 


\subsection{Equity Types of Private Equity: Venture Capital and Leveraged Buyouts}

Venture capital is simply investment in small firms with the hope that the firm will thrive and mature to the point of going public (i.e., using an initial public offering, IPO, to become a publicly traded firm) or that the firm will be acquired by a large firm. Each individual venture has a payoff somewhat like a lottery ticket - that is, a large probability of loss of most or all of the investment and a small probability of a huge payoff. Most institutions obtain access to venture capital through venture capital funds, a type of private equity fund that specializes in these small, undeveloped firms. In venture capital, investors or investment managers usually play an important role in assisting the management of the enterprises and not just in contributing capital.

Venture capital differs by industry, time of inception (vintage), geographic location, and stage of development and financing. Venture capital firms typically begin with noninstitutional funding (often provided by entrepreneurs or by so-called angel investors, such as friends, family members, and wealthy investors interested in such firms). If the firm shows promise, financing may progress to the seed capital stage at which time institutions often provide financing through private equity firms. Financing rounds may continue with additional investment during first or early stages, second or late stages, and so forth through to the exit into public markets through an IPO.

Leveraged buyouts, along with other forms of buyouts, occur when a publicly traded firm is taken into a private structure through the purchase of a controlling or total interest in a firm's equity. Buyouts vary according to the entities leading the purchase with LBOs characterized by a private equity firm or other outside investor making the acquisition and typically financing the acquisition with a large percentage of debt financing. Management buyouts occur when the target firm's management leads the acquisition, whereas management buy-ins occur when an outside management team leads the acquisition.

The motivations for initiating buyouts vary, but most are attempts to release value that is perceived to be hampered by a publicly traded firm's existing structure or management. The buyout might be designed to improve a firm's profitability by lowering costs, disposing of poorly performing assets or assets that do not fit with a new strategy, adjusting leverage, or replacing or shaking up management or might be intended to realize gains for private equity investors rather than investors in public markets. 


\subsection{Debt Securities as Private Equity}

Many types of debt that are private are considered to be alternative investments because of their illiquidity and often because they are not commonly held by traditional investors. This debt is often classified as a form of private equity rather than being treated as another asset class, such as fixed income, to simplify a lineup of major alternative investment categories. This asset also is referred at as "private debt."

Mezzanine Financing. Mezzanine financing often emerges from LBOs and advanced-stage venture capital. The term "mezzanine" indicates that the nature of the financing lies between the safety of senior debt and the high risk of equity. Accordingly, the risk of mezzanine financing can be viewed as emanating from a blend of the fixed cash flows of debt and, typically, some upside participation with equity-like exposures.

Bank Loans and Leveraged Loans. Bank loans, often termed leveraged loans, are senior debt issued by companies that contain substantial credit risk because of the low credit ratings of the issuing firm or the existence of substantial debt on the borrower's balance sheet that has priority over the leveraged loan. The loans are usually floating-rate loans that have less interest rate risk than high-yield or junk bonds. The loans are usually made to middlemarket companies - those firms too small to issue publicly traded bonds but too large to be classified as seeking venture capital.

Distressed Debt. Distressed debt consists of debt issues that have become highly risky because of the deterioration of the credit worthiness of the issuing firm. As the value of the assets of a firm declines to or below the face value of the firm's debt, the firm's debt becomes increasingly like equity (and the equity becomes increasingly like an out-of-the-money call option). This sounds like a risky investment, but the high yields on distressed debt can compensate for the risk.

\subsection{Access to Private Equity}

Institutional access to all types of private equity is usually obtained through private equity funds using limited partnership structures as illustrated in Figure 9.1. The key features of limited partnerships are (1) that they allow institutions to invest while limiting their losses to the amount of money invested, and (2) for the purposes of income taxation, limited partnerships are flow-through entities, meaning that income taxes are assessed on the partners if they are taxable investors, not on the partnership itself. 
Figure 9.1. Common Institutional Access to Private Equity Investments

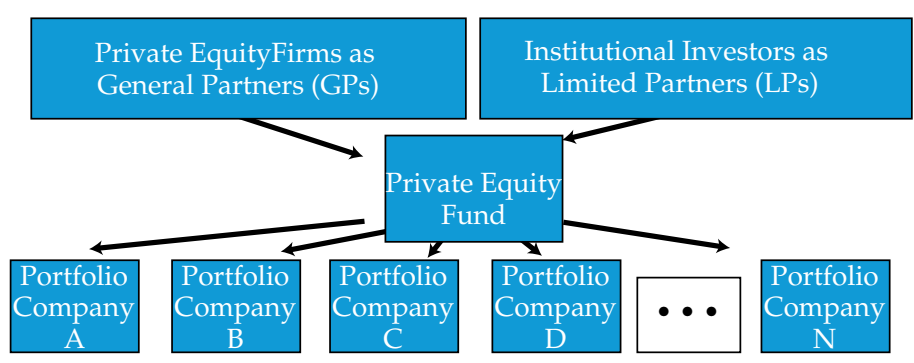

The general partners of a private equity fund are usually private equity firms; outside investors (institutional or individual) are known as limited partners. Private equity firms are organizations with personnel who are experienced in venture capital or buyouts and who have their own capital. Some of the largest private equity firms are Apollo Global Management LLC, Ardian, The Blackstone Group L.P., The Carlyle Group, and KKR \& Co. L.P. The general partners typically provide a relatively small portion of the fund's total capital. Most funds mature in 7-10 years from inception but may allow extensions of 2 or 3 years. The general partners select the portfolio companies and often are involved in working with their management. Limited partners may become involved in advisory committees, but they must play limited roles in managerial activities to retain their limited liability protections.

The portfolio companies shown in Figure 9.1 are the ventures selected by the fund managers that receive the invested capital. Investments in the portfolio companies are often made in the form of convertible debt or convertible preferred stock that gives the private equity investor both participation in the upside of the venture's equity and a high priority in the firm's capital structure in the case of poor performance. The goal of private equity investing is to identify portfolio companies that will eventually go public (i.e., raise capital through an IPO) or that will be purchased by other large corporationsboth of which can generate large profits for its private investors. The prices eventually received for the private equity positions are called realizations, and the ultimate profitability of a fund is driven by the number and size of these realizations.

Selection of the private equity funds to which one ultimately allocates capital begins with the selection of the manager, with the private equity firm serving as the general partner. Each established, large, private equity firm eventually offers many funds through the years that differ in their focus (e.g., 
early-stage venture capital, late-stage venture capital, LBOs, and so forth). Funds also differ by their geography (e.g., United States, Europe) and their vintage, which is the year that the fund began its operations. For example, in 2017, KKR launched Asian Fund III, with the name indicating that investment would take place in the Asia-Pacific region and that KKR had previously launched two other such offerings. Selection of funds involves the substantial need for due diligence, which is discussed in Chapter 13.

Managerial Life Cycle. A key issue in selection of a private equity manager involves the managerial life cycle. ${ }^{13} \mathrm{~A}$ private equity fund management team may pass through stages, including those of establishing a quality reputation, harvesting the benefits of that reputation, and perhaps experiencing a decline in quality or an exit from the field.

Successful management teams often exhibit superior performance persistence-that is, the ability to generate attractive returns on a series of funds. A successful management team launches a series of funds spanning many vintage years. A key to successful private equity investing is to identify a management team that is in the stage when it generates persistent attractive returns.

Once a private equity fund manager has demonstrated superior results, numerous investors often will want to participate in subsequent funds, which may create a situation where the private equity firm has to ration investment opportunities. In many such cases, fund managers give priority to investors who participated in previous vintages.

Institutional investors strive to identify potentially successful fund managers before their reputation becomes obvious so that the investors can be assured access to that manager if their services are sought by more investors than can be accommodated. It may be that only those institutions obtaining and maintaining access to superior managers will be able to enjoy superior returns.

Uncertain Exits, Illiquid Secondary Markets, and Monitoring. In most investments, illiquidity refers to the inability to sell existing investments at reasonably attractive prices without needing to take the time to engage in a search process for buyers. In the case of private equity funds, illiquidity can be especially severe when a fund has remaining capital calls or when an investor attempts to liquidate a position before its termination. The secondary markets for limited partnerships, where a limited partner's interests in the fund are sold to another investor, are not highly liquid. They may provide unattractive liquidation values, especially during periods of stress. Because of the illiquid

${ }^{13}$ This material is based in part on Thomas Meyer and Pierre-Yves Mathonet, Beyond the J-Curve: Managing a Portfolio of Venture Capital and Private Equity Funds (Chichester: Wiley, 2005). 
nature of private equity, most funds do not offer redemption features from the fund, because investors must wait for the sale of the fund's positions in portfolio companies through mergers or IPOs and for the distribution of proceeds from these transactions, which often are called exits.

Monitoring private equity fund investments may provide relatively diminished benefits because an investor's options are more limited than in the case of public investments as a result of potentially unattractive exit values and limited control over managers. Nevertheless, monitoring is advisable and limited partners can play valuable roles in working with fund managers. As the fund managers are likely to launch a new private equity fund in some future vintage year, this monitoring activity can be quite valuable-particularly when considering which upcoming fund launches the investors would like to allocate to.

Capital Call Risk. Investment in a private equity fund typically involves committing to a specific level of total investment (called the commitment) and then fulfilling that commitment through a series of payments by the limited partner to the general partner. These payments are called capital contributions and are made in response to capital calls (i.e., the demands by the general partner for the limited partner investors to deliver cash to satisfy investor commitments).

The total potential size of capital calls is specified before investing in a fund, but the timing of the calls and whether or not all of the capital allowed to be called will actually be called are uncertain. In the depth of the financial crisis, many institutional investors, including major university endowments, experienced the financial pain of having to meet new capital calls (because private equity managers found the low prices attractive) at a time when (1) their cash was depleted, (2) their other assets, such as equities, had low valuations, and (3) fund prices of existing private equity funds were so low that they discouraged the institutions from selling their limited partnerships on the secondary market.

Uncertain capital calls and uncertain exits (with regard to both size and timing) raise substantial cash management issues for private equity fund investors. Because it is unclear when the committed capital will be called and how much cash will be generated in the interim in the form of distributions from previous private equity investments, it is difficult for an institutional investor to predict and control the total size of its investment in private equity. An institutional investor that sets aside large amounts of cash to meet potential calls runs the risk of diluting performance because of relatively low returns on cash. Institutional investors often pursue an overcommitment strategy in which 
forecasted capital calls (i.e., outstanding commitments) exceed current cash balances. The goal is to avoid unnecessary cash balances by accurately forecasting the schedule of cash calls and the distributions from previous investments.

\subsection{Private Equity Fund Fees}

Chapter 3 discussed hedge fund fees, including both management fees and incentive fees. This section discusses fees for private equity funds by contrasting those fees with hedge fund fees. There are numerous potential private equity fund fees, some of which differ substantially from the fees typically collected by hedge fund managers.

Fee Size. Typical hedge fund fees for large investments, 2 and 20 (2\% management fee and 20\% incentive fee), have tended to decline toward 1 and 10 in recent years, whereas the fees of private equity funds with well-regarded managers remain more stubbornly fixed at 2 and 20. This fee difference has led some hedge fund managers to venture into private equity investing in search of higher fees or larger fund sizes. Incentive or performance fees in the area of private equity often are termed carried interest.

Fees Based on Exits. Most hedge fund portfolios are substantially or fully invested in assets with highly reliable market prices or at least in assets with values that can be somewhat objectively and accurately estimated. Therefore, most hedge funds are regularly valued (i.e., their net asset values, or NAVs, are regularly computed and made known to partners). Accordingly, hedge fund incentive fees are levied more on a pay-as-you-go basis. Both management fees and incentive fees are assessed on a regular basis, such as quarterly. By their nature, most private equity investments cannot be reliably valued until the investments are exited-either through a public offering or through a private sale. Therefore, private equity management fees are assessed on estimated portfolio values and incentive fees are assessed on exits.

Fund-as-a-Whole Fees. The challenges of estimating values for a portfolio of private equity investments raise an important issue with regard to the levying of incentive fees (carried interest). Private equity fund fees can by levied on a fund-as-a-whole basis or on an investment-by-investment basis. A fund-as-a-whole basis is designed to allow carried interest based on the total and final success of the fund-with excellent outcomes of some projects being offset by losses on projects with bad outcomes.

Let's view a simplified example to see the difference that the method can make on carried interest. Suppose that a private equity fund has 25 investments of $\$ 5$ million each for a total investment of $\$ 125$ million. Twenty of the 
investments perform poorly with total losses of $\$ 5$ million each. Five of the investments generate huge gains when exited with an average profit of $\$ 40$ million each. The fund-as-a-whole generates a $\$ 75$ million profit, and at $20 \%$, the carried interest would be $\$ 15$ million. Carried interest of $20 \%$ of the profits, however, calculated on only the five successful funds, would generate $\$ 40$ million in carried interest if the profits were not offset by the losses according to a fund-as-a-whole approach.

Clawbacks. To address the problem of both profits and losses occurring through time within a portfolio, some private equity funds have clawback clauses in which performance fees based on early successful exits can be, at least in theory, clawed back or recovered by the limited partners from the general partner to offset the losses on subsequent failed investments. Clawbacks ensure that fees based on the fund-as-a-whole approach are adjusted to reflect a full netting of profits and losses in the long run.

Hurdle Rates or Preferred Returns. An attractive feature of many private equity funds from an investor perspective is that carried interest is often charged not on the gross profits of the portfolio but only on the amount by which the profits exceed a hurdle rate or preferred rate of return. Thus, fund managers collect carried interest only on profits in excess of the hurdle rate.

Other Fees. Some private equity funds are famous-or perhaps notorious-for charging myriad other fees, including fees from transactions, such as deal fees, and ongoing fees, such as advisory and directorship fees.

\subsection{Challenges of Internal Rate of Return}

Chapter 8 discussed the internal rate of return (IRR) as a metric that facilitates performance analysis of illiquid investments. The IRR of a terminated investment is based entirely on the cash flows that went into the investment and those that came out of the investment. The IRR of an investment that is still active is focused on all of the past cash flows and an estimate of the investment's current value.

$$
\begin{aligned}
0= & C F_{0}+\left[C F_{1} /(1+\mathrm{IRR})\right]+\left[C F_{2} /(1+\mathrm{IRR})^{2}\right]+\ldots \\
& +\left[C F_{T} /(1+\mathrm{IRR})^{T}\right]+\left[\text { Value }_{T} /(1+\mathrm{IRR})^{T}\right] .
\end{aligned}
$$

An IRR is viewed as a cash-weighted measure, which means that performance as measured by IRR depends on, and varies based on, the cash flows into and out of the investment being analyzed. 
IRRs are used for illiquid investments when regular interim valuations are not available or reliable. Returns on liquid investments usually are reported on a time-weighted basis, meaning that the returns for each subperiod are based on three values: the market value at the start of the time interval, the market value at the end of the time interval, and the total distributions made during the period:

$$
\text { Return }_{0,1}=\frac{P_{1}+\text { Distribution }_{0,1}-P_{0}}{P_{0}} .
$$

The analysis in Chapter 8 focused on commercial real estate properties that typically involve three stages of cash flows: a single initial cash investment, a series of cash inflows to the investor from the investment income, and a final termination value or appraisal. IRR is especially useful as a metric to compare investment performance when it is used to analyze investment opportunities that exhibit cash flow patterns similar to those experienced in real estate investing. IRR does a potentially poor job of ranking investment performance when the timing of the cash flows from the available investments differs substantially from that pattern.

IRRs from projects with differing longevities and sizes should be compared or aggregated with great care. Earning $20 \%$ per year on a small, short-lived investment is vastly inferior to earning $18 \%$ on a large, long-lived investment. Additionally, IRRs for existing illiquid investments depend heavily on the estimation of the investment's current value, which may not match the value of the investment when exited.

As indicated in this chapter, private equity can involve an initial series of investments (capital calls), several years of little or no income, and eventually widely varying distributions resulting from exits. As a cash-weighted performance measure, the widely varying cash flow streams from various private equity investments cause problems when comparing IRRs across investments or, in extreme cases, make it difficult to interpret even a single IRR.

\subsection{The J-Curve}

A popular graphic in private equity shows the IRR of a private equity fund or an individual firm over time. With performance to date (i.e., IRR since inception) on the vertical axis and time on the horizontal axis, the typical diagram looks like Figure 9.2.

Let's examine the concept of a J-curve from the perspective of a private equity fund. The negative IRR in the first few years is a combination of the 
Figure 9.2. The J-Curve of Private Equity

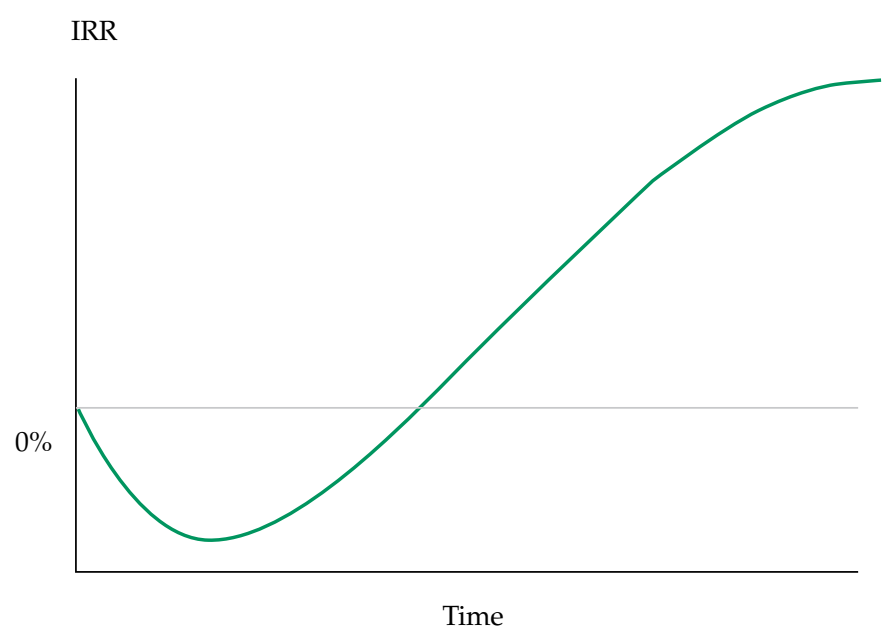

recognition of two losses: (1) write-offs of the fund's organizational and management expenses and (2) write-offs of investments that have perceived to have declined in value or gone bankrupt. The J-curve in Figure 9.2 shows a dip in the fund's initial years that reflects fund management fees, fund expenses, and the early recognition of investment losses on the portfolio companies that failed.

Eventually, the fund begins to experience success in a few of the underlying portfolio companies. The increased value of these investments usually is realized when the investments are successfully exited, such as through an IPO as the venture goes public (or the fund receives the proceeds from selling the venture to an acquiring firm). Figure 9.2 shows these profits in the later years as the IRR turns positive.

The $\mathrm{J}$-curve is a manifestation of conservative accounting practices rather than an economic reality. Early fees and organizational expenses are used to create future benefits, and in a perfect world, they would be capitalized (i.e., recognized for accounting purposes as providing a future benefit that creates a current value) rather than written off. But traditional accounting conservatism lowers the NAV of the fund because recognizing and valuing potential benefits from these early expenditures is not generally feasible. Similarly, most venture capital projects fail, with the losses on the failed investments being recognized more quickly than the profits on the investments that eventually are revealed in later years. The net result is the early recognition of many relatively small losses followed by, hopefully, the recognition of a few 
large profits. These conservative accounting principles generate the commonly observed J-curve.

Note also that the since-inception IRRs on the left side of Figure 9.2 are computed over relatively short time intervals. The result is that relatively small initial dollar losses produce somewhat large initial declines in the IRRs. Conversely, the IRRs on the right of the figure are measured over long periods of time, and therefore, even large dollar profits generate only modest increases in IRRs.

\subsection{Key Sources of Returns from Private Equity}

We cover three key sources of returns from private equity: first-mover advantage, illiquidity premiums, and diversification. As discussed throughout this book, an investment's source of return explains why the investment can be expected to generate an attractive risk-adjusted return. In other words, when we expect that an investment offers superior risk-adjusted returns, we must ask why the seller or issuer of such a security would sell the security at a low price that offers the buyer a high expected return. Issuing or selling a security at a low price causes the cost of capital to the issuer to be high or implies a high opportunity cost to the seller.

First-Mover Advantage. The first-mover advantage is the idea that initial investors in new types of projects tend to reap the greatest rewards. The first-mover advantage in private equity is emblematic of this concept, which applies to many kinds of alternative investments.

For example, hedge fund strategies, such as merger arbitrage and convertible bond arbitrage, generated very high returns for pioneer investors (in the 1980s). Investment strategies that generate phenomenal success attract a flood of new entrants and eventually prospective returns will be driven toward competitive levels. Investing in private equity today may offer little or no first-mover advantage. Identifying new managers who have superior skill or new areas of promising private equity investing that are not yet crowded, however, may offer an advantage.

Illiquidity Premium. Investing is made less risky by the ability of the investor to enter and exit positions at competitively determined prices at the times that suit the investor. The illiquidity of private investments, such as private equity, hinders the ability of an investor to enter and exit at the time and quantity she desires. The illiquidity is not just an inconvenience; it is a substantial source of risk. An investor forced to liquidate private equity investments, especially during periods of distress, such as the recent financial crisis, may find liquidation values to be extraordinarily low. Furthermore, the absence of readily available market prices from competitive markets subjects investors to increased 
costs of data gathering and financial analysis to (1) acquire assets, (2) monitor assets, and (3) exit assets.

The risks and potential added costs of investing in illiquid assets must be offset in the long run by the added benefit of increased compensation (i.e., higher average return). Therefore, everything else equal, private equity investing might well be expected to offer consistently higher returns as compensation for bearing the risks of illiquidity. Investors with a high tolerance for illiquidity may find these higher returns to be worth the higher risks. Historically, over long time periods, returns to venture capital and private equity have exceeded the returns to public equity indexes by more than $3 \%$ per year net of fees.

Diversification and the Full Market Portfolio. Modern portfolio theory indicates that, in competitive markets, the portfolio that offers the highest risk-adjusted return is the total market portfolio. The market portfolio is that portfolio containing all accessible assets. Any portfolio other than the market portfolio contains diversifiable risk-also called unsystematic, unique, idiosyncratic, nonmarket, or firm-specific risk. By definition, diversifiable risk vanishes in a perfectly diversified portfolio. Investors bearing diversifiable risk do so without compensation in the form of a corresponding risk premium.

Investment in private equity is an important and perhaps necessary part of achieving the highest possible combination of risk and return. Private equity, therefore, offers a potential source of returns to investors with a tolerance for illiquidity and an ability to access funds with attractive prospects.

\subsection{Conclusion}

Institutional investment in private equity offers the potential advantages of improved diversification and attractive returns. Major forms of private equity investment, however, can involve unpredictable needs to meet capital calls and unpredictable timing and magnitude of distributions being received, both of which cause the investor's total allocation to private equity to vary through time.

Investors in private equity should consider the challenges of generating attractive returns in this way. Private equity cannot be accessed through an index fund in which the investor can be confident of receiving performance representative of the entire asset group. Access to the best managers and best opportunities may be limited to those institutions that have established relationships with top-notch managers. Private equity fund investing involves numerous and potentially large fees. The potential returns are high, however, and allocations to private equity can be a valuable part of a well-diversified portfolio for investors with a tolerance for the illiquidity and uncertainty of private equity. 


\section{Financial Derivatives}

Financial derivatives are an important component of hedge fund strategies as well as other forms of alternative investing, such as private equity. Therefore, a basic understanding of derivatives is essential to managing a portfolio that includes alternative investments. This chapter provides an overview of derivatives, especially as they relate to a better understanding of alternative investing. This chapter also provides the foundation for Chapter 11 on structured products.

\subsection{Motivations for Using Derivatives}

Investment in alternative investments often involves explicit options and implicit options. Explicit options are present in hedge fund strategies that use listed and unlisted calls and puts. The investments of private equity funds in underlying ventures often involve securities that include explicit options, such as convertible preferred stock. Explicit options are central to a deep understanding of structured products. Implicit options are also common. An implicit option is a security, position, or trading strategy that produces an option-like payoff even though it is not structured as a put or call option. For example, the performance fees widely used in hedge funds and private equity are implicit call options held by the fund managers on the performance of the fund's underlying assets.

Motivations for using financial derivatives vary. This section briefly discusses three: leverage, completing the market, and transaction cost reduction.

Leverage. Many financial derivatives offer implicit leverage-financial exposures that are more sensitive to changes in market valuations than some reference assets. For example, an institution seeking exposure to commodity prices can establish long positions in commodity futures contracts by posting a relatively small quantity of cash or other collateral. The "notional" or face amount of the futures contracts represents the exposure to commodity price movements and thus can be a large multiple of the amount of cash invested. Similarly, long positions in call options provide investors with substantial upside return potential while limiting the funds required to establish the position and limiting the downside exposure (relative to the upside exposure).

Completing the Market. Completing the market is a term from financial economics that refers to the process of expanding the array of investment opportunities such that market participants are better able to form portfolios that meet their preferences.

As an analogy, consider the fruit department of a food store that prepackages its produce into packs containing relatively large quantities of particular 
fruits, such as a dozen apples or a pound of grapes. Many shoppers might be quite frustrated because the available items do not match their shopping preferences. In this example, the grocer would be "completing the market" by offering packages containing a smaller number of apples or grapes, possibly in combination. Selling quantities or combinations of fruit not previously available appeals to the preferences of some of the shoppers and thus increases the value of the grocery store's offerings.

In financial markets, derivative products emerge that provide financial managers with better opportunities to manage risk or to form risk exposures better suited to their preferences or viewpoints. Let's look at an example.

Consider an equity trader who understands better than other traders exactly when important information will be revealed regarding the value of a firm. The trader, however, does not know what the news will be; that is, he or she does not have better information than other traders that the forthcoming news will be good or bad for the firm. The trader can invest in a combination of owning both a call option and a put option on the stock (i.e., a straddle or a strangle). If the trader is correct, the net profit on the options should be positive because the profit on the winning option should exceed the loss on the losing option because of the limited loss exposure to both options. Therefore, such options allow traders access to a more complete market by managing the exposure of a portfolio to changes in anticipated volatility and to large changes in market prices.

Completing the market is an umbrella term that, in the case of financial derivatives, describes a major reason for the development and use of financial derivatives.

Transaction Cost Reduction. Perhaps the most important motivation for using financial derivatives is to reduce transaction costs. Most exposures available through financial derivatives can be engineered using cash securities (i.e., products other than financial derivatives). Therefore, financial derivatives can provide the same exposure with lower transaction costs or perhaps better tax implications.

For example, consider a hedge fund that wishes to take long and short positions in the debt of major corporations. If the fund wishes to trade the position relatively rapidly, trading costs could be an important factor. Credit default swaps (CDS), discussed in Section 10.3, provide the opportunity to take long positions with greater liquidity and lower transaction costs than the cash markets (i.e., the market for buying and selling corporate bonds). Short positions in corporate bonds using cash markets are generally much more difficult and illiquid compared with synthetic short positions using CDS. 
A potentially helpful analogy that illustrates the convenience of financial derivatives is automobile rentals. When traveling by air, it is extremely convenient to be able to rent a car at the destination. The car rental contract can be viewed as a sort of cost-effective derivative in which the traveler contracts for brief exposure to the benefits of car ownership without taking actual legal ownership of the car. But there is a "cash market" alternative. The traveler could buy a car, use it for a few days, and then sell it. Of course, the cash alternative would be a huge waste of time and money, involving hefty transaction costs, tax implications, and paperwork.

Similarly, a portfolio manager wishing to temporarily reduce the risk exposure of a large stock portfolio could do so in the cash market by selling off large quantities of shares with the idea of later buying those shares to restore the original positions. Financial derivatives, however, offer the portfolio manager a much easier and lower-cost solution-that is, to establish derivative positions that hedge the portfolio's risk exposures. Managers vastly prefer the financial derivatives approach because of lower transaction costs and taxes.

\subsection{Options, Futures, Forwards, and Swaps}

Traditional portfolios with long-only exposures to equities and bonds can have different risks than the many hedge funds that use financial derivatives. Financial derivatives can be used to increase or decrease risk exposures. This overview of common financial derivatives focuses on the risk exposures of derivatives rather than the mechanics and other details of derivative trading.

Call options give the holder the right but not the obligation to buy the underlying asset, whereas put options provide a right but not the obligation to sell the underlying asset. Call options represent bullish exposures and put options represent bearish exposures with regard to their underlying assets, but asset allocators are wise to focus more on whether the options are held as long or short positions.

For long positions in a call or put option, the loss is limited to the amount invested in the option. The potential rewards are often small probabilities of large gains. In this sense, buying either a call or a put option can be likened to buying a lottery ticket. Short positions in calls and puts tend to offer small but likely profits and larger but unlikely losses. In this sense, short positions in options can be likened to underwriting or selling insurance: The option seller (or "writer") receives a relatively small premium for offering the option but is obligated to provide a relatively large payout if the option goes "deep into the money."

In a portfolio of options, the total call exposures compared with the total put exposures determine the directional risk of the portfolio (i.e., its 
responsiveness to large movements in the assets underlying the options). The other important measure of the risks of a portfolio with options involves combining the total long positions in options and the total short positions to determine the portfolio's exposure to volatility. As discussed later in this chapter, being net long or net short options influences the exposure of a portfolio to the effects of changes in anticipated market volatility.

For purposes of this discussion, forward contracts and futures contracts are quite similar. Neither futures nor forwards are purchased. Instead, they are contractual agreements with an exchange or trading counterparty regarding exposures to underlying assets. From the perspective of an asset allocator, long or short positions in forward contracts and futures contracts are often best viewed as being tantamount to long or short cash positions in the assets that underlie the contracts. Thus, a long position in a Hang Seng Index futures contract has a risk of exposure that is quite similar to that of a long position in a Hang Seng exchange-traded fund (ETF). The primary difference is that derivatives contracts can be entered for less cash than a purchase of an index fund. This efficient use of cash may incur a financing cost or cause the investor to fail to earn dividends on their forward or futures market investment.

Swaps are contracts that call for a periodic exchange of cash flows. It often is easier and more effective to view swaps as exchanges of risks. For example, interest rate swaps are often used to turn a position without interest rate risk into one that has interest rate risk, or vice versa. Currency swaps can transform a risk exposure in one currency into a risk exposure in another. CDS, an important financial derivative for handling default risk, are detailed in the next section.

\subsection{Structured Products}

Chapter 11 provides more detailed information about a particular type of product known generally as a collateralized debt obligation (CDO). CDOs, however, are simply one subset of structured products. This section provides an overview of other contracts that generally are grouped within the category of financial derivatives or structured products.

Credit Default Swaps. Swaps were discussed in the previous section as vehicles for shifting and managing various risk exposures, such as the risks inherent in various equity indexes, interest rates, and currencies. A CDS transfers the risk of a bond's default from a credit protection buyer to a credit protection seller. For example, holding cash and being a CDS protection seller can be tantamount to owning the risky bond underlying the CDS. Owning a corporate bond and being a CDS protection buyer can be tantamount to holding cash. 
A hedge fund manager wishing to change a risk exposure regarding corporate debt can use derivatives in general and CDS in particular to make those changes quickly and cost effectively. Similarly, fixed-income arbitrage hedge fund managers can take positions as buyers in some CDS and sellers in others to implement their skills in analyzing credit risk. Finally, important structured products, discussed in Chapter 11, can use CDS to mimic cash exposures to corporate bonds. In each of these cases, CDS can be used to create synthetic exposures to corporate bonds that provide portfolios with greater liquidity, lower transaction costs, and increased ability to construct short exposures to credit risk.

Other Financial Swaps. The previous discussion of CDS centered on their role in bearing the risk of default in a corporate bond by being a CDS protection seller or in laying off (i.e., hedging) the risk of a corporate bond default by being a CDS protection buyer. Currency swaps can be used to transfer risks regarding changes in foreign exchange rates. A currency swap may allow a German manufacturer to convert an anticipated inflow of US dollars into flows fixed in euros. Commodity swaps allow investors to establish synthetic long positions in commodity prices without taking physical possession of commodities and allow commodity producers to lock in their revenues from selling their future production. A popular use of interest rate swaps is to convert fixed interest rate cash flows into variable interest rate cash flows. Swaps are often used to create synthetic long and short positions in equity indexes, such as the FTSE, or to convert the natural exposure of a portfolio to one country's equity market to synthetic exposure to another country's equity market.

Insurance- and Equity-Linked Products. Structured products with potentially complex payoff structures based on equity indexes or other investments have soared in popularity in recent years. The products are financially engineered to have risk and return characteristics that are perceived as being attractive to the buyers of structured products. For example, a structured product may be engineered to provide an investor with the potential to receive a portion of the upside return to an equity index while also providing full protection that downside losses will not exceed a prespecified level. These products are offered through major financial institutions and tend to have characteristics that differ from one institution to the next.

\subsection{Volatility Products}

Volatility products are a relatively new and increasingly important class of products. For centuries, financial practitioners and scholars have analyzed 
and managed the risk of various financial asset classes, especially equities. This section provides an overview of volatility products and their potential role in an institutional-quality investment portfolio.

The focus of these traditional efforts has been on enabling market participants to manage the risk that a particular asset or asset class will perform well or poorly. For example, a long position in the S\&P 500 at 2200 will increase or decrease by 10 when the index rises to 2210 or falls to 2190 .

Volatility-related products take the management of risk to a higher level. These new products enable market participants to manage the risk of changes in the risk of a particular asset or asset class. Thus, a position in a volatility product moves up or down based on whether the expected volatility of the index moves up or down. For example, a typical volatility index will move when the expected volatility of the S\&P 500 rises from $13 \%$ to $14 \%$ or when it falls from $13 \%$ to $12 \%$.

These new volatility-related products are not direct bets ${ }^{14}$ on whether markets will rise or fall (although, as will be discussed, they typically are correlated with the direction of the market on a short-term basis). They are bets on whether the anticipated or realized fluctuations in the S\&P 500, in this case, will widen or narrow.

Volatility and Variance. The volatility of an asset refers to the standard deviation of returns of an asset as discussed in Chapter 14. Volatility is somewhat intuitive, with an asset having an annualized volatility of $20 \%$ indicating that the asset's return typically deviates from its mean return by roughly 20 percentage points $(-10 \%$ or $+30 \%$ if the mean return is $+10 \%)$. Variance is the square of volatility, so an asset with a volatility of $20 \%$ (i.e., 0.20 ) has a variance of 0.04 .

Realized Volatility Products. Variance swaps and volatility swaps are contracts that call for an exchange of cash flows between the parties to the contract based on the realized variance or volatility that actually occurs in a specified asset as observed over a specified time period.

For example, consider a variance swap on the S\&P 500 with a variance swap rate (set at the inception of the swap by mutual agreement between the parties) of 0.0400 . Over the observed reference period, suppose that the actual (realized) variance of the returns of the $\mathrm{S} \& \mathrm{P} 500$ contract is 0.0441 .

\footnotetext{
${ }^{14}$ The use of the term bets is not pejorative. To the contrary, financial derivatives in general and VIX-related products in particular are viewed by the authors as potentially valuable vehicles to manage risks and enhance economic efficiency by guiding market prices toward their intrinsic values. The authors use the word bets as an easy-to-understand reference to the underlying risk transfer.
} 
The contract will require a payment of the difference between the realized variance $(0.0441)$ and the variance swap rate $(0.0400)$ scaled by (i.e., multiplied by) the notional size of the contract (e.g., \$100,000). In this case of realized variance exceeding the variance swap rate, the swap buyer receives a payment (e.g., \$410) from the swap seller that is scaled by the prespecified notional size described in the swap agreement. Had the realized variance fallen short of 0.0400 - say, to 0.0300 — the swap seller would receive a payment from the swap buyer (e.g., \$1,000).

Why, then, are there two types of swaps (volatility and variance)? Volatility swaps specify payments based on standard deviation or volatility (i.e., the square root of the variance). In the previous example, the corresponding volatility swap rate might be 0.20 and the realized volatility might be 0.21 . Participants select the notional size of the swap based on their target risk level exposure. The appropriate notional size would vary based on whether the contract was a variance swap or a volatility swap.

Payments generated by variance swaps and volatility swaps are affected differently for large movements in the underlying variances and volatilities. The variance change in the previous example was 0.0041 (from 0.0400 to 0.0041 ), whereas the volatility change was 0.01 (from 0.20 to 0.21 ). For this relatively small change, the variance change was $41 \%$ of the volatility change. For a larger change, if the realized volatility rose to 0.30 , the realized variance would be 0.09 . The variance change corresponding to the larger shift $(0.05$ for variance and 0.10 for volatility) would be $50 \%$ of the volatility change. Simply put, the payments to variance swaps can be viewed as being a nonlinear function of the payments to volatility swaps.

Implied Volatility Products. The implied volatility of an index, such as the S\&P 500, is the standard deviation of the returns of the index that is expected by market participants. A key innovation in recent years has been the development of indexes that measure the implied volatility of a market index through analysis of the levels of options prices. All else being equal, high options prices indicate that options traders anticipate high volatility in the underlying asset.

Three important but potentially confusing levels of financial engineering are used to facilitate trading in anticipated volatility:

1. VIX Indexes: The Chicago Board Options Exchange (Cboe) has created VIX indexes to measure the anticipated volatility of various indexes over various time horizons using real-time options prices. Volatility indexes offered by the Cboe include the following underlying indexes or ETFs: eight US equity indexes (e.g., S\&P 500, NASDAQ), four non-US equity 
indexes (e.g., emerging markets ETF), two US interest rate indexes (10-year Treasury note and interest rate swap), five commodity indexes (e.g., crude oil ETF and gold ETF), four currency-related indexes (e.g., euro and yen), five individual stock indexes (e.g., Amazon.com, Inc., and Apple Inc.), and an index measuring the volatility of the VIX. VIX indexes are generally not tradable; they serve as foundations or reference values for derivatives that are tradable. The VIX index interpolates actual options data on implied volatility to estimate the implied volatility on hypothetical options contracts with a 30-day time to expiration (on those days when there are no options with 30 days to expiration).

2. VIX Futures and Options on Futures: Futures contracts on the VIX allow futures traders to establish long and short positions that settle on the values of the VIX contracts. The futures contracts are structured to expire on the one day each month when the options underlying the computation of the VIX are the actual options that have exactly 30 days to expiration. Options are available on the futures contracts.

3. VIX ETFs and ETNs: A problem with futures contracts is that they decline in their time to settlement as time passes, affecting their returns and requiring a rollover strategy. ETFs and exchange-traded notes (ETNs) on VIX futures contracts provide investors with exposures to the VIX futures contracts on a constant-maturity basis (30 days to settlement) and do not need to be rolled over.

The VIX contract based on the S\&P 500 measures the anticipated volatility of the S\&P 500 using an average of the implied volatilities of a wide range of options on the $\mathrm{S} \& \mathrm{P} 500$.

A position with long exposure to the VIX index will rise when anticipated volatility in the S\&P 500 rises and will fall when the anticipated volatility falls. Generally, especially over the short term, the level of the S\&P 500 moves in the opposite direction of its anticipated volatility. This is especially true for a rapid decline in the $\mathrm{S} \& \mathrm{P} 500$. For example, on a day when the S\&P 500 drops a few percentage points, the most popular VIX-related products (e.g., VXX) will likely rise $10 \%$ or more.

The popularity of VIX products has soared in recent years. A family of products has emerged offering exposure to the volatility of various indexes other than the S\&P 500 and including time horizons other than 30 days. VIX-related products can exhibit dramatic returns. They can be used for hedging purposes or speculation. Some hedge funds (discussed in Chapter 4) implement skill-based investment strategies based on volatility products and correlation-based strategies and products. The performance of 
correlation-based products and strategies is based on realized or anticipated correlations of returns between assets, such as pairs of stocks.

\subsection{The Greeks}

The risk of a traditional portfolio of unlevered, long-only stocks and bonds is well measured and managed with traditional linear risk measures, such as beta (for stocks) and duration (for bonds). This section discusses important risk measures, collectively referred to as the Greeks, which are useful in the analysis of portfolios containing alternative assets and strategies that often have nonlinear exposure.

Many of the risks involved in derivative contracts, especially options, are complex, so specialized terms have emerged to measure and report risk. This section reviews the most common risk measures. The risk measures are referred to as the Greeks because all of them (except vega) are denoted with letters of the Greek alphabet.

Delta. Delta measures the sensitivity of the price of an option or the price of some other position with respect to a change in the value of the security that underlies that contract. For example a call option with a delta of 0.65 will rise $\$ 0.65$ when the price of its underlying asset rises by $\$ 1$. A put option with a delta of -0.40 will fall by $\$ 0.40$ if its underlier rises by $\$ 1$. A share of stock has a delta of +1.0 , and a long position in a futures or forward contracts has a delta of roughly +1.0 . Being short an asset (via short selling or short positions in futures or forward contracts) has a delta of -1.0 .

From an asset allocator's perspective, delta can be used to aggregate the directional risk of each asset to form the delta of an entire portfolio with respect to underlying asset prices. Furthermore, positions in derivatives, such as options or swaps, can be established to manage the risk of the entire portfolio toward a target value. In other words, decisions may be made throughout the portfolio to pursue perceived opportunities for superior returns irrespective of the effect of the decisions on directional risks because the directional risks at the portfolio level as measured by delta can typically be managed through trades in financial derivatives.

Vega. Vega measures the sensitivity of the price of an option or other position with respect to a change in the anticipated volatility of the security that underlies that contract. For example, a call option with a vega of 0.10 would rise $\$ 0.10$ for a $1 \%$ increase in the anticipated volatility of the asset underlying the option.

Vega is an important risk measure for options and volatility strategies. Most stocks and bonds have little or no direct vega risk. Note, however, 
that large changes in anticipated volatility tend to be highly correlated with changes in price levels of stocks and bonds.

Gamma. Gamma measures the sensitivity of the delta of an option or other position with respect to a change in the value of the security that underlies that contract. It is a second derivative and is an extremely important measure, particularly with regard to options.

In a nutshell, gamma is a key measure of the risk of options positions, indicating whether the position's value will increase in risk or decrease in risk as the market moves substantially in a single direction. Gamma shows that the delta of call options rises as the underlying price rises, whereas put deltas rise (become more negative) with a decline in the underlying price.

Theta. Theta measures the sensitivity of the price of an option or other position with respect to the passage of time while holding other values constant. Time decay becomes faster as maturity approaches. Longer-dated options have higher prices than shorter-term options because the time value of an option decays over time.

Other Greeks. Other Greeks include measures of the sensitivity of options or other positions with respect to a change in another variable, such as interest rates or credit spreads.

\subsection{Aggregation of Risks to the Portfolio Level}

The previous section focused on describing the Greek risk measures, mostly from the perspective of an individual position. This section discusses the aggregation of risk measures into a portfolio and highlights the potential value of these portfolio risk measures to an asset allocator.

Portfolio Delta. The delta of a portfolio can be estimated as the weighted average of the deltas of the assets in the portfolio. The deltas can be estimated for directional exposures to a variety of underlying factors (i.e., indexes), such as those represented by an equity index, a bond index, and so forth. Long cash positions, long futures contracts, long calls, and short puts generally contribute to a positive delta, whereas their counterparts contribute to a negative delta. An aggregated portfolio delta indicates the direction and magnitude of a portfolio's exposure to directional moves in the value of the underlying index or price. Asset allocators can use aggregated delta values to ascertain portfolio exposures to immediate, smaller moves in various asset markets.

Portfolio Vega. The vega of a portfolio can be estimated as the weighted average of the vegas of the assets (i.e., the options and volatility products) in 
the portfolio. Vegas are estimated for a variety of exposures to anticipated volatility levels, including anticipated volatilities related to an equity index, a bond index, and so forth. Long positions in options and many VIX-related products contribute to a positive vega, whereas short positions contribute to a negative vega.

Portfolio Gamma. The gamma of a portfolio can be estimated as the weighted average of the gammas of the assets in the portfolio. The gamma of the portfolio provides insight into the portfolio's exposure to large directional movements in an underlying index, such as an equity index. Specifically, a positive gamma indicates that the delta of a portfolio will increase when the underlying market rises and will fall when the underlying market falls. Long options positions create long gamma, and short options positions generate short gamma. Therefore, the gamma of a portfolio signals the vital information of whether the portfolio's net exposure to a particular index tends to be net long options or net short options. Being net long options creates the potential benefit of large profits and small losses, whereas being net short options increases the likelihood of large losses and small profits. But there is no free lunch. Being net long options tends to cause negative performance when markets experience low volatility. Generally, gamma is closely related to theta.

\subsection{Conclusion}

Derivatives are double-edged swords. On the one hand, they can provide valuable hedging capabilities and transaction-cost efficiencies. On the other hand, they can produce dangerous levels of leverage and intricate complexities that can explode portfolio values in periods of economic stress.

The gamma of a portfolio can be a key measure of the sensitivity of a portfolio to large changes in the value of a market index or other driving factor of the portfolio's returns. A portfolio with a positive gamma offers an attractive exposure to large market changes in that it will tend to gain at an increasing rate as markets move in its favor and it will lose at a decreasing rate as markets move against it. This advantage is likely offset by lower returns on such a portfolio when markets experience low volatility. A portfolio with a negative gamma offers an unattractive exposure to large market changes in that it will tend to lose at an increasing rate as markets move against it and it will gain at a decreasing rate as markets move in its favor. This disadvantage is likely offset by its high returns when markets experience low volatility. Thus, asset allocators of portfolios containing alternative assets and strategies are well advised to understand and monitor gamma. 


\section{Structured Products: Collateralized Debt Obligations}

This chapter spotlights a popular structured product called a collateralized debt obligation (CDO). CDOs were at the epicenter of the financial crisis that shook the world's markets and institutions in 2008. These powerful instruments are important investment vehicles that should be overseen with great care. This chapter introduces the CDO, discusses its development, describes its important characteristics, and illustrates some popular types and frameworks of this relatively new innovation in capital markets.

\subsection{Overview}

In its simplest form, a CDO is a structured product that takes the cash flows emanating from a security or portfolio of securities and distributes them into tranches-that is, classes of securities with claims to cash flows that differ in priority. The CDO traces its roots to the earliest types of securitized lending that altered the way that loans are managed. Since then, CDOs have evolved into novel risk management tools, represented by dozens of variations designed to appeal to distinctive risk appetites. For example, distressed debt CDOs securitize a portfolio of high-yield debt into tranches of collateralized securities with vastly different credit ratings. This transformative process allows institutions to move certain assets off their balance sheet by placing them into the hands of willing investors. The result for the institution can be improved regulatory compliance and reduced capital requirements; it also provides investors in the tranches with improved investment opportunities, such as enhanced diversification and credit risk protections.

\subsection{How the Market for CDOs Developed}

The evolution of the CDO dates back to a time when small banks and savings and loan associations (S\&Ls) were experiencing disruptive change in their industry. Traditionally, S\&Ls had been in the business of aggregating small deposits and lending money via mortgage loans. During what has been considered the good old days, the managers of S\&Ls operated under the 3-6-3 rule, meaning that they borrowed money at $3 \%$, lent money at $6 \%$, and were on the golf course every Wednesday at 3 o'clock in the afternoon.

Because mortgages exhibit a relatively low incidence of default, and because S\&Ls developed an expertise in originating and servicing these loans, the 3-6-3 rule worked as long as market interest rates stayed within 
certain bands that kept their mortgage portfolios safe. In the 1970s, when mortgage rates rose quickly and entered a regime of high volatility, the interest rate risk embedded in the very structure of the S\&L model was exposed for its worst features. Long-duration mortgage loan portfolios generated fixed-income returns that lagged behind the swiftly increasing money market rates that investors could obtain elsewhere. Because S\&Ls were prevented by Regulation $\mathrm{Q}$ from raising deposit rates to competitive levels, depositors withdrew money, straining S\&L cash flows to the point at which deregulation finally allowed S\&Ls to offer more competitive rates. But these higher deposit rates caused the S\&Ls to officially enter into the 10-5-7 rule: borrowing short-term at $10 \%$, earning an average of $5 \%$ on loans, and spiraling toward Chapter 7 bankruptcy. The days of having financial institutions hold massive mortgage loan portfolios were over.

The mortgage-lending business became securitized with pass-through certificates: securities that allowed investors to own pro rata positions in portfolios of mortgages. These first-generation mortgage-backed securities allowed banks and S\&Ls to continue to originate and service mortgages while also moving them off the balance sheet. Investment banks were active intermediaries issuing and managing these new structures (collateralized mortgage obligations, CMOs) as a way to earn fees.

Not all investors wanted to hold these mortgage pass-through securities that offered cash flows for the next 25-30 years. Some investors wanted the short-term cash flows only, and other investors, such as pension funds and insurance companies, were happy to invest primarily in the long-term cash flows. The key innovation of the CDO instrument is the creation of tranches that have claims to cash flows with different priorities and thus diverse cash flow and risk characteristics. So, for example, investors with high interest rate risk appetites could gravitate to the long-term tranches, whereas lowrisk investors with shorter time horizons could gravitate to the short-term tranches. As discussed in Chapter 10, derivatives can be valuable innovations when they help complete a market, allowing investors to tailor portfolios to their capacity to tolerate risk.

The mortgage CDO market (i.e., CMOs) of the 1980s and 1990s focused on creating tranches that differed by interest rate risk only (i.e., uncertain longevities). The cash flows to the tranches contained interest rate risk (in this case, experienced as the inclination of the borrowers to prepay some or all of the mortgage principal). Nevertheless, the power of structured products to slice and dice the interest rate risk enabled investors to assemble risk exposures that caused a minor financial crisis caused by rising interest rates in 1994 . The rising interest rates coupled with the risk exposures enabled by misuses 
of CMOs led to fund collapses (e.g., Askin Capital Management), financial institution collapses (e.g., Kidder Peabody Group Inc.), and substantial losses by governmental entities (most famously, California's Orange County).

The success of CDO mortgage products led to expansion of the concept to other asset types-in particular, bonds and mortgages that contained default risk. CDOs with substantial exposures to assets with default risk were at the center of the financial crisis in 2008. CDOs composed of bonds with default risk divvied up the impact of bond defaults by varying the exposure of each tranche to the losses of defaults in the CDO's collateral pool.

For example, consider a financial institution with an asset bucket of $\$ 100$ million of below-investment-grade loans that will be moved off the balance sheet through a CDO arrangement. The institution has created a subsidiary known as a special purpose vehicle (SPV) whose legal status is separate from the institution and whose obligations do not directly affect the financial health of the institution.

The term bankruptcy remote is typically used to describe this arrangement because the reference portfolio is held in trust as a single-purpose entity. In this relatively simple arrangement, the SPV takes ownership of the reference portfolio of $\$ 100$ million, issues a new set of securities to investors with the reference portfolio serving as collateral, and uses the money raised by the sale of the tranches to compensate the financial institution for the collateral portfolio. In return for the operation and management of the CDO, the CDO manager will charge a fee equal to a percentage of assets under management. This arrangement is depicted in Figure 11.1.

\subsection{The Creation of Tranches}

Figure 11.1 is illustrative of how the CDO can be used to move assets from inside the financial institution to the SPV, but it does not detail the distinctive feature of the CDO. Figure 11.2 demonstrates a typical CDO arrangement, called a sequential ordering, where tranches created out of the SPV's assets have different cash flow priority and risk expectations. Specifically, the reference portfolio of

Figure 11.1. The Creation of a CDO Instrument

$\$ 100$ Million $\$ 100$ Million

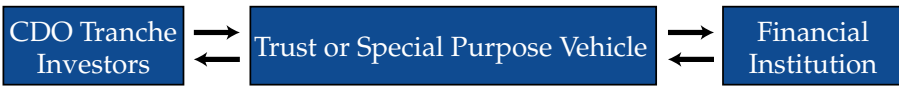


Figure 11.2. Tranching and the Waterfall of CDO Cash Flows

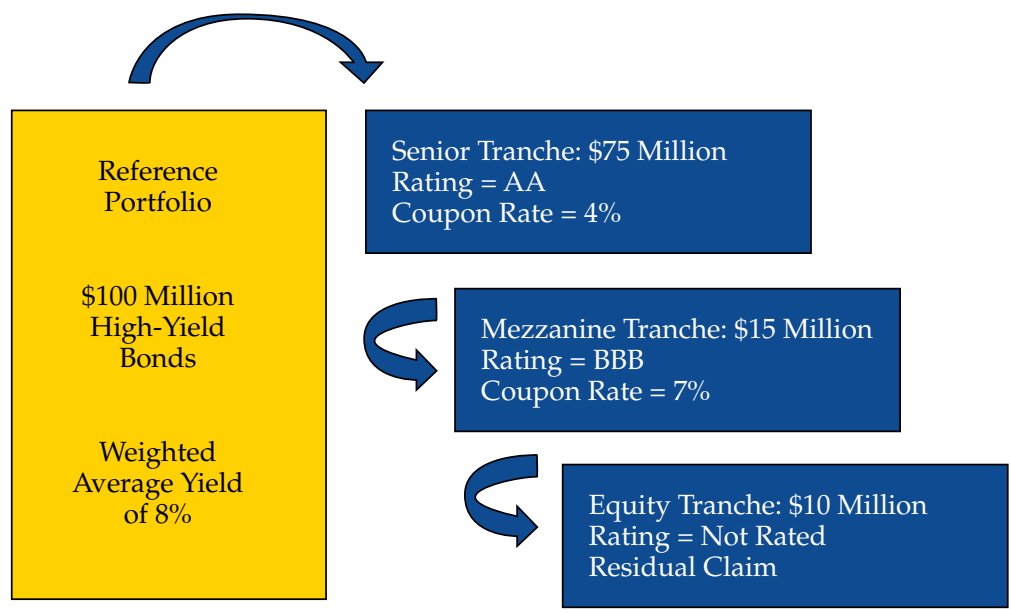

8\% high-yield bonds has been carved into three risk tranches: a senior (low-risk) tranche, a mezzanine (middle-risk) tranche, and an equity (high-risk) tranche. These risk levels arise from the way that the cash flows from the SPV are layered. Notice that the cash flows from the reference portfolio are assigned in order: first to the senior tranche and second to the mezzanine tranche. The equity tranche, with no fixed coupon rate, receives any residual amount.

Credit Ratings. Credit ratings are also shown in Figure 11.2. A typical CDO structure dictates that the SPV hire an outside rating agency to provide investment-grade ratings to most of the tranches of the CDO. The agency will base the rating on the priority of the cash flows from the reference portfolio and on the level of default protection. For example, in Figure 11.2, the senior tranche receives the next-to-highest credit rating of AA because this tranche has first claim to cash flows and is protected from default by the subordinated tranches. The mezzanine tranche, with both lower priority to cash flows and less default protection, is assigned a lower rating of BBB. The equity tranche, as a residual claimant and the first to absorb losses resulting from default, does not qualify for an investment-grade rating.

Default Potential. Next consider how the potential for default moves through the waterfall. Although the cash flows from the reference portfolio flow from top to bottom, default moves in the opposite direction, from bottom to top. Figure 11.3 illustrates end-of-year cash flows from the reference portfolio assuming that, during the year, $11 \%$ of the reference portfolio's loans 


\section{Figure 11.3. Default Moving Up the Waterfall}

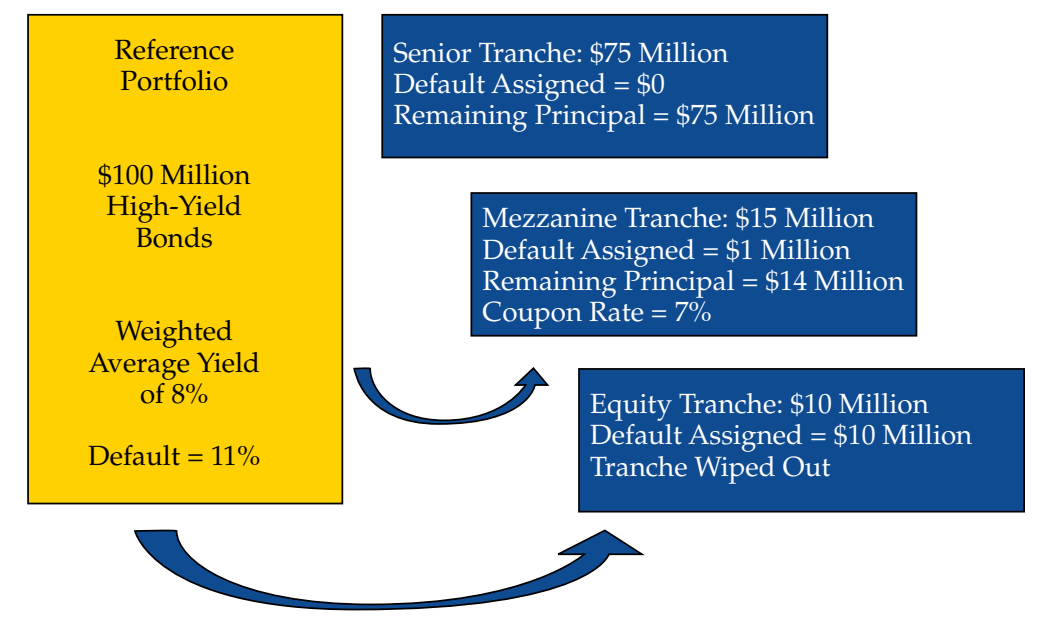

default with no recovery. The figure shows the amount of default that the CDO structure will assign to each tranche as well as the tranche's remaining principal balance.

The equity tranche is first to absorb any default. In fact, the entire tranche is wiped out because the total amount of assumed annual default ( $\$ 11$ million) is greater than the principal (\$10 million). This rather drastic example illustrates the parallel between investing in the bottom tranche of this CDO and investing in the equity of a typical corporation, because equity investors are subject to losses before bond investors are permanently impaired.

The remaining $\$ 1$ million of default moves up the ladder and is next assigned to the mezzanine tranche. The principal balance of the mezzanine tranche that began the year with $\$ 15$ million falls to $\$ 14$ million. The senior tranche, protected through subordination, escapes this round with zero default assigned.

Overcollateralization. The coupon rates in Figure 11.2 correlate with the credit rating and reflect the internal credit enhancement of the CDO. Because defaults are first posted against the bottom or equity tranche, the equity tranche holders may be viewed as providing credit protection to the higher-rated tranches. Said differently, the senior tranche is overcollateralized by 33\% ( $\$ 100 / \$ 75=1.33)$, meaning that 33\% more assets are available relative to the size of this specific tranche.

Attachment, Detachment, and Tranche Width. Attachment and detachment points describe, respectively, the point at which losses first 
penetrate (i.e., become attached to) the tranche and the point at which losses wipe the tranche out (remove the tranche from the CDO). The conventional way to describe these two points follows the format attachment\%/ detachment $\%$. For example, the mezzanine tranche would be described as a $10 \% / 25 \%$ tranche, meaning that losses penetrate (reduce the value of) the tranche when they move beyond $10 \%$ and completely eliminate the tranche when they hit $25 \%$. In a similar way, the equity tranche can be described by $0 \% / 10 \%$, and the senior tranche can be described by $25 \% / 100 \%$.

A related way to portray attachment and detachment is through the concept of tranche width. Tranche width is the distance between attachment and detachment. It is the percentage of the CDO's capital structure accounted for by a particular tranche. For the CDO illustrated here, tranche width is $10 \%$ for equity, $15 \%$ for mezzanine, and $75 \%$ for the senior tranche. The CDO trust can use the concept of tranche width when assigning the number of tranches and when managing the expected credit ratings for each tranche. In fact, the details of a CDO are a subject of negotiation between the creators of the product and the rating agency retained to assign credit ratings to the tranches.

\subsection{Example of the Waterfall of Cash Flows}

Consider how cash flows move through the waterfall. Figure $\mathbf{1 1 . 4}$ brings the equity tranche back from the previous example to examine the CDO cash flows assuming zero defaults. The collateral assets earn an average yield of $8 \%$, or $\$ 8$ million on the $\$ 100$ million reference portfolio. Fees to the CDO

Figure 11.4. First Annual Cash Flows through the Waterfall (no defaults, $0.90 \%$ fees)

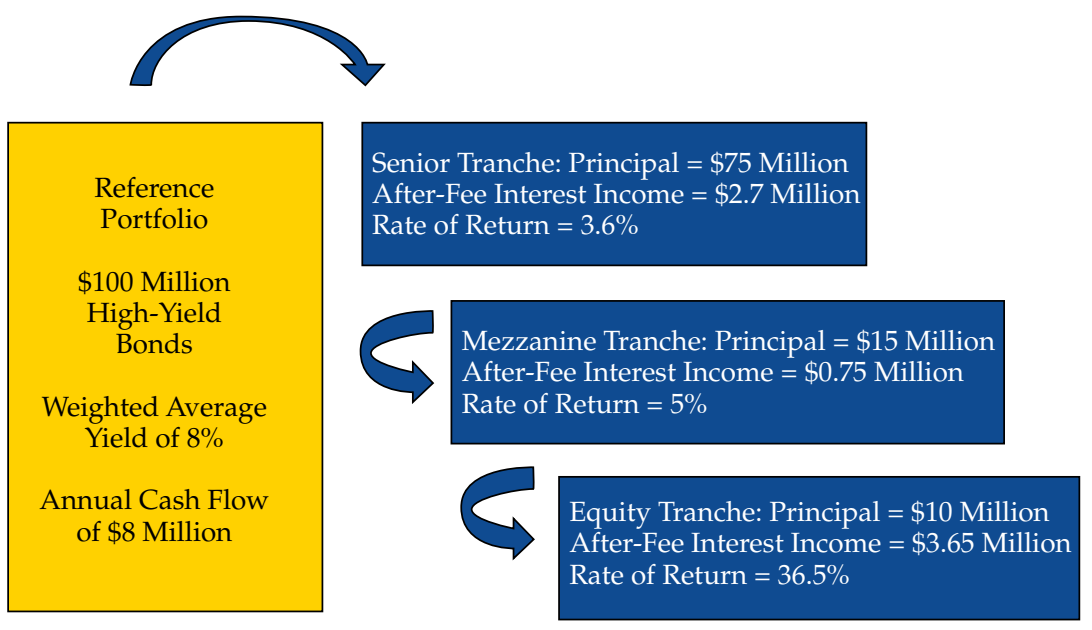


trust totaling $0.90 \%$ for both expenses and the management of the assets will be deducted from the income of the collateral pool of assets. The total amount of after-fee income from the assets is $\$ 7.1$ million.

After-fee income moves top down, pouring first to senior tranche investors and last to equity tranche investors. Because defaults are set equal to zero for illustrative purposes, the example in Figure 11.4 is a best-case scenario. The rate of return analysis illustrates that the top two tranches are fixedincome investments, whereas the bottom tranche is an equity or a residualclaim investment. The assumption of zero defaults does not affect the income or rate of return of both the senior and mezzanine tranches, but it creates a fantastic rate of return for the equity tranche.

Next, Table 11.1 displays after-fee interest income and rates of return for all three tranches across various default scenarios assuming no recovery. The first row of Panels A and B correspond to the zero default example given earlier, whereas the bottom row of Panels A and B illustrate outcomes with substantial default to the reference portfolio. The rows in between illustrate the growing influence of default to the various tranches. For an individual tranche, the decline in income begins at the attachment point, and income goes to zero at the detachment point. Defaults reaching

Table 11.1. Tranche Income and Return with Default (no recovery, $0.90 \%$ fees)

\begin{tabular}{lccc}
\hline Default Percent & $\begin{array}{c}\text { Senior Tranche } \\
25 \% / 100 \%\end{array}$ & $\begin{array}{c}\text { Mezzanine Tranche } \\
10 \% / 25 \%\end{array}$ & $\begin{array}{c}\text { Equity Tranche } \\
0 \% / 10 \%\end{array}$ \\
\hline A. After-Fee Interest Income & (in millions) & \\
$0 \%$ & $\$ 2.70$ & $\$ 0.75$ & $\$ 3.67$ \\
$1 \%$ & 2.70 & 0.75 & 3.57 \\
$10 \%$ & 2.70 & 0.75 & 0 \\
$11 \%$ & 2.70 & 0.68 & 0 \\
$25 \%$ & 2.70 & 0 & 0 \\
$26 \%$ & 2.67 & 0 & 0 \\
B. After-Fee Rate of Return (assuming no recovery on defaulted bonds) & $56.50 \%$ \\
$0 \%$ & $3.60 \%$ & $5.00 \%$ & 25.70 \\
$1 \%$ & 3.60 & 5.00 & -100 \\
$10 \%$ & 3.60 & 5.00 & -100 \\
$11 \%$ & 3.60 & -2.13 & -100 \\
$25 \%$ & 3.60 & -100 & -100 \\
$26 \%$ & 3.56 & -100 & \\
\hline
\end{tabular}


$25 \%$ wipe out the mezzanine tranche and, at this point, expose the senior tranche to losses.

An illustrative example is the case of $11 \%$ default within the reference portfolio. Because $11 \%$ is greater than the detachment point of the equity tranche, this subordinated bottom layer vanishes and leaves equity investors with zero income and no rate of return. With the bottom layer now gone, it's solely up to the mezzanine tranche to shield senior investors from impairment. The $11 \%$ default rate passes the $10 \%$ threshold and is now large enough to have direct consequences on both the income earned and the rate of return to mezzanine investors. The remaining $\$ 14$ million of principal reduces mezzanine income to $\$ 0.68$ million ( $\$ 14$ million $\times 7 \%-\$ 0.3$ million) and the rate of return to $4.53 \%$ ( $\$ 0.68$ million $/ \$ 15$ million).

A second illustrative example is the case of defaults beyond $25 \%$, such that all of the original protective barriers surrounding the senior tranche have vanished. The $26 \%$ default scenario results in a small decline in senior tranche income (from $\$ 2.70$ million to $\$ 2.67$ million) and a rate of return (from $3.60 \%$ to $3.56 \%$ ). Of course, any additional amount of default will continue to erode income and return to the senior tranche, demonstrating that defaults within the reference portfolio are indeed the most important underlying risk factor to the $\mathrm{CDO}$ structure.

The Diversity Score and Option Theory. This section's analysis also highlights the importance of default interconnectedness (i.e., the correlation) among the assets held in the reference portfolio. For example, consider the equity tranche. Finance theory describes an equity claim as a call option on the underlying assets of the firm. As residual claimants, equityholders have the option to stay invested if their claim is above water or, alternatively, to walk away if values substantially sink. This creates the envious position of unlimited upside and limited downside, and it is illustrative of the income and return scenarios of the CDO's equity tranche holders.

Viewing the equity tranche as a call option on the CDO's reference portfolio provides a good introduction to the diversity score, one of the common terms associated with the CDO. The same agencies that provide tranche ratings typically publish a measure of correlation within the reference portfolio's assets. Diversity scores range from 1 to 100. The lowest diversity score, 1 , denotes perfectly correlated assets because, with a score of 1 , holding $n$ different assets would be equivalent to holding one asset because either everything defaults or nothing defaults. The highest diversity score, 100, denotes minimal correlation among the many assets in the portfolio. Diversity scores between 1 and 100 signal the extent to which the reference portfolio's assets are entwined. 
With respect to tranche risk, a high diversity score lowers the risks of investors in the most senior tranches because low correlation of defaults lowers the riskiness of the asset pool that protects the senior tranches from risk. But equity tranche investors, with limited downside and unlimited upside, may suffer from high diversity scores. The default experience within the reference portfolio should be consistently moderate. All moderate losses, however, are borne by the equityholders. Of course, market prices of the tranches reflect these considerations before investment. When correlations of defaults among assets in the collateral or reference portfolio are lower than expected, there is an ex post wealth transfer from the junior tranches to the senior tranches relative to the case of more correlated defaults.

An opposite relationship exists between tranche risk and low diversity scores. First, for the senior tranche, the association is clear; highly correlated risk within the reference portfolio represents bad news because losses can quickly cascade up the waterfall. But equity tranche investors, with limited downside and unlimited upside, tend to be buttressed by the potential for linked losses. Equity investors often prefer high probabilities of extreme profits and losses because they have unlimited gains from the extreme profits and limited losses from extreme losses.

When the CDO is first structured, and assuming good access to important and relevant information, coupon rates and attachment and detachment points will be set commensurate with expectations. Once the CDO is issued, should market conditions unexpectedly change, we then expect to see wealth transfers between tranches. An unexpected rise in both average default rates and correlation among defaults within the portfolio will result in senior tranche investors becoming relatively worse off. If the correlations are low, however, the senior tranche is less likely to be affected than if correlations are high. This is consistent with option theory, which holds that the senior bondholders of a corporation are short a call option and that the value of their securities rises and falls with decreases and increases, respectively, in the volatility of the underlying assets.

\subsection{Types of CDOs}

Balance sheet CDOs, like the high-yield debt structure illustrated earlier, are not the only type of CDO. A balance sheet CDO is a CDO created by the desire of a lending institution to divest itself of loans. This section summarizes the key features of the main variations in the growing structured product market.

Arbitrage CDOs. As its name implies, the main goal of the arbitrage $\mathrm{CDO}$ is for the money managers to choose undervalued assets to place in the 
reference portfolio. Ideally, the yield on the assets in the CDO would exceed the yield paid to the investors, which could occur through active loan selection such that, on average, the actual default rate is less than average. In a typical arbitrage CDO arrangement, the money managers will carve out the equity tranche for themselves under the expectation that higher returns in the reference portfolio translate into higher than expected returns for their investments.

Synthetic CDOs. The CDOs described in this chapter are sometimes referred to as cash-funded CDOs, meaning that the reference portfolio assets are purchased and physically held within the SPV using cash supplied by the tranche investors. A different type of CDO is one in which these physically held assets are replaced by a set of derivatives (e.g., credit default swaps) bundled to create cash flows that match those of the collateral pool. For example, the trust may take positions in credit default swaps that mimic high-yield fixed-income securities. The cash can be placed in interest-bearing securities.

If the CDO is designed properly, the holders would not care that their income is being delivered through derivative contracts because, due to arbitrage, the interest on the cash plus the cash flows of the CDS should equal the cash flows from buying the corporate bonds directly. The formation of a synthetic CDO does add a layer of additional risk, called counterparty risk, if the other side of the derivative contract reneges on its promises. Also, in some cases, the tranche holders may contract with the $\mathrm{CDO}$ using financial derivatives rather than cash.

Cash Flow vs. Market Value CDOs. A cash flow CDO is managed to satisfy the claims of tranche investors. In other words, the collateral pool is invested with an anticipated longevity that matches the longevities of the liabilities of the CDO (i.e., the tranches). The investment strategy is a buy-andhold strategy in which cash flows from the assets will match the cash flows owed to the tranche holders. While a cash flow CDO is managed as a buyand-hold strategy, market value CDOs are actively managed, where the fund manager seeks to trade assets to increase the income and total return of the CDO. For example, the sample CDO detailed in this chapter, if structured as a market value $\mathrm{CDO}$, would be actively managed rather than relying solely on interest and principal from the original high-yield bonds.

Bespoke CDOs. CDOs can take many forms, and this final type is tailored to meet the specific risk and return profile of the investor. The unique aspect of this arrangement is that these investors then purchase the single tranche of the CDO so that the arrangement allows for complete customization with respect to rating, coupon, maturity, and amount of subordination. Investors are motivated by the ability to invest in a security whose characteristics as a whole are designed to meet their preferences. 


\subsection{Conclusion}

This chapter described the history and evolution of the CDO. In its purest form, the $\mathrm{CDO}$ is an instrument that pools assets and then repackages the cash flows from those assets into sleeves or tranches that have varying risks and expected rates of return. The chapter featured a cash-funded, balance sheet CDO whose reference portfolio was made up of high-yield bonds. The motivation to form the CDO likely came from an investment manager seeking to earn fees by assembling and managing the portfolio. The motivation to invest in the CDO's different tranches likely came from investors with different risk appetites.

CDOs are powerful tools of financial engineering. The tremendous ability of the structures to meet the diverse preferences of investors has generated tremendous economic efficiencies. CMOs are credited with having substantially lowered the borrowing costs for hundreds of millions of mortgage borrowers since the early 1980s. CDOs, however, have been at the heart of two economy-wide financial crises: the 1994 crisis involving government-insured mortgages and the 2008 financial crisis involving subprime mortgages.

At the heart of both CDO crises was an investment industry that was pushing the envelope of investing in attempts to crank out extra returns-for their clients and, in some cases, for the sake of their bonuses. The skill level of the financial engineers on Wall Street should not be underestimated. It is doubtful that any due diligence or government regulations will eliminate the hidden risks of the complex securities that will emerge in the future.

Asset allocators with direct exposures to CDOs in their portfolios or indirect exposures through investment pools face the challenge of accessing a large spectrum of attractive investment opportunities without bearing avoidable losses. The risks and returns of CDOs are analyzed using tremendously complicated models. These models have been so misunderstood by investors and rating agencies that some of the world's top investors suffered catastrophic losses through long positions in AAA rated securities. Overseers of portfolios with exposures to CDOs should control risk exposure through arrangements that limit losses. 


\section{Tail Risk}

This chapter provides an overview of tail risk. Tail risk refers to the probability and severity of extreme negative performance-that is, to the risk of landing in the left tail of the return distribution. Tail risk has the obvious consequence of poor financial outcomes, but it also raises the risk of headline risk. To an institution, headline risk is the possibility of an outcome that raises substantial public concern that a pool of investments has not been managed with appropriate care and diligence.

\subsection{Tail Risk from Investment Strategy}

Some alternative investments and alternative investment strategies contain more tail risk than traditional investments. This risk is often discussed in the context of a return distribution that has a negative skew or high kurtosis (i.e., is leptokurtic).

Most investment strategies, whether traditional or alternative, expose investors to some degree of tail risk. Thus, the issue is not whether a strategy has tail risk, but rather the extent to which that tail risk is extreme and the extent to which it is understood and managed. This section discusses the tail risk that occurs from a fund following its investment strategy in the absence of fund errors or fraud. An example case of that risk being realized is Carlyle Capital Corporation (CCC).

Carlyle Capital Corporation. CCC was an investment company affiliated with Carlyle Group that plummeted in 2008 from an earlier price of about $\$ 20$ per share to almost zero in a period of only 10 months. What makes this epic failure even more incredible is the simplicity of the strategy's positions: long positions in AAA rated mortgage-backed securities (MBS). CCC incurred these losses when the MBS shockingly collapsed in market value during the financial crisis. The fund's collapse was driven by massive use of leverage-perhaps 30:1. A massive amount of leverage can turn small asset losses into huge equity losses. The collapse was caused by errors in risk measurement made by ratings agencies that assigned the topnotch credit ratings to structured products that did not deserve such ratings and that eventually soured.

The lesson is that seasoned professionals should carefully analyze investment strategies to detect risks inherent in the strategy. These professionals should have expertise in the markets, securities, and exposures indicated in the fund's investment strategy. The next section looks at the problem of strategy drift. 


\subsection{Tail Risk from Investment Strategy Drift}

Tail risk often arises from changes in an investment strategy through time. When a fund's original investment strategy (including the amount of leverage applied) is working well, there is little or no reason to change the strategy. When the investment strategy begins to drift toward the higher use of leverage, new types of positions, new markets, and new securities, it can signal that the fund's original strategy is no longer working. This drift can lead the fund into uncharted waters with unanticipated dangers. Long-Term Capital Management (LTCM), a hedge fund, collapsed from a risk that was being carefully monitored but that had been slowly increasing to the point that the unexpected happened (i.e., the fund collapsed).

Long-Term Capital Management. The hedge fund Long-Term Capital Management provides an excellent example of an investment strategy with underappreciated risks. LTCM was organized in 1994 by an experienced investment professional, John W. Meriwether, and an all-star team of investment professionals. The partnership team included two distinguished scholars known for their path-breaking modeling of financial derivatives prices: Robert C. Merton and Myron S. Scholes. Both Merton and Scholes were named Nobel Laureates in Economics in 1997.

LTCM's investment strategy focused on fixed-income arbitrage. Fixedincome arbitrage involves efforts to identify fixed-income assets and derivatives that are relatively mispriced. The key to identifying mispriced assets is to have a model that identifies a theoretically proper relationship that should exist among two or more assets.

LTCM intended to establish long positions in those assets perceived to be relatively underpriced and short positions in assets perceived to be relatively overpriced. The goal was to earn a trading profit when the positions eventually returned to their assumed proper relationship.

For example, LTCM noted that recently issued Treasury bonds (called onthe-run issues) traded at slightly higher valuations than seasoned issues (called off-the-run issues) because of the higher liquidity of the newly issued bonds. As time passes, eventually a new Treasury bond is issued and the previously onthe-run issue becomes another off-the-run issue and presumably declines in value as its liquidity declines. LTCM's strategy was to short sell (i.e., establish a negative position in) the highly priced, highly liquid on-the-run bond and hedge away the interest rate risk by establishing a long position in an otherwise similar off-the-run and relatively underpriced Treasury bond. The trade was considered to be low risk and to offer an attractive return when the bond prices eventually converged by returning to their theoretically predicted relative prices. 
LTCM, like other fixed-income arbitrageurs, applied this strategy with a great deal of leverage to create the potential for high returns. LTCM's highly credentialed team was perceived to have the skill to identify attractive trades and to manage the risks properly.

After enjoying high returns through 1997, LTCM returned billions of dollars to outside investors apparently without a corresponding reduction in its positions. The net effect was to increase the leverage of the fund. Eventually, LTCM's large positions became so leveraged that when prices failed to revert on a timely basis to the relationship that LTCM predicted, the fund got caught in a liquidity crisis that forced liquidations at losses that devastated the fund. The spectacular collapse and failure of the hedge fund in 1998 shook world financial markets. The details are intriguing and have been the subject of investigations, several books, and countless articles. This example illustrated the dreaded headline risk borne by both the principals and outside investors.

The collapse of LTCM involved the massive use of leverage and offers an important lesson that relates to the famous quote (often attributed to John Maynard Keynes but its origin is uncertain) that "markets can remain irrational for longer than you can remain solvent." In other words, no matter how well a model describes how assets should be relatively priced, it is often possible that the mispricing will persist or even worsen such that the speculator will be forced out of the positions at ruinous prices. It is also possible that LTCM underestimated the susceptibility of the fund to other major financial institutions that had strategic reasons to deny LTCM's requests for additional credit.

Porsche, Volkswagen, and Hedge Funds. Porsche Automobile Holding SE began accumulating a large position in the stock of Volkswagen in $2008 .{ }^{15}$ In the process, Volkswagen AG's stock price moved higher and higher. Eventually, a number of hedge funds accumulated large short positions in anticipation that the price would eventually revert to lower levels. But in October 2008, Porsche disclosed that it owned 40\%+ of the outstanding stock and that it had options to buy another $30 \%+$ of the outstanding shares.

The funds that held short positions realized that they would have to pay enormous prices to buy enough shares to cover their short positions (i.e., to return the shares that they had borrowed). The funds were caught in a classic short squeeze. The share prices soared further from the buying pressure exerted by the funds attempting to cover their shorts. A successful short squeeze can cause dramatic upward spirals in the security underlying the squeeze. At the height of the Volkswagen short squeeze, the total market

${ }^{15}$ Reported by the New York Times (30 October 2008). 
value of Volkswagen's stock passed that of Exxon Mobil Corporation's stock to become the largest in the world-on paper.

More than 30 hedge funds filed legal actions against Porsche in US and European courts, accusing Porsche of fraud in its attempt to "corner the market.” As of 2017, Porsche was victorious in the major cases.

Investment Strategy Drift to Higher Risk. Increased use of leverage (especially leverage in excess of that originally envisioned or deployed) and huge concentrated positions (especially short sales) should be a source of concern about tail risk. Increased leverage can be a sign of managerial hubris, but it is often a symptom of trades becoming "crowded." A crowded trade occurs when numerous traders observe the success of a particular trade and place increasing quantities of capital into the trade. The effect of crowded trades is to lower the spread being earned by each participant.

As the available spread, or potential return on assets (ROA), narrows, the traders may opt to increase the size of the positions in the trade using leverage to retain the same return on equity (ROE). Eventually, the positions in the trade become so large that small fluctuations in values can trigger the need for participants to cover their margin debts by liquidating positions. The liquidations are so large and sudden that the market prices move further against the crowded traders, igniting a spiral of collapses and "fire-sale" prices.

Some traders scan markets looking for crowded trades in which market participants are near or at their limits regarding how much leverage they can incur. These contrarian traders take the opposite position as the crowded traders in an attempt to push market prices to the point of forcing the funds to liquidate their positions, thus driving the prices even further in favor of the contrarians. These traders are in a position of benefiting from limits being placed on leverage-or of even having existing leverage withdrawn. Traders also search for overcrowded short positions susceptible to squeezes. Evaluation of tail risk requires expertise in the potential for such events.

The Collapse of Amaranth Advisors LLC. The collapse at Amaranth Advisors LLC is another case of investment strategy drift, although its demise can be linked to other risks as well. The fund, founded by a convertible bond trader, was organized as a multistrategy fund—that is, one designed to pursue a variety of investment strategies including long-short equity, leveraged loans, and merger arbitrage. But it was trading in energy derivatives that eventually destroyed the fund.

Amaranth enjoyed enormous success before 2006, much of which was attributable to trading in energy derivatives, such as natural gas, by its star trader, Brian Hunter, who reportedly helped generate more than $\$ 1$ billion in profits in 2005 
and who received an estimated $\$ 75$ million bonus. Soon Amaranth's trading in energy derivatives dominated the fund's positions and profits.

The primary trade implemented at Amaranth in the time period preceding its collapse was reported to be a spread. A spread is when simultaneous long and short positions are established in two highly similar securities. In Amaranth's case, the spreads involved huge positions in natural gas futures contracts that differed by delivery date. Amaranth's trading attempted to profit from relative price changes between contracts in winter and nonwinter delivery months. (Natural gas typically sells for a higher price in winter than in other seasons.) By early 2006, Amaranth's positions in natural gas contracts were so huge that they dominated the positions on the New York Mercantile Exchange. The fund's culture was apparently intoxicated by the enormous trading profits (and perhaps bonuses) that the fund was enjoying.

But natural gas derivatives prices began to move against Amaranth and the fund began incurring huge losses in early 2006. By September 2006, the fund had collapsed. In retrospect, Amaranth's investment strategy had clearly drifted. First, the strategy drifted from the original expertise on which it was founded (experience in convertible bond arbitrage) to attempts to arbitrage energy futures contracts. Second, the leverage being applied increased along with the fund's assets and confidence. Finally, the control exerted over its principal trader appears to have waned, reducing the effectiveness of the fund's risk management strategy. This final issue, that of limited controls over huge trading activities, raises the topic of rogue traders, discussed in the next section.

\subsection{Tail Risk from Rogue Traders}

Investors should consider the inherent conflict of interest between traders within an organization and the investors in that organization. Most traders can be viewed as having a compensation scheme that explicitly or implicitly resembles that of a long call option on a portfolio. Specifically, when a trader's portfolio exhibits superior returns, the rewards to the trader can be enormous. The downside to the trader, however, is generally limited to the loss of his job.

The call option-like nature of a trader's compensation scheme becomes even more pronounced when a trader has generated recent losses. Traders who have experienced substantial recent losses are often in a position in which they will lose their job if the losses cannot be recouped. Traders have an especially strong incentive to take increasingly large risks as the losses mount and time passes because they have little to lose and much to gain.

A conflict of interest exists between traders and operational risk managers. The risk management officials implement policies and procedures to measure risk and portfolio values accurately and promptly. Traders have an 
incentive to develop strategies to manage returns and circumvent risk controls. Most firms offer much higher compensation to successful traders than to risk managers-presumably generating a team of traders with greater experience, knowledge, and incentives than the risk managers.

Several famous examples of rogue trading, each of which generated losses in excess of $\$ 1$ billion, include Nick Leeson with losses that destroyed Barings Bank in the mid-1990s, Yasuo Hamanaka at Japan's Sumitomo Corporation in 1996, UBS's Kweku Adoboli in 2011, and Jérôme Kerviel at France's Société Générale S.A. bank in January 2008. These rogue traders reportedly received prison sentences averaging about six or seven years. Note that these losses occurred inside major banks, not hedge funds. Losses from rogue traders are relatively rare in hedge funds and certainly are less well known.

\subsection{Tail Risk from Operational Failure}

Technology advances have generated enormous efficiencies in the placing and managing of trades. Computerized trading now allows high-frequency traders to formulate and execute trades in fractions of a second. This increasing speed and use of technology, however, raises serious concerns regarding tail risk. Tail risk from technology snafus can be generated by problems within a fund or as fallout from price volatility generated by technology snafus in the market.

An example of a technology snafu that brought down a firm is Knight Capital Group in 2012. Knight Capital Group was a massive market maker; indeed, it was the largest equity trader in the United States by trading volume. A market maker serves as the counterparty to other traders by buying when other traders are placing market orders to sell and selling when other traders are placing market orders to buy. The firm's profits are generated by consistently buying at bid prices and selling at offer prices because the offer prices exceed bid prices at each point in time. In doing so, a market maker establishes long and short positions in various securities resulting from its efforts to fill trades and offset temporary supply and demand imbalances in the marketplace (i.e., provide liquidity). Properly executed, the primary risk of this strategy is that the market prices will consistently move against the long and short positions that the market maker takes while providing liquidity.

The problem that arose at Knight in the summer of 2012 was that new software at the firm began reversing the firm's strategy from buying at the bid and selling at the offer to selling at the bid and buying at the offer. Apparently, Knight had inadvertently reversed its strategy and was incurring small losses on most of its trades. As the saying goes, they were losing a little on each transaction but trying to make up for it through higher volume. As Knight's losses mounted and as the firm's willingness to execute trades diminished, the 
demand for its services plummeted. The disruptions at Knight caused its market value to plummet, and the firm was eventually sold to Getco Electronic Trading Company, LLC. This example of a devastating loss involves a traditional firm rather than an alternative asset fund. The events involving Knight Capital Group are well known because they are emblematic of the potential for rapidly traded quantitative strategies to go awry.

The increased use of technology allows for increasing speed to identify and execute trades. The technology also allows for massive trading mistakes or intentional market manipulations to take place. Fat-fingered trades are trades of enormous magnitude that are made when a trader misunderstands the scale of a derivative contract or other security and enters a trade for perhaps 100 times the intended size. The trades create a temporary supply-anddemand imbalance that shocks the market price of the asset involved. The trades can devastate the firm executing the trade as well as other firms with large exposures to the securities involved. Fat-fingered trades are the result of poor operational risk controls that allow trades of unreasonable size. Ideally, a firm's trading systems should be programmed to reject orders for trades that exceed a firm's asset size or risk limits. Investors should confirm that the systems employed by an asset manager, agent, or counterparty include these vital operational risk controls.

\subsection{Tail Risk from Fraud}

Perhaps the most famous example of pure investment fraud perpetrated by a single entity is that of Bernard L. Madoff Investment Securities LLC. Madoff used false reports of trading profits to induce investors to entrust their funds to his management. Notably, the Madoff fraud was a hoax, not a hedge fund. In fact, Madoff's hoax did not even pretend to be based on a hedge fund.

Clearly, careful due diligence of a prospective investment can help avoid some or perhaps most instances of pure fraud. The case of Bernard L. Madoff Investment Securities is one such example. Some investors suspected fraud, and at least one went so far as to repeatedly report his concerns to the SEC. Chapter 13 on due diligence provides an overview of the procedures and practices that can mitigate exposure to the risks of losses resulting from fraud, along with other potential risks, such as errors.

Another type of fraud that is on the increase involves massive orders placed intentionally to disrupt markets. The term spoofing describes the intentional placing of orders to disrupt market prices with no intention of honoring the trades. The goal of the fraudster may be to cause a huge price change that enables the fake trader (or an accomplice) to exploit the temporary price shock using real trades. 


\subsection{Conclusion}

Many alternative investment strategies offer the potential for both increased alpha and increased tail risk. Asset allocators and their overseers are tasked with evaluating the potential risks and rewards of myriad complex investment strategies. It is necessary to bear some tail risk in the pursuit of a welldiversified portfolio with attractive returns. The following four tasks may be useful in avoiding tail risks that are unnecessary as well as those that are not rewarded through appropriately higher expected returns.

Do the Due Diligence. Chapter 13 provides an overview of the due diligence that should be performed before investing in a fund or other asset-in particular, a private fund. The procedures involved in full due diligence of a private fund are numerous and can be complex. Extensive help has emerged in recent years through excellent published standards and from consultants specializing in performing some or all of the tasks.

Monitor the Funds. Ongoing monitoring of investments is vital, particularly for private investments that lack continuous and reliable liquid market prices. The level of monitoring should be proportional to its potential benefits. In particular, the benefit to monitoring a fund is greater when that monitoring can trigger useful actions by the investor, such as exerting influence on the fund managers or exiting a fund before erosion of its value.

Follow the Money. The investment world, including alternative investments, has numerous conflicts of interest. Asset allocation decisions should be based on a thorough understanding of the incentives involved with every investment and with realistic views of the difficulty of locating and exploiting opportunities for alpha.

Pay Attention to the Fund Culture. Asset allocators should seek fund managers who are dedicated to respecting regulations and serving the financial interests of their investors. The values and priorities that drive the fund can be revealed through a thorough examination of the entire organization's attention to the documentation of its procedures, its documented adherence to following those procedures, and the commitment of the fund's personnel to respecting regulatory authority and honoring the fund's obligations to its clients. 


\section{Investment Process, Operations, and Due Diligence}

Top-level oversight of traditional public investments requires little or no knowledge of day-to-day issues involving investment processes and operations underlying the assets of a portfolio. For example, an institution establishing a position in a huge, well-known fund, such as the Vanguard 500 Index Fund, might do so without investigating Vanguard's investment process and operations and with little analysis of the investment other than its stated objective, expense ratio, and long-term performance relative to the S\&P 500 Index.

Issues regarding investment processes and operations, however, are essential to institutional investors in private investments, especially those with sophisticated or rapid trading technologies.

This chapter provides an overview of the challenges involved with overseeing alternative investments and investigating and monitoring their investment processes and operations. The focus of this chapter is on private fund structures, such as those used in private equity funds and hedge funds. The principles involved, however, are applicable to other investments as well, including investments in private infrastructure funds, managed futures funds, and separately managed accounts.

In many discussions of fund organization, the fund's investment process is viewed as a subset of its operations. In many discussions of due diligence, investment processes are viewed as being alongside of operations. For clarity, Section 13.1 discusses the investment process and Section 13.2 discusses noninvestment operations.

\subsection{The Investment Process}

The investment process consists of the procedures and personnel directly involved in investment activities, which are often referred to as the front office.

The Investment Mandate. The investment mandate of a fund is an explicit or implicit statement of the intended (or allowed) investments and strategies of the fund. Broadly speaking, the investment strategy of a fund describes the goals and risks of the fund's investment activities.

The investment mandate and strategy should be clearly and carefully described in various documents, including the fund's offering documents and marketing material. Offering documents often include extremely broad language allowing the fund to operate in virtually any market with effectively no 
constraints to protect the manager from allegations of implementing disallowable trades.

Details that should be disclosed in a fund's mandate include information on the markets and securities in which the fund may invest, the extent of anticipated and permitted use of leverage and financial derivatives, limits to risk exposures, limits to position sizes, the identities and roles of the investment team, and the fund's risk management procedures.

Investment Strategy Drift. A primary concern regarding a fund's investment activities is investment strategy drift - that is, the pursuit of investment goals and risks away from those initially envisioned and disclosed. Investment strategy drift includes moving into new markets, new investments, new position sizes and direction, and risk exposures that previously have not been experienced.

Investment strategy drift is often a signal that the initial investment strategy is failing to generate the returns previously experienced or envisioned. A prominent example is increased leverage, which can be a warning signal that the original investment strategy is offering lower returns than originally expected. The fund's investment team may be using leverage to prop up the performance of an investment strategy with deteriorating performance. Reduced returns to a strategy, before adding leverage, can be a signal of increased competition in the markets from other investors crowding into the strategy. At other times, increased leverage can represent potential overconfidence of the investment team. In both cases, the higher leverage increases the likelihood of large losses and fund failure. A fund's history of leverage use should be part of an institution's due diligence, and monitoring leverage after investing in a fund should be ongoing.

Investment Process Risk. The investment process includes the policies and procedures used to implement the investment mandate through investment decisions and actions. Investment process risk is the susceptibility of the decisions, activities, policies, and procedures within the front office to errors or purposeful decisions that result in exposures that are inconsistent with the investment mandate, such as inappropriate levels of leverage and inappropriate levels or types of asset risk.

Investment processes should be reviewed and analyzed before investment, and positions, exposures, and performance of the fund should be reviewed as part of an ongoing monitoring process after an investment in the fund has been made.

\subsection{Noninvestment Operations}

Noninvestment operations include the operational activities, business activities, and governance of the fund. 
Operational Activities. Noninvestment operational activities are often termed middle-office and back-office activities and are performed by middleoffice and back-office personnel. Virtually any activity in a fund involves investments. The terms front office, middle office, and back office often are delineated by the expertise and job description of the personnel involved in the activities rather than by whether the activities are related to investments. Noninvestment activities include providing support to the investment personnel with respect to data, recordkeeping, and documentation.

Noninvestment operational activities generally include the following four primary functions:

1. Execution - the process of completing a trade. After the investment team decides to implement a trade, it may be placed by the investment team or in operations by a trading desk. In either case, the process of completing a trade involves policies and procedures for directing, communicating, and working the trade.

2. Posting and settlement - the process of logging the trade (posting) and the process of reconciling the trade with confirmations from third parties.

3. Allocation - the predetermined process of dividing a trade into the various accounts and funds for which the trade was intended.

4. Reconciliation - the process of reviewing internal records of trades against external records of those trades, such as those provided by the prime broker, the administrator, or counterparty.

\subsection{Due Diligence}

In law, due diligence is defined as the care that a reasonable person exercises to avoid harm to other people or their property. Due diligence has been a long-term issue in securities law and securities regulation. Alternative investments in general, and private alternative investments in particular, require even greater care in meeting the challenges of performing due diligence.

Due Diligence Procedures. Due diligence procedures generally have been conducted by internal staff using questionnaires and other materials to provide structure, organization, and a comprehensive view of risks. Lists of requested documents (e.g., offering, organizational, and governance) should be carefully compiled, and attorneys should review documents received in response to ensure that they are appropriate. In many cases, the investor's internal staff conducts most or all of the due diligence and staff may be dedicated entirely to performing the due diligence function. Alternative due 
diligence approaches include (1) the use of employees in which due diligence is all or part of their job description or (2) the use of external consultants and firms to perform due diligence tasks.

Thorough background checks on the fund's principals should be carefully conducted-a task that increasingly is outsourced. The fund's service providers should be interviewed, including prime brokers, administrators, custodians, and providers of pricing and other data. Procedures to monitor personal trading and communications should be reviewed as well as fund governance procedures.

An onsite visit is considered to be part of best practices, although due diligence without an onsite visit, called a desk review, is sometimes used.

The goal of operational due diligence is to ensure that operations are based on processes and procedures that are well understood and consistently followed. The operations should have sufficient scalability to facilitate potential growth. The operations personnel should know current regulatory and accounting issues and be equipped to recognize and respond to regulatory and accounting changes.

Operational Areas of Special Interest. Foremost concerns with regard to operational risk are errors, fraud, and perverse incentives.

A key area of focus is to ensure that the reported values of investments are properly calculated. Due diligence requires well-constructed valuation procedures that are consistently monitored. Cash management procedures should be given extra scrutiny.

Business Activities. Like any other organization, an investment fund requires personnel that support information technology, infrastructure, human resource management functions as well as other activities that reinforce operations. Although business activities are not typically described as operational activities, due diligence and ongoing monitoring of the fund's business activities should be addressed.

Business continuity and disaster recovery plans should be carefully reviewed. How would the fund respond to an emergency in which the facilities normally used for their investment processes and other operations become unavailable? How is the organization equipped to deal with losses of key personnel? Along a related line, what insurance coverage does the fund have, such as errors and omissions insurance? The information needs to be collected and verified.

Organizing the Scope and Details of Due Diligence Processes. Institutional investors in alternative assets increasingly rely on experienced external consultants to assist with these due diligence processes. Organizing the process of using external consultants and performing internal due 
diligence both require unbiased and comprehensive information on industry due diligence standards and practices.

Institutional investors may find it useful to use the resources of two notfor-profit organizations: the Standards Board for Alternative Investments (SBAI) and the Alternative Investment Management Association (AIMA).

The SBAI serves as

a standard-setting body for the alternative investment industry and acts as custodian of the Standards. [It] provide[s] a powerful mechanism for creating a framework of transparency, integrity and good governance which improves how the industry operates, facilitates investor due diligence and complements public policy. ${ }^{16}$

The SBAI publishes Standards for Alternative Investments, which addresses key issues relating to alternative investment practices, including disclosure, valuation, risk management, fund governance, and shareholder conduct. ${ }^{17}$

The resources provided by SBAI can be used to better understand the standards for such issues as risk disclosure, which is a foundation for due diligence. In particular, the SBAI offers an open protocol and insurance open protocol that standardize "the collection, collation and representation of risk information of hedge funds and other types of investment funds. This provides a uniform framework with consistent data inputs, standard calculation methodologies and regular and timely reporting." ${ }^{18}$ These and other resources are moving the hedge fund and other alternative asset communities toward more uniform and effective practices and policies.

Due diligence questionnaires can be used to organize an internal due diligence process or to evaluate and monitor due diligence activities performed by external consultants. AIMA publishes information on due diligence questionnaires that can be especially helpful.

AIMA “is a global, not-for-profit trade association" based in the United Kingdom "committed to developing industry skills and education standards." In particular, "for 20 years, AIMA has been providing guidance and standardization for its members around the world in the form of Due Diligence Questionnaires (DDQs)." ${ }^{20}$ AIMA publishes a variety of questionnaires and

\footnotetext{
${ }^{16}$ See Standards Board for Alternative Investments (www.sbai.org/standards).

${ }^{17}$ See "Summary of the Standards for Alternative Investments," Standards Board for Alternative Investments, www.sbai.org/standards/summary-of-standards/ (accessed 17 October 2017).

${ }^{18}$ See www.sbai.org/toolbox/open-protocol-op-risk-reporting/.

${ }^{19}$ See "Our Structure," Alternative Investment Management Association Limited (www. aima.org/about/our-structure.html).

${ }^{20}$ See “Due Diligence Questionnaires," Alternative Investment Management Association Limited (www.aima.org/sound-practices/due-diligence-questionnaires.html).
} 
makes them available to its members. AIMA has "more than 1,900 corporate members . . that collectively manage more than $\$ 2$ trillion in assets." ${ }^{21}$ For nonmembers, other due diligence questionnaires are available from a variety of sources and can be located using a web search.

\subsection{Risk Alert and Due Diligence Regulations regarding Alternative Investments}

The review of a fund's investment and operational processes involves myriad topics. The final sections of this chapter draw on a 2014 report to give attention to issues of potentially special importance.

In 2014, the Office of Compliance Inspections and Examinations in coordination with the SEC issued a Risk Alert entitled "Investment Adviser Due Diligence Processes for Selecting Alternative Investments and Their Respective Managers." 22

The stated purpose of the alert is to "highlight . . . risks and issues that the staff has identified in the course of examinations regarding investment adviser due diligence processes for selecting alternative investments and alternative investment managers." 23 The Risk Alert "describes factors that firms may consider to (i) assess their supervisory, compliance, and/or other risk management systems related to these risks, and (ii) make any changes, as may be appropriate, to address or strengthen such systems." ${ }^{24}$ The document provides an excellent overview of those areas of increasing concern regarding investor due diligence for alternative investments.

The Risk Alert notes that "the due diligence process can be more challenging for alternative investments due to the characteristics of private offerings, including the complexity of certain alternative investment strategies." 25 The document concludes that the staff "hopes that this [document] concerning the due diligence practices of advisers will help to support the compliance programs of registrants." 26

The document calls on advisers that exercise discretion to purchase alternative investments on behalf of clients must determine whether such investments:

\footnotetext{
${ }^{21}$ See Alternative Investment Management Association Limited (www.aima.org/about.html). 22“'Investment Adviser Due Diligence Processes for Selecting Alternative Investments and Their Respective Managers," National Exam Program, Risk Alert 4, no. 1 (28 January 2014): www. sec.gov/ocie/announcement/risk-alert---selecting-alternative-investments-and-managers.html. ${ }^{23}$ www.sec.gov/about/offices/ocie/adviser-due-diligence-alternative-investments.pdf.

${ }^{24}$ Ibid.

${ }^{25} \mathrm{Ibid}$.

${ }^{26}$ Ibid.
} 
(i) meet the clients' investment objectives; and (ii) are consistent with the investment principles and strategies that were disclosed by the manager to the adviser (as set forth in various documents, such as advisory disclosure documents, private offering memoranda, prospectuses, or other offering materials provided by the manager). ${ }^{27}$

The first point highlights the requirement to ensure that the stated investment strategy of an investment is suitable for the client. The second point is designed to ensure that the fund manager follows the stated or anticipated investment and operational processes.

\subsection{Industry Trends in Due Diligence}

The Risk Alert noted four due diligence trends with increasing and widespread usage that presumably indicate a professional consensus regarding their importance. ${ }^{28}$ Each trend is reviewed in the following sections.

Advisers Seeking Enhanced Information from Managers. The Risk Alert noted that advisers are seeking greater information, including positionlevel transparency (i.e., the ability of advisers to see the exact positions underlying their funds) and separately managed accounts.

Position-level transparency refers to regular, prompt, and detailed disclosure by the fund manager of the fund's securities holdings. Although some managers are reluctant to provide position-level transparency (which may reveal their proprietary trading strategies), advisers can benefit from positionlevel transparency by being better able to understand and manage their aggregate risks.

Separately managed accounts (rather than investment funds and other pools) may provide greater transparency, better monitoring, greater control, and reduced likelihood of incurring unauthorized fees or having assets be misappropriated. Use of separately managed accounts is a matter of negotiation between investment advisers and fund managers involving the potential benefits to the adviser as well as such issues as potentially higher expenses, the potential lack of limited liability, and reduced efficiency.

Using Third Parties for Additional Information. The Risk Alert discusses the trend among investment advisers to use third parties as sources of additional information. The alert identified six categories.

${ }^{27}$ Ibid.

${ }^{28}$ This section follows closely "Investment Adviser Due Diligence Processes for Selecting Alternative Investments and Their Respective Managers," National Exam Program, Risk Alert 4, no. 1 (28 January 2014): www.sec.gov/ocie/announcement/risk-alert---selecting-alternativeinvestments-and-managers.html. 
Portfolio information aggregators (risk aggregators) are third-party service providers who collect and process information from various private investments to report and assess the combined risks to investment advisers. A potential advantage of using portfolio information aggregators is that fund managers may be more willing to provide portfolio details to these aggregators rather than directly to investment advisers. A risk aggregator can download the positions held in each fund in an investor's portfolio directly from the prime brokers, verifying actual positions and reducing the risk of fraud or understated risk. Without disclosing actual positions to investors, the risk aggregation system can give fund-level and portfoliolevel disclosures of betas, leverage, and risk, including options and futures positions. Top risk aggregation systems also can perform scenario analysis, stressing how an investor's portfolio across all fund investments would fare if the market conditions of previous events, such as the 2007-09 global financial crisis, were to repeat in the future.

Advisers are increasingly contacting a fund's third-party service providers to independently verify information regarding the fund's assets and the existence of its alternative investment relationships. Advisers also are conducting some due diligence on key service providers to ensure that the service providers adequately meet the needs of the investment.

Some advisers will invest only in funds with independent third-party administrators. Their goal is to mitigate investment and operational risks related to key fund administration services, such as "performing net asset value calculations, fund accounting, trade reconciliation, and processing and recording shareholder activity." 29

Another trend is increasing reliance on the transparency reports (of investment positions) directly from and independently produced by thirdparty administrators. The information sought includes the fund's

(i) net asset value and the percentage of its investments that are confirmed by the administrator with independent custodians; (ii) custodians holding its investments; (iii) percentage of investments that are priced by a thirdparty administrator; and (iv) assets and liabilities which are measured at "fair value" and are categorized using the fair value hierarchy (Level 1, 2, or 3) established under FASB ASC 820, Fair Value Measurements. ${ }^{30}$

Third parties increasingly are performing independent background checks of principals to supplement the fund's own reviews regarding "employment

${ }^{29} \mathrm{Ibid}$.

${ }^{30} \mathrm{Ibid}$.

() 2018 CAIA Association. 
history, legal and regulatory matters, news sources, and independent reference checks." ${ }^{1}$

According to the Risk Alert, investors are reviewing regulatory documents to research the firms and personnel related to an investment decision. Webbased sources of regulatory documents include information on investment professionals and firms in the Financial Industry Regulatory Authority's BrokerCheck and information on registered firms and their personnel in the SEC's Investment Adviser Public Disclosure website. The information gathered can inform investors of potential regulatory issues or control weaknesses with regard to the fund's manager.

Additional Quantitative Analyses and Risk Measurement. The Risk Alert also discussed quantitative analyses and risk measurement and identified two key areas for which increased effort is needed to detect performance manipulation and to supplement decision making.

One area of increased concern involves the "detection of manipulation of performance returns" ${ }^{2}$ by fund managers. SEC staff had observed advisers using quantitative analysis to detect aberrations in returns that might identify "falsified or other-wise manipulated" 33 returns and their managers. The following three measures of returns were noted: (1) the bias ratio, which attempts to indicate when returns have been manipulated and thus do not exhibit a distribution consistent with competitive markets, (2) indications of serial correlation (i.e., correlation of returns between different time periods), and (3) measures of skew (i.e., the tendency of a return distribution to have higher tail risk; discussed in Chapters 12 and 14).

Another area of increased quantitative analysis and risk measurement noted was the "supplementation of investment-level decision making." ${ }^{4}$ SEC staff also observed increased use of quantitative risk measures to make investment-level decisions. The goals included using statistical techniques, such as factor analysis, to indicate whether returns are consistent with the stated investment strategy and sophisticated quantitative analysis of returns to detect potential problems before they become severe.

Additional Due Diligence. The final industry trend regarding due diligence noted in the Risk Alert is "additional due diligence." The alert discussed this issue in five subsections, which are highlighted in the following paragraphs.

\footnotetext{
${ }^{31}$ Ibid.

${ }^{32}$ Ibid.

${ }^{33}$ Ibid.

${ }^{34}$ Ibid.
} 
Operational due diligence focus has increased, including the establishment of operational due diligence groups. For example, the Risk Alert noted the existence of dedicated operational due diligence teams that had veto-level authority over the selection of fund managers recommended by the investment due diligence team. The scope of the groups may include "evaluation of the manager's policies and procedures regarding valuation." ${ }^{35}$

Legal document reviews are included by most advisers in their due diligence process to detect "legal document risk," such as legal provisions affecting the ability of investors to liquidate their funds during specified events. The adviser's legal staff "may include the review of offering materials, side letters, subscription agreements, and counterparty agreements." 36

Investment fund redemption terms and liquidity of the portfolio are essential when assessing liquidity issues. Some investors experienced unanticipated and problematic redemption restrictions during the financial crisis of 20082009. All investors should closely examine potential redemption restrictions to evaluate their appropriateness for an investor's liquidity needs given the liquidity of the investor's other holdings. Although the Risk Alert did not emphasize the issue, lenient redemption restrictions for funds are not always good. In fact, they may be problematic if the fund's net asset value could be adversely affected by redemptions from other investors.

Onsite visit requirements are part of adviser reviews. The advisers indicated that onsite visits accomplish three helpful tasks: "(i) understand the culture of the manager; (ii) detect instances where dominant individuals and inadequate control environments may exist; (iii) and provide increased access to review documents and to speak with the manager's personnel." ${ }^{37}$

Audited financial statement reviews still are performed but with an increased effort to "identify possible related party transactions and to identify valuation concerns." 38

\subsection{Warning Indicators or Awareness Signals}

The Risk Alert noted three "warning indicators or awareness signals" that "led advisers to conduct additional due diligence analysis, to request that the manager make appropriate changes, or to reject (or veto) the manager or the

\footnotetext{
${ }^{35}$ Ibid.

${ }^{36}$ Ibid.

${ }^{37}$ Ibid.

${ }^{38}$ Ibid.
} 
alternative investment." ${ }^{39}$ These three types of indicators or signals include investment, risk management, and operations.

\section{Investment Warning Indicators or Awareness Signals.}

1. Manager unwillingness to provide transparency

2. Investment returns inconsistent with the investment strategy

3. Lack of clarity in the investment process

4. Lack of controls and segregation of duties

\section{Risk Management Warning Indicators or Awareness Signals:}

1. Concentrated positions

2. Insufficiently knowledgeable investment personnel

3. Investment strategy drift

4. Overly complex or opaque investment descriptions

\section{Operational Warning Indicators or Awareness Signals:}

1. Lack of a qualified third-party administrator

2. Unknown or unqualified auditor

3. Multiple changes in third-party service providers

4. Concerns noted in the audited financial statements, including relatedparty transactions

5. Unfavorable indications from background checks of key personnel

6. Findings of undisclosed conflicts of interest

7. Inadequate operational infrastructure and compliance programs

8. Questionable fair valuation process

\subsection{Compliance Programs and the Code of Ethics}

The Risk Alert also noted five issues related to compliance with applicable laws, rules, and regulations and discussed codes of ethics, which all advisers

\footnotetext{
${ }^{39}$ This section follows closely "Investment Adviser Due Diligence Processes for Selecting Alternative Investments and Their Respective Managers," National Exam Program, Risk Alert 4, no. 1 (28 January 2014): www.sec.gov/ocie/announcement/risk-alert---selecting-alternative-investments-and-managers.html.
} 
registered with the SEC must adopt. ${ }^{40}$ These issues and the code of ethics requirement are summarized in the following paragraphs.

Annual reviews of an asset management firm's compliance program are required to be written each year by each US Registered Investment Adviser. The goals are to review an assessment of the effectiveness of the compliance program and to identify potential revisions to the program. The Risk Alert noted that some advisers do not include alternative investment due diligence policies and procedures in their reviews despite recommending alternative investments to their clients.

Disclosures made to clients should not deviate from the actual practices followed by advisers. According to the Risk Alert, advisers should "review disclosures for consistency with fiduciary principles" and "describe notable exceptions made to the adviser's typical due diligence process." ${ }^{41}$

Marketing claims must not contain "information about the scope and depth of the due diligence process that could be misleading or statements that appeared to be unsubstantiated," according to the Risk Alert. ${ }^{42}$ Furthermore, the staff noted that advisers with detailed documentation on policies and procedures were more likely to consistently apply due diligence processes. Additionally, SEC staff noted that advisers who do not apply a consistent program of oversight of third-party service providers (e.g., periodic reviews of whether the terms of agreements were being followed) are more likely to have deficiencies.

All advisers registered with the SEC are required to adopt and enforce a written code of ethics. That code must reflect the adviser's fiduciary duties to her clients, including minimum standards of conduct and personal securities trading policies and procedures. Advisers must avoid conflicts of interest, such as an adviser acquiring preferential investment terms relative to those received by the clients. Advisers must maintain records of decisions to approve the personal acquisition of securities by an "access person," defined by the Risk Alert as a "supervised person who has access to nonpublic information regarding clients' purchase or sale of securities, is involved in making securities recommendations to clients or who has access to such recommendations that are nonpublic." ${ }^{43}$

\footnotetext{
${ }^{40}$ This section follows closely "Investment Adviser Due Diligence Processes for Selecting Alternative Investments and Their Respective Managers," National Exam Program, Risk Alert 4, no. 1 (28 January 2014), www.sec.gov/ocie/announcement/risk-alert---selecting-alternative-investments-and-managers.html (accessed 24 June 2017).

${ }^{41}$ Ibid.

${ }^{42}$ Ibid.

${ }^{43}$ Ibid.
} 


\subsection{Conclusion}

Perhaps the central issue when performing due diligence on a fund manager is to ascertain the extent to which the manager promotes a fund culture that places its fiduciary duties to its clients as a top priority. Such managers should view the rigorous development, documentation, and adherence to regulations, policies, and procedures involving due diligence as essential to their responsibilities. Indications that fund employees view regulatory supervision, compliance issues, and careful development, documentation, and adherence to policies and procedures such as due diligence as bureaucratic wastes of time should serve as important warning signals to prospective and current fund investors. 


\section{Measurement and Management of Returns and Risk}

Chapter 10 discussed important risk measures popular in the management of options and other financial derivatives (the Greeks). This chapter continues this discussion with additional measures of risk and return focusing on the risk measures used most in alternative investment analysis. The chapter begins with a review of the measurement of returns and the use of probability distributions to model the uncertainty of future security returns.

\subsection{Measurement of Return and Return Distributions}

This section discusses return computation and the normal probability distribution. Although most investment returns do not form a normal probability distribution, that distribution is the basis or a point of departure for understanding the dispersion in prospective returns.

Measurement of Simple Return. The returns for a liquid asset, $r$, are calculated as the sum of the change in an asset's price and any cash distributions received, divided by the asset's price at the start of the time interval over which the return is being measured.

$$
r=\frac{\left(P_{1}-P_{0}\right)+D_{0,1}}{P_{0}},
$$

where $P_{1}$ is the end-of-period security price, $P_{0}$ is the security price at the beginning of the period over which the return is calculated, and $D_{0,1}$ is the total dividends or other per share distributions to the security holder.

Returns can be expressed over any specified time interval and can differ by compounding assumptions. A return computed over one time interval (e.g., monthly) can be restated in terms of an annual rate or rate based on another time interval (e.g., quarterly). The remainder of this chapter essentially ignores these details and focuses on the methods used to analyze returns and risk.

Return Probability Distributions. The uncertainty of future security returns is represented by the security's return probability distribution-that is, the relationship between each potential return and its probability. Let's examine the nature of returns of most securities, such as the equity of a 
publicly traded firm. Note that the return of an equity or other cash security is limited to $-100 \%$ to the left but theoretically is unlimited to the right:

$$
-100 \% \leq r<\infty \text {. }
$$

The left bound to returns as well as the nature of typical asset exposures (such as equities that tend to have a call option-like exposure to their underlying assets) usually result in a distribution for a single asset that is skewed to the right, as depicted in Figure 14.1.

In part to correct for the natural skew of equity returns, the returns on cash securities are often expressed as logarithmic ("log") returns. Log returns are formed by taking the natural logarithm of $(1+r)$ to express an asset's performance as a continuously compounded growth rate. A security with a price change of $10 \%$ will have a log return of $9.53 \%$. This indicates that when compounding is factored into the rate, an asset continuously growing at an annual rate of $9.53 \%$ will grow by a total of $10 \%$ by the end of the year because of compounding.

Risk analysis is simplified to the extent that returns form a symmetric distribution, as illustrated in Figure 14.2. Unfortunately, few, if any, traditional or alternative assets have return distributions that are consistently symmetrical.

Measurements of Dispersion. A mean return (i.e., average or expected return) usually well describes the location of a return distribution in terms of its generally high or low returns. The dispersion of returns around its mean, however, is more complex.

Intuitively, investment analysts want to know the average amount by which a security's return is likely to differ from its mean. That measure of risk, known as the mean absolute return, turns out to be statistically clumsy and is rarely used. Instead, analysts focus on a similar metric: the standard deviation of an asset's returns.

Figure 14.1. Positively Skewed Return Probability Distribution

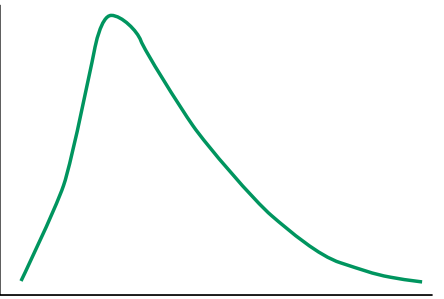




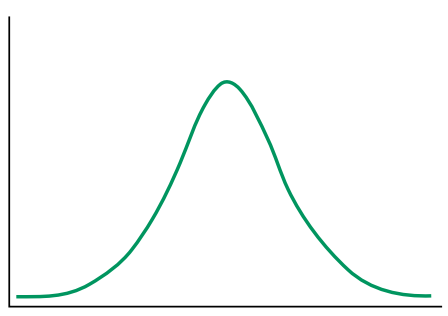

Symmetric

Standard Deviation (Volatility or Sigma). Sigma $(\sigma)$ is the Greek letter that symbolizes the standard deviation of a random variable. In investments, sigma is used to denote the standard deviation of the returns of an asset, which frequently is termed volatility. Sigma is a measure of the total risk of an asset, which includes both the systematic risk (i.e., market risk, nondiversifiable risk, beta risk) and the unsystematic risk (i.e., nonsystematic risk, diversifiable risk, unique risk, firm or entity specific risk).

Volatility can be expressed over any time unit (e.g., daily, monthly), although annualized volatility is the most common. Volatility can be interpreted loosely as the average amount by which an asset's return deviates from its mean or expected return. For example, in recent years, the annualized volatility of the returns of developed market equity indexes have tended to range from perhaps $10 \%$ to $15 \%$. In other words, in a given year, a typical outcome is likely to be a return that is roughly within 10-15 percentage points of its expected return. In recent decades, the daily volatility of developed country equity markets typically has been less than $1 \%$.

Investment analysis uses the mean return and volatility (standard deviation of an asset's return) to summarize the underlying uncertainty of an investment's future performance. Clear interpretation of the mean and volatility requires an understanding of the shape of the probability distribution.

The Normal Distribution and Security Returns. A normal probability distribution is symmetrical and is observed throughout nature and human activities. The normal distribution has tails that diminish quickly but extend without limit both to the right (higher values) and to the left (lower values). First, the returns (i.e., log returns) of major equity indexes can be somewhat reasonably approximated by the normal return distribution in the region near its mean. Asset returns are notoriously leptokurtic or fat-tailed, however, meaning that they have much higher probabilities of extreme outcomes than are found 
in the normal distribution. Figure 14.3 illustrates the increased probability of extreme outcomes found in securities with fat-tailed return distributions.

Linking the Normal Distribution to Mean, Volatility, and Confidence Intervals. Return variability is often described in terms of the number of standard deviations that a particular return differs from its mean or average return. Analysts sometimes assume that returns are normally distributed when describing the likelihood of various outcomes. Figure 14.4 illustrates the use of the normal distribution to estimate probabilities of various returns.

The normal distribution is described following the 68\%-95\%-99.7\% rule, illustrated in Figure 14.4, which explains the probabilities that outcomes will lie within 1, 2, or 3 standard deviations of its mean. For example, when a variable is normally distributed, it has about a $68 \%$ probability that a particular outcome will be within one sigma (i.e., standard deviation) of the mean. This means that if we approximate the stock market as having a return standard deviation of $0.5 \%$ in one day (and a mean return of roughly zero), then there is a $68 \%$ probability that tomorrow's return will be greater than $-0.5 \%$

Figure 14.3. Fat-Tailed (Left) and Normal (Right) Probability Distribution

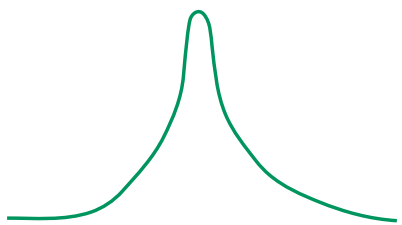

Leptokurtic Distribution

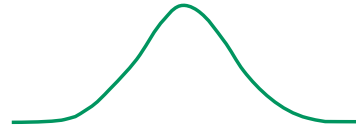

Mesokurtic Distribution

Figure 14.4. Confidence Intervals for the Normal Distribution Using Standard Deviation

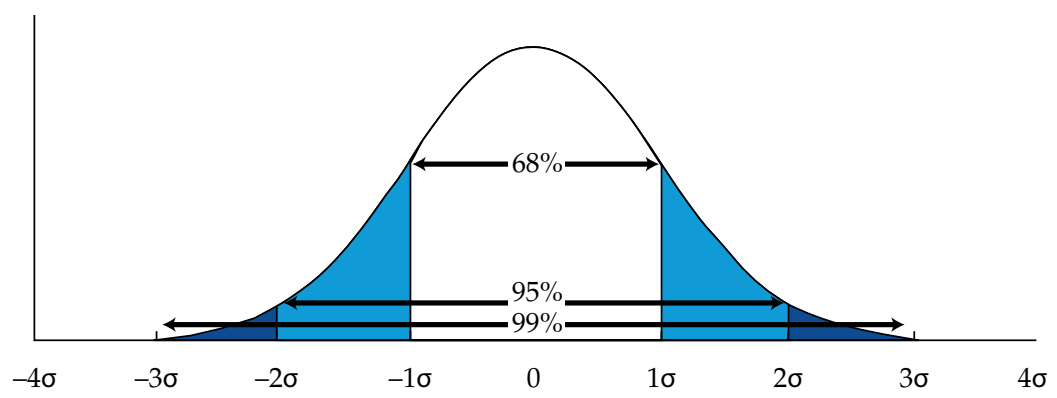


and less than $0.5 \%$. There is a $95 \%$ probability that the next return will be within $-1 \%$ and $+1 \%$ and a whopping $99.7 \%$ probability that the outcome will be within $-1.5 \%$ and $+1.5 \%$. The problem with using probabilities associated with the normal distribution to analyze actual return probabilities is that market prices generally have much higher probabilities of huge losses than are predicted using the normal distribution.

Outcomes that are normally distributed are common outside investing. Therefore, we have formed an intuitive sense of probabilities of extreme outcomes. For example, the height of human males tends to average about 70 inches with a standard deviation of 3-4 inches, which means that about 19 out of 20 adult males will have heights between 5'3" and 6'5" and that 1 out of a million adult males should be 7 feet or taller-and that is approximately what we observe. More important, the odds of happening to see someone 8 feet or 9 feet tall are almost zero. In other words, for human height, and many other examples, the normal distribution provides a familiar and useful reference for understanding the probabilities of various outcomes.

Figure 14.4 illustrates confidence intervals that can be used to understand risky returns based on the assumption that the returns are normally distributed. For example, an asset with an expected return of $10 \%$ and a volatility of $15 \%$ (both annualized) could be expected to have a $68.27 \%$ chance of experiencing an annual return within one standard deviation of its mean (i.e., between $-5 \%$ and $+25 \%$ ), a $95.45 \%$ chance of experiencing an annual return within two standard deviations of its mean (i.e., between $-20 \%$ and $+40 \%$ ), and a $99.7 \%$ chance of experiencing an annual return within three standard deviations of its mean (i.e., between $-35 \%$ and $+55 \%)$, which is $[10 \%-(3 \times$ $15 \%)]$ and $[10 \%+(3 \times 15 \%)]$, respectively.

Confidence Intervals and Asset Returns That Are Not Normally Distributed. The normal distribution wildly underestimates the probabilities of returns found in the tails of the distributions of actual security returns. A catastrophic return such as the crash of 19 October 1987 (by some estimates, a 20-standard deviation event-meaning that the actual return on that day was 20 standard deviations away from its mean) is extremely unlikely to happen even once in the history of the universe. Even for events of 3 or 4 standard deviations, the probability is massively higher of the return occurring in real life than is indicated by estimates based on the normal distribution.

The returns of alternative investments tend not to be as well approximated by the normal probability distribution as traditional investments. The two primary reasons for this are as follows: (1) the tendency of alternative investment returns to be less symmetric (i.e., more skewed) than traditional asset 
returns and (2) the tendency of alternative investment returns tend to have fatter tails (i.e., positive excess kurtosis) than traditional investment returns. Thus, although traditional investment analysis relies heavily on the normal distribution, alternative investment analysis requires substantial attention be paid to the complexities of managing assets with return distributions that differ markedly from normality.

\subsection{Measures of Risk}

Many measures focus on risk and ignore return. This section discusses the most prominent of these measures. All of the risk measures in this section are designed to provide condensed views of return distributions in a single measure. The previous sections detailed the central measure of an asset's total return risk: the volatility or standard deviation of returns. This section discusses those risk measures used in alternative analysis to understand risk when return distributions are markedly non-normal.

Semistandard Deviation. The standard deviation of an asset's return describes the dispersion of the asset's return above and below its mean or expected return. The semistandard deviation of an asset's return describes the dispersion of the asset's return below its mean or expected return. Therefore, semistandard deviation is a measure of downside risk rather than a measure of risk that blends upside and downside risks. The intuition of semistandard deviation is that investors concerned about risk are focused on the downside of possible returns. Given identical volatilities, an asset with a return distribution skewed to the downside (left) should have a higher semistandard deviation of returns than an asset with a symmetrical return distribution or with a distribution skewed to the upside (right).

The problem with semistandard deviation as used by statisticians and most financial economists is that it is not scaled in the same way as the regular standard deviation (or volatility) because it is based on the whole number of observations within a sample (or the entire area under the probability distribution) rather than on the number of downside observations, which is presumably about half as large. For example, an asset such as an equity index with an annualized standard deviation of returns of $16 \%$ would be expected to have a semistandard deviation of about $11 \%$ even if the return distribution is symmetrical. ${ }^{44}$ Therefore, semistandard deviations as defined within statis-

\footnotetext{
${ }^{44}$ For a symmetrical distribution, the ratio of the semistandard deviation to the standard deviation approaches 0.707 depending on sample size, according to Donald R. Chambers and Qin Lu, "Semivolatility of Returns as a Measure of Downside Risk," Journal of Alternative Investments 19, no. 3 (Winter 2017): 68-74.
} 
tics cannot be easily compared with standard deviations. A proposed solution is discussed in the next section on semivolatility.

Semivolatility. Semivolatility has been proposed ${ }^{45}$ as an improved measure of downside risk that is comparable to standard deviation or volatility. Semivolatility is designed to have the same scale as the regular standard deviation (or volatility) because it is based only on the number of downside observations within a sample (or the downside area under the probability distribution) rather than all observations. The result is that semivolatility can be more directly compared with volatility to ascertain the extent to which skew or other forms of tail risk are affecting downside risk.

The distinction between semistandard deviation as defined by statisticians and semivolatility as just discussed is not broadly understood. Most published research calculates semistandard deviation using the more formal statistical definition. Practitioners are mixed in their calculation methods. Asset allocators should strive to ensure that they are correctly interpreting downside risk measures, including semistandard deviation.

Value-at-Risk. Value-at-risk ( $\mathrm{VaR})$ is an approach based on quantiles. A quantile identifies an outcome that is exceeded a specified proportion of the time. For example, a 5\% VaR tells an analyst the level of losses that are expected to be met or exceeded in $5 \%$ of the outcomes over a prespecified time horizon. For example, if losses are measured as percentages, a $5 \%$ oneday VaR on a position in the FTSE 100 might be estimated as a $1 \%$ loss, which means that the probability of an investor in the index losing $1 \%$ or more in a single day is $5 \%$ (and the probability of either gaining or else losing less than $1 \%$ in a single day is $95 \%$ ). Figure $\mathbf{1 4 . 5}$ illustrates VaR for a symmetrical distribution. VaR could be reported for any probability ( $1 \%$ is also common) and for any time horizon (two days and one week are also common). Further, the loss threshold can be expressed as a currency amount or a percentage, and the performance can be expressed as deviations from an expected outcome or, when the time period is short, zero.

Analysts use $\mathrm{VaR}$ for two main reasons. The first reason to use $\mathrm{VaR}$ is that it is an easy-to-interpret measure of the risk exposure of a position or a portfolio. VaR lets an asset allocator know the analysts' best estimate of the likelihood of various loss levels. The second reason to use $\mathrm{VaR}$ is that it can be helpful in describing risks when the outcomes do not form a normal probability distribution. Properly estimated, VaR computations can be quite useful. They provide in a single measure an intuitive and straightforward indication of potential loss.

${ }^{45}$ Ibid. 
Figure 14.5. VaR for a Symmetrical Distribution

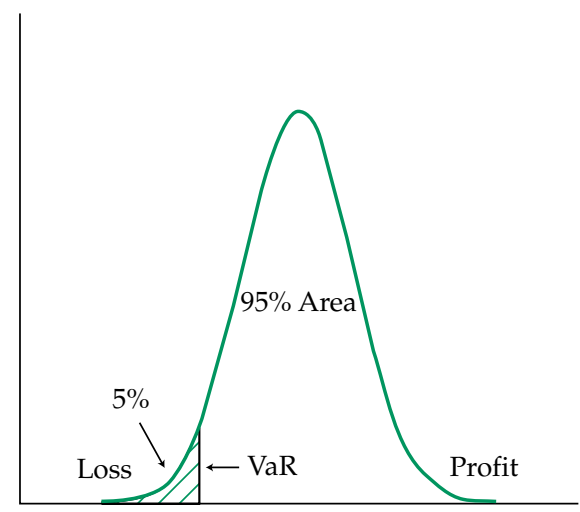

Non-Normal Distribution and Extreme Outcomes. A problem with applying the normal distribution to market prices is that many market prices are notoriously non-normally distributed. Asset allocators should be aware that the return distributions of some alternative assets (e.g., hedge funds) are dramatically non-normal. Asset allocators tend to know this. When investment professionals observe a sequence of modest profits and losses over a period of several years, however, they may be lulled into implicitly thinking that the outcomes will continue to be roughly normally distributed. Then extreme values-large losses-occur.

As previously discussed, the October 1987 crash generated losses that were unimaginable when viewing security returns through the lens of the normal distribution, which demonstrates that stock returns are not normally distributed and that our intuition may be seriously flawed in ascertaining the likelihood and potential extent of economic meltdowns.

VaR computations are commonly formed based on the assumption that outcomes will be normally distributed. Asset allocators must understand the assumptions behind the VaR computations to ensure that the computations are not based on the normal distribution.

Extreme value theory studies the formal approaches used to analyze probability distributions that contain relatively high probabilities of extreme values. Less formal approaches to adjusting VaR computations and other risk analyses involving market prices for non-normality base the probability of future extreme outcomes on careful observations of past outcomes in related asset markets. As a simplified example, consider the challenge of estimating a $1 \% \mathrm{VaR}$ for the daily returns of the UK stock market. Rather than assuming normality and 
estimating VaR using the asset's volatility, an analyst might simply rank the historic returns of the UK stock market from highest to lowest and estimate the VaR based on the historic return closest to the 99th percentile from the top.

\subsection{Measures of Return vs. Risk}

Several performance measures exist that include the ratio of reward to risk taken.

The Sharpe Ratio. The Sharpe ratio is perhaps the most popular measure of risk-adjusted performance in traditional investments. The Sharpe ratio measures the excess realized or expected return of an asset per unit of volatility (standard deviation of returns).

$$
\frac{E\left(R_{i}\right)-R_{f}}{\sigma_{i}},
$$

where $E\left(R_{i}\right)$ is the expected return (or alternatively, the mean realized return) of asset $i, R_{f}$ is the riskless return or rate of interest, and $\sigma_{i}$ is the volatility of the returns of asset $i$. For example, it may be useful to estimate the Sharpe ratio of the total stock market as an overall benchmark of the reward for bearing risk. Perhaps a reasonable expectation of total market risk and return would be an expected return of $8 \%$, a riskless rate of $2 \%$, and a volatility of 15\%. The resulting Sharpe ratio of 0.40 may form a reasonable standard on which to evaluate all annualized Sharpe ratios.

The Sharpe ratio has fabulous intuition: It is the estimated reward for bearing the total risk. The numerator is the asset's anticipated annualized risk premium or excess return (i.e., return above the riskless return). A potential drawback is that the measure of risk (i.e., volatility) ignores the potential benefits of diversification. For a fully diversified portfolio, investors may wish to use the Treynor ratio, which measures the ratio of excess return to the portfolio's beta. Note also that the Sharpe ratio can be expressed in nonannualized terms, such as quarterly, and should be done so with care and uniformity.

The Sortino Ratio. A problem with using the Sharpe ratio occurs in the case of assets that do not have symmetrical distributions. For example, an asset such as a bank loan with a higher probability of large losses (the left tail of its probability distribution) than large profits (the right tail) will have a volatility that is formed by a mixture of the risks contained in both the tails. Volatility would underestimate the downside risk caused by the left skew of this asset's return distribution. 
The Sortino ratio modifies the Sharpe ratio by substituting a measure of the asset's downside risk in place of the volatility:

$$
\frac{E\left(R_{i}\right)-R_{f}}{\text { Downside risk measure }} \text {. }
$$

Equation 14.4 depicts the general form of the Sortino ratio and does not specify the measure of downside risk. In fact, the Sortino ratio as originally published in the early 1980s subtracts a target rate of return from the asset's average return in the numerator. The ratio is illustrated with a riskless return for consistency with its more common usage. The original ratio also measured downside risk relative to a target rate of return. To compare the Sortino ratio with the Sharpe ratio, it may be preferable to use the semivolatility, detailed in Section 14.2, as the denominator. In any case, the Sortino ratio provides a measure of the risk premium available per unit of downside risk.

Jensen's Alpha and M-Squared. Several risk-adjusted performance measures, such as Jensen's alpha and M-squared, estimate excess performance based on single-factor market models, such as the capital asset pricing model. Generally, these approaches tend to be less useful for the analysis of alternative assets because the risks of alternative assets are not well explained by single-factor models. Even though the approaches can be extended to multifactor models, the usefulness may be constrained by the failure of those models to explain the returns of alternative assets well.

Capture Ratios. Capture ratios measure the ability of a skill-based manager to succeed in timing a market-presumably from having positive or increased systematic risk during bull markets and having negative or decreased risk during bear markets. Upside capture ratios greater than 1.0 indicate success, whereas measures less than 1.0 indicate failure. An upside or up-market capture ratio includes the returns of a strategy in its numerator and the returns of an index in the denominator and computes those returns including only those subperiods in which the index was up. A downside ratio analyzes performance only during those periods in which the index was down.

Upside capture ratios greater than 1.0 and downside capture ratios less than 1.0 indicate successful market timing. An upside or up-market capture ratio of 1.1 would indicate that the manager was successful in generating a return $10 \%$ greater than the index when looking at only those periods in which the index rose. A downside capture ratio of 0.8 would indicate that the 
manager succeeded by losing only $80 \%$ as much as the index, looking only at those periods in which the index declined.

Benchmarking. As will be discussed in detail in Chapter 15, benchmarking is the process of comparing an investment return with a benchmark return that is designed to indicate a normal or appropriate level of return commensurate with the risk of the investment whose performance is being analyzed. Benchmarking is an especially valuable tool in the case of many alternative investments in which risk exposures are intentionally altered through time in an attempt to earn superior returns.

\subsection{Investment Monitoring and Gaming}

Investment managers and their clients both desire attractive risk-adjusted returns. There are inherent conflicts of interest, however, between investment managers and their clients. In particular, investment managers wish to maximize the probability of retaining clients and earn hefty incentive fees, goals that at times generate risk-taking strategies that are in sharp conflict with the best interests of the clients.

The risks of traditional long-only unlevered portfolios can be altered through time by holding cash, by selecting concentrated risks, or by overweighting securities with high or low risks. These risk-altering strategies can be detected easily through portfolio listings and transaction logs (being careful to not rely solely on end-of-period statements, which can be "windowdressed" to obscure intraperiod risks).

The case of monitoring actively traded alternative investment strategies is more problematic. The risks of portfolios with varying leverage, short positions, financial derivatives, and active trading vary through time by design. Therefore, it is a far more challenging task to monitor performance and detect potential problems. In addition to analyzing trading throughout a reporting period, overseers of portfolios with alternative assets need to be particularly concerned with the objectivity and accuracy of asset valuations in cases in which the assets are not Level I assets (assets with observable market prices).

Valuation of Level II assets (those assets with values approximated by models with observable inputs) raises serious oversight concerns because of the opaqueness of the technical details of complex models. Valuation of Level III assets is even more problematic. Level III asset valuations are based on unobservable inputs and often relatively high degrees of subjectivity, as found in valuations of venture capital. The financial crisis of 2007-2009 starkly illustrated these points in the case of collateralized debt obligations. 


\subsection{Conclusion}

Numerous measures of risk and risk-adjusted performance exist. Although traditional investments are often viewed in the context of the normal probability distribution, alternative assets require skill-based strategies. Returns from these alternative assets are more likely to have extreme outcomes than are found in assets with normally distributed returns. Measurement and management of portfolio risk are not easy tasks done in isolation. The process is made more complex by the diversity of risk exposures inherent in alternative investing and the natural conflicts of interest that exist between all investment managers and their clients. This chapter has introduced the most important concepts in overseeing the risks and returns of a portfolio containing alternative assets. 


\section{Benchmarking, Return Expectations, and Performance Attribution}

This chapter focuses on benchmarking issues raised in alternative investing. Benchmarking is more than just comparing the return of an asset or portfolio with a target return. It is a statement of the appropriate performance standards for an asset or a portfolio, and implicitly, it is a statement of its perceived risks. Most benchmarking approaches are based either on the performance of indexes or on the average returns of peer groups (comparison groups). In either case, the determination of appropriate benchmarks should be based on expectations of risk and return consistent with a broad understanding of competition, financial economics, and investment theory.

\subsection{Alpha, Beta, and Models of Expected Return}

A topic as nuanced as alternative investments requires precision in the use of financial terms. Chapter 14 provided detail on sigma (standard deviation), a measure of total risk that is one of the most important measures used in alternative investing. This section details two other vital terms: alpha and beta. Generally, alpha is a measure of performance, and beta is a measure of systematic risk. This section also discusses the relationship between expected return and risk. These concepts serve as the foundation of benchmarking.

Alpha. Alpha is the well-known expression in investments for the return of an asset in excess of the benchmark after adjustment for the differential risk of the asset and the benchmark (and the time value of money). Previous chapters have discussed alpha without delving into these more nuanced issues. The term alpha has two distinct meanings.

First, alpha is the amount by which the return of an underpriced asset is expected to exceed the return of other assets of comparable risk. The focus of this use of alpha is on expected or anticipated returns. In this interpretation, alpha represents an expected superior profit or "free lunch" investors may gain for using superior skill in the selection of investments. For example, a merger arbitrage hedge fund might be believed by some analysts to offer an alpha of $3 \%-5 \%$ in markets with a normal level of merger activity, which means that the analysts expect the fund to consistently outperform competitively priced assets of similar risk by an average of $3 \%-5 \%$ per year.

Second, alpha represents the difference between the observed return of an asset and the observed return of its benchmark or other comparable 
performance measure, after adjusting for risk differences between the asset and the benchmark. The focus of this use of alpha is on realized or historic returns. In this interpretation, alpha represents return differences that may be attributable to a combination of luck, skill, or both. For example, an analyst may observe returns over the past three years and report that "fund A generated an alpha of $12 \%$ last year." This statement would be correct if, and only if, the fund outperformed its properly constructed benchmark by $12 \%$ in that year. By "properly constructed benchmark," we mean a benchmark containing essentially the same beta risks (e.g., equity market risk, bond duration risk) as the fund, but lacking any extra return because of a fund manager's luck, skill, or special knowledge.

Beta. Beta is unambiguously a measure of systematic risk (i.e., market risk, nondiversifiable risk). In most traditional investing applications, each asset has one beta and that beta has a specific meaning: It is the responsiveness of the asset to changes in the level of the market portfolio (the portfolio comprising all available assets-often proxied in the United Kingdom by a stock market index, such as the FTSE 100 Index). The beta with respect to the entire market portfolio of all available assets is known as the market beta.

In alternative investments, beta usually refers to a set of systematic risks or to the overall tendency of an asset to correlate with a variety of systematic risks. For example, the phrase "the alternative asset has substantial beta" tends to indicate that much of the risk of the asset is due to factors that are common to other investments, such as equity market risk, interest rate risk, and currency risk.

In alternative investments, the risks of assets often are described with several risk factors, with a beta measure corresponding to each of those factors to indicate each asset's exposure to that factor. For example, an equity hedge fund may have three or more betas, with each corresponding to factors within the equity market, such as size, growth, momentum, and quality. Multifactor or multibeta models are discussed later in this chapter.

Risk Premiums and Expected Returns. There are two primary components to the reward anticipated from investment: (1) the time value of money and (2) compensation for bearing necessary risk. The term necessary risk is meant to exclude the possibility of an asset offering compensation for risks that serve no fundamental economic role. Investment in real estate, equipment, technology, and so forth play the vital role of providing society with the ability to produce the goods and services of a modern economy. Accordingly, institutional investment involves bearing those risks in anticipation of enhanced expected returns realized through risk premiums. 
Unnecessary risks, such as holding poorly diversified portfolios, buying lottery tickets, and gambling in casinos, should not be expected to offer risk premiums or to generate enhanced expected returns. The following equation expresses the idea that capital investments generally receive expected returns from time value and risk bearing:

Expected return $=$ Reward for time + Rewards for systematic risks.

The reward for the time value of money is the riskless or risk-free interest rate: the yield or return on short-term risk-free government securities. The reward for systematic risk is the risk premium: the equilibrium quantity by which assets subjected to one or more systematic risks earn higher expected returns than otherwise-equivalent assets that are not subjected to those risks.

The Capital Asset Pricing Model. The foundation for benchmarking relative return assets is a statement of the relationship between risk and expected returns in a competitive market. The capital asset pricing model (CAPM), developed by Nobel Laureate William Sharpe and others in the 1960s, states that the expected return of an asset depends solely on that asset's market beta $(\beta)$, the riskless rate of return, and the expected return of the "market":

$$
E\left(R_{i}\right)=R_{f}+\beta_{i}\left[E\left(R_{m}\right)-R_{f}\right] .
$$

The intuition of the model is easy. An asset should earn the time value of money $\left(R_{f}\right)$ and a risk premium. The risk premium for asset $i$ is the product of its systematic risk $\left(\beta_{i}\right)$ and the expected reward in the market for being in a well-diversified portfolio of all available risky investments (i.e., the "market") rather than riskless bonds. That reward is the term $\left[E\left(R_{m}\right)-R_{f}\right]$.

The CAPM is an economic model. It is an equilibrium theory describing the expected returns of all assets as lying on a straight line connecting the riskless rate and the expected return of the market portfolio. The CAPM is based on numerous restrictive assumptions, the most important of which is that exposures to all the assets in the world are available to all investors in a single portfolio - that is, the market portfolio. In practice, in the United Kingdom, the market portfolio is proxied as the FTSE 100 Index or a total world stock portfolio; this simplification tends to obscure the theory's assumption that all assets are tradable.

The CAPM equation illustrates a highly simplified view of the concept of benchmarking. To the extent that the CAPM is an accurate description of 
security return expectations, it provides a benchmark for all assets in which each asset's benchmark should be determined based solely on its beta (given the riskless rate and the expected return of the market portfolio). But the CAPM does not fully and accurately describe the complex world of illiquid investments, tax differentials, transaction costs, and other market imperfections. The theoretical market portfolio of the CAPM is not investable or even observable. Therefore, other benchmarking approaches are needed.

\subsection{Benchmarking Absolute Return Investments}

Chapter 1 briefly introduced the terms absolute return to describe returns that are statistically independent of market indexes and relative returns to describe returns driven by or correlated with the returns of major asset classes. No clear index serves as an effective benchmark for all absolute return assets. The best benchmark depends on the investor's goals and circumstances. For example, an institution's choice of benchmark for a particular asset may be affected by its other assets (e.g., private real estate) or the nature of its liabilities.

The Allure of Absolute Return Assets. Absolute return assets include such funds as market-neutral funds and arbitrage funds pursuing investment strategies that generate returns that are uncorrelated with the returns of the assets in the markets in which the fund invests. Investors in these funds bear risk, but the risk is nonsystematic risk. According to the theory of informationally efficient markets, no manager should be able to consistently generate returns in excess of the riskless rate without bearing systematic risk. Therefore, in efficient markets, the expected return of all absolute return strategies should be equal to the riskless rate. As discussed in Chapter 1, however, markets tend to be efficiently inefficient, with enhanced risk-adjusted returns consistently available to those analysts who have the best investing skills.

Investors seek the best absolute return managers with the expectation that the risks will be unsystematic and will be diversified away to the extent that the investor holds numerous absolute return assets that are uncorrelated with each other. Simply put, absolute return funds offer the allure of earning premium returns for a portfolio without taking additional equity market risk, interest rate risk, or credit risk.

Absolute Return Benchmarks. In practice, absolute return benchmarks are typically fixed, such as 5\% annualized, or fixed in excess of the riskless rate or inflation, such as "real 3\%" (inflation plus 3\%). Investors selecting a fixed benchmark typically select one based on historical averages of assets with similar investment strategies or based on the minimum average return with which the investor would be satisfied. Fixed absolute return benchmarks 
should be adjusted to reflect the levels of riskless interest rates, which is why a fixed rate above the riskless rate or above inflation makes sense. In recent years, absolute return funds should not have been expected to earn the high returns available on cash in previous decades.

A simple benchmark for a fund without systematic risk is to add a risk premium to the riskless interest rate:

$\begin{aligned} & \text { Benchmark for } \\ & \text { absolute return product } i\end{aligned}=R_{f}+\begin{gathered}\text { Premium for } \\ \text { fund } i \text { 's specific risk. }\end{gathered}$

The risk premium should consider the following:

1. The size of the investment in the absolute return product relative to the total portfolio

2. The estimated (annualized) volatility of the absolute returns being considered

3. The correlations, if any, of the fund's return with the returns to other portfolio assets

4. The return-to-risk ratio of the investor's next best investment opportunity

Regarding the first two considerations, the greater the size of the investment or its volatility, the higher the risk premium required. The reason a large investment in a fund should require a higher risk premium is that numerous small investments provide better diversification than a few large investments. Similarly, positive correlations with other investments reduce the diversification benefits to the investment and should increase the risk premium required. Finally, the risk premium required on an investment should consider the opportunity cost of the capital. Simply put, if investors can achieve attractive risk/ return opportunities elsewhere, they should require a higher expected return.

Admittedly, this approach is a bit unscientific. It assumes that a risk premium is available in the market for taking nonsystematic risk when the CAPM says there isn't one. The alternative, however, is to assume a zero risk premium for taking nonsystematic risk, which has the weakness of producing an easy (numerically low) benchmark.

\subsection{Benchmarking and Performance Attribution}

Benchmarking is usually performed by comparing the actual return of an investment with a previously selected performance standard to generate a measure of how much an investment exceeded or fell short of the standard. Return attribution (i.e., performance attribution) is a more rigorous analysis 
and decomposition of past performance used to explain which factors caused the performance to be what it was.

When the risk exposures of a fund or other portfolio are static, benchmarking and performance attribution are generally similar: Both processes attempt to differentiate between performance attributable to prespecified risk exposures and those attributable to luck or skill. For example, the performance of a long-only actively managed large-cap equity portfolio would be contrasted with a passive large-cap index. The index would typically serve as a benchmark and also would be used in a performance attribution. The two processes would be similar.

When the risk exposures of a fund or other portfolio are dynamic, the issues of how to benchmark become more complex. For example, an actively managed fund with exposures changing between markets and between long and short exposures typically would be benchmarked against a peer group or comparison group of funds with similar investment mandates, such as managed futures, global macro, or various types of market-timing funds. The performance attribution process would attempt to determine the extent to which the performance could be explained by indexes related to the markets used by the fund manager.

The use of peer groups or comparison groups is discussed later in this chapter. The next two sections discuss the application of single-factor and multifactor pricing models to perform return attribution.

\subsection{Single-Factor Asset Pricing and Performance Attribution}

The CAPM is a special case of single-factor market model. More generally, single-factor models can be illustrated as follows based on realized returns:

$$
R_{i}=\alpha_{i}+\beta_{i}\left(R_{m}-R_{f}\right)+\varepsilon_{i} .
$$

Single-factor models differ from the CAPM in important ways. Singlefactor models can allow assets to have nonzero alpha estimates, whereas the CAPM assumes zero alpha for each asset. Conversely, the CAPM's intercept is equal to the risk-free rate as part of an equilibrium in which all investors select the same portfolio weights. Also, single-factor models merely indicate that the returns of all assets have a single factor in common. The CAPM specifies that that factor is the risk of being exposed to a cap-weighted market portfolio of all risky assets.

The greater flexibility of single-factor models relative to the CAPM allows them to be used for performance attribution and for estimation of realized 
alpha. The single-factor model forms the basis of an effective benchmarking model for investments with risks that can be substantially and consistently captured by its correlation with a single index (shown as $R_{m}$ even though the approach does not require that the index be the market index):

$$
\text { Benchmark return }=R_{f}+\beta_{i}\left(R_{m}-R_{f}\right) .
$$

A portfolio including a proportion $\beta_{i}$ invested in the market and a proportion $\left(1-\beta_{\mathrm{i}}\right)$ invested in the riskless asset can be used as a replicating portfolio of the fund being analyzed. Therefore, the corresponding combination of the return of the index and the riskless asset can serve as an effective benchmark. The difference between the return on this replicating portfolio and the actual portfolio can be attributed to the skills of the portfolio manager (or in the short run, perhaps luck).

For example, suppose the mean return on a fund is $10 \%$ over some historical period, its beta with respect to a broad investable index is 0.8 , the mean return on the index over that period is $11 \%$, and the riskless rate is $3 \%$. Then, a portfolio consisting of $80 \%$ in the index and $20 \%$ in the riskless asset would be the best replicating portfolio of this fund (i.e., the portfolio of indexes or benchmarks that most closely mimics the fund). The benchmark return on the fund would be $9.4 \%$, given by $3 \%+0.8(11 \%-3 \%)$. This means the fund had an alpha of $0.6 \%$ over the period measured, found by subtracting the $9.4 \%$ benchmark from the $10.0 \%$ mean return of the fund.

In traditional long-only equity investing, this benchmark model can be quite effective. In other words, when a single beta of a fund or other asset with respect to a particular index (not necessarily a proxy for the entire market) is used as an effective measure of its systematic risk or sensitivity to an index, Equation 15.5 can be used to estimate an effective benchmark return. An alternative, discussed in a later section, is to benchmark an asset's performance by comparing it with the returns of a peer group. Alternative investing tends to focus on multifactor models because the returns of many alternative assets are driven by multiple risk factors. That approach is discussed in the next section.

\subsection{Multifactor Asset Pricing and Performance Attribution}

Multifactor return models and multiple indexes are commonly used to benchmark alternative assets with returns that are driven by several sources of systematic risk. 
Multifactor Asset Pricing. At the core of multifactor return models for performance attribution is the assumption that an asset's returns can be substantially explained by the returns of two or more tradable and observable assets, such as indexes of various markets or asset classes. The following equation describes the realized returns of asset $i$ as being driven by or explained by multiple systematic risk factors (with factors denoted by the subscript $j$ ):

$$
R_{i}=\alpha_{i}+\Sigma \beta_{i, j}\left(R_{j}-R_{f}\right)+\varepsilon_{i},
$$

where $\beta_{i, j}$ indicates the responsiveness of asset $i$ to factor $j$. Because the return factors are assumed to represent tradable assets, $\alpha_{i}$ estimates the alpha of asset $i$ for the time period over which the returns are observed. The logic follows the previously discussed logic of the single-factor case in which factors can be used to form the best replicating portfolio of the asset's return. The excess of an asset's actual mean return over the return of its best replicating portfolio using tradable factors is a measure of its excess return (alpha).

The multifactor model is sometimes extended into a CAPM-like model to describe the expected returns of assets that are driven by multiple sources of systematic risk and that do not offer alpha:

$$
E\left(R_{i}\right)=R_{f}+\Sigma \beta_{i, j} \pi_{j},
$$

where $\pi_{j}$ indicates the expected return in excess of the riskless rate for bearing one unit of systematic risk $j$ (i.e., $\beta_{j}=1$ ). Equation 15.7 conveys the intuition behind benchmarking an asset's return by considering several risk premiums corresponding to multiple sources of risk (e.g., equity market risk, interest rate risk, credit risk, illiquidity risk). Any excess of the asset's mean return above its expected return would be an indication of alpha.

Return Expectations with Multiple Indexes. Multiple indexes are often used to benchmark alternative assets that are exposed to multiple markets rather than being driven primarily by correlation with a single market, such as a specific equity market. For example, a global macro fund (currency hedged) might have risk exposures to global equity markets, global bond markets, and commodity markets. An asset allocator may wish to formally or informally develop an unconditional expectation for the returns to the global macro fund. Its expected return should be linked to the risk premiums for all three markets, as Table $\mathbf{1 5 . 1}$ shows.

Combined with a riskless rate of $2 \%$, this asset pricing model would generate an expected return of $8 \%$ for the fund. If the analyst believed that the 
Table 15.1. Return Expectations with Multiple Indexes

\begin{tabular}{lccc}
\hline Market & Market Risk Premium & Fund Beta & Asset Risk Premium \\
\hline Equities & $6 \%$ & 0.5 & $3.0 \%$ \\
Bonds & 2 & 2.5 & 5.0 \\
Commodities & 1 & -2.0 & -2.0 \\
& & & $6.0 \%$ \\
\hline
\end{tabular}

fund manager's superior skill would drive the expected return to $11 \%$, then the analyst would be assigning an expected alpha of $3 \%$.

Return Attribution with Multiple Indexes. Asset pricing models also can be used to explain observed or realized returns as part of benchmarking past performance or to complete the more general task of performance attribution (i.e., return attribution). For example, suppose that the fund in the previous example generated an actual return of 15\% during a period in which the actual market returns were as shown in Table 15.2. ${ }^{46}$

In this example, the fund's actual return (15\%) exceeded the original model forecast of $8 \%$ and the analyst's forecast of $11 \%$ by substantial amounts, yet the return attribution analysis indicates that the fund's observed alpha was only $1 \%$. The performance attribution shows that the asset's risk exposures were well-timed and accounted for almost all of the high performance. In particular, the fund was heavily exposed to the bond market, which performed well during the measurement period.

Table 15.2. Return Attribution with Multiple Indexes

\begin{tabular}{lccc}
\hline \multicolumn{1}{c}{ Market } & Market Return & Fund Beta & $\begin{array}{c}\text { Asset Return from } \\
\text { Factor }\end{array}$ \\
\hline Equities & $-4 \%$ & 0.5 & $-2.0 \%$ \\
Bonds & 8 & 2.5 & 20.0 \\
Commodities & 2 & -2.0 & -4.0 \\
& & & $14.0 \%$ \\
& & Actual return of fund & $15.0 \%$ \\
& & Estimated alpha of fund & $1.0 \%$ \\
\hline
\end{tabular}

\footnotetext{
${ }^{46}$ This example can ignore the riskless rate because the betas were specifically chosen to sum to one and the riskless rate is included in the returns of each of the market indexes.
} 


\subsection{Benchmarking Relative Return Assets with Peer Groups}

When the systematic risks of an asset vary substantially through time or are otherwise difficult to measure, the most common method of benchmarking relative value funds is used: peer group (or comparison group) analysis. A similar approach is to rely on an index of returns published for a group of funds with similar investment mandates. The method is easy to apply and easy to interpret. A group of funds with similar investment mandates is identified, and their returns are averaged and used as a benchmark for the fund being analyzed. The fund's return can be described as a quantile-for example, "the fund's performance was in the top quartile" of comparable funds.

\subsection{Conclusion}

Performance or return attribution is designed to clarify the reasons for realized returns on various investments and is vital in the processes of monitoring investments and managing risk. A clear and explicit understanding of return expectations based on anticipated risk exposures for each investment is essential for constructing portfolios and forming portfolio return expectations.

Benchmarking is the process of developing a standard that can be used to evaluate the performance of a portfolio. In traditional investing, benchmarking of most assets is quite easy because of their relatively constant risk exposures and narrow mandates. For example, in long-only equity funds, a portfolio can be benchmarked against a single index or market factor that represents the performance of a pool of underlying equities that fall within the investment mandate of the portfolio. Alternatively, funds containing traditional assets can be benchmarked against peer groups or comparison groups of similarly managed portfolios. For example, fixed-income performance can be viewed relative to funds with similar durations and average credit ratings.

Almost by definition, the performance of most alternative investments cannot be closely associated with a single market index or a single risk measure. One of the main reasons for investing in most alternative assets is to generate returns that are absolute returns or at least are not strongly correlated with major asset classes or macroeconomic variables. Benchmarking alternatives with indexes or factors typically requires the use of multiple indexes or multiple factors. Benchmarking alternatives with peer groups should be performed with an understanding of the diverse range of risk exposures that often exists among most groups of hedge funds and other investment pools with similar mandates. 


\section{Portfolio Construction and Management}

This chapter discusses the key asset allocation issue of the method by which each asset class is weighted in an institutional portfolio of traditional and alternative assets. The analysis begins with a description of traditional (60/40 and liability-driven) asset allocation approaches and moves to a description of three major types of quantitative portfolio construction: risk budgeting, risk parity, and mean-variance optimization.

\subsection{The $60 / 40$ and Liability-Driven Asset Allocation Models}

Traditional investing typically has an extremely simple three-step structure:

1. An equity portfolio seeking to attain an attractive combination of risk and return is formed.

2. A bond portfolio seeking to attain attractive expected returns or yields based on tolerances for credit risk and interest rate risk is formed.

3. The mix between stocks and bonds is made based on the investor's goals, tolerance for risk, and financial circumstances.

In this discussion, bonds are defined as including cash and all other fixedincome products. The oft-cited traditional asset mix is $60 \%$ equities and $40 \%$ bonds. Institutions commonly depart from the classic 60/40 mix based primarily on risk tolerance, with higher equity allocations favored by institutions, such as endowments with long-term investment horizons and greater tolerance for risk.

Institutions with liability structures substantially determined by their line of business (e.g., insurance companies and pension funds) tend to make asset allocation decisions based on projections of the cash flows required by their liabilities. In the cases of insurance companies and pension funds, actuaries form projections of the cash needed to fund the liabilities. Asset portfolios, especially fixed-income allocations, are designed based in large part on the cash flow characteristics of the projected liability stream-hence, the description of the process as liability-driven asset allocation. The asset mix for individual investors is often based on age, although wealth level, attitude toward risk, financial sophistication, and so forth also are included in most asset allocation decisions. 
The introduction of alternative assets into the asset allocation decision raises many challenging issues. The percentage of an institutional portfolio allocated to alternative assets tends to be driven by the allocator's perception of the ability of alternative investments to provide benefits, such as enhanced diversification or expected return.

By what method does an asset allocator decide how much to allocate to alternative investments and how to divide that allocation among available classes of alternative assets? The following sections discuss popular methods.

\subsection{Naive or $1 / N$ Diversification}

Naive or $1 / N$ portfolio diversification refers to constructing a portfolio with equal allocations assigned to various assets, which often is accomplished within a particular asset class, such as hedge funds or equities. The theoretical justification for naive and $1 / N$ diversification is that the strategy minimizes portfolio risk when the opportunity set of available investments is made up of assets with equal volatilities and asset pairs with equal correlations.

Accurate forecasts of asset volatilities are difficult to make. Accurate forecasts of asset correlations can be prone to error. In practice, a $1 / N$ diversification strategy can make sense. For example, an asset allocator selecting among diverse hedge funds may be wise to make approximately equal allocations to each attractive fund.

But there are clear cases in which the $1 / N$ diversification makes no sense. For example, Chapter 9 briefly described the theoretical justification for using market weights in allocating among public equities. Consider two computer firms with stocks trading on the NASDAQ: Cray and Apple Inc. In 2017, Cray had outstanding stock worth approximately $\$ 700$ million (i.e., its market cap). Apple had a market cap of well over $\$ 700$ billion. So for every dollar of Cray stock, there was more than $\$ 1,000$ of Apple stock available for investment. Investors in general, and institutions in particular, cannot consistently select equal allocations to the two stocks because there simply is not enough Cray stock to equal the demand for Apple stock. Prices and expected returns must adjust such that the aggregate demand for shares of Apple is 1,000 times the aggregate demand for Cray. At that point, diversification is maximized for every investor by holding 1,000 times as much Apple stock as Cray stock. In theory, every investor in a perfect market attains the most attractive investment opportunities by using market weights as portfolio weights.

This theoretical discussion on individual stocks also applies to the weighting of asset classes and asset subclasses. In practice, preferences of investors differ. Their tax rates differ; they have different information sets, different expectations, different borrowing costs, different transaction costs, 
and different opportunities and access. For all of these reasons, the use of market weights as portfolio weights may not be optimal for each investor. Nevertheless, the theoretical optimum of using market weights as portfolio weights can serve as a valuable reference point from which to depart. Whether deciding between domestic and international equity allocations, between sovereign bonds and corporate bonds, between infrastructure funds and highyield bonds, or any other such decision, institutions should have a thoughtful process for determining portfolio weights.

\subsection{Risk Budgeting Portfolio Selection Models}

Risk budgeting addresses the issue of portfolio risk in asset allocation decisions by targeting specified levels of risk. Risk budgeting is best viewed as being part of an asset allocation process rather than being a standalone asset allocation process. Ultimately, risk budgeting is the process of placing constraints regarding various portfolio risks on the portfolio optimization process. Risk budgeting is often described as the setting of target risk levels (risk budgets) in which the asset allocator spends risk across risky investments (i.e., bears various risks judiciously for the sake of receiving benefits, such as higher expected return). The asset allocator can set a risk budget for the total portfolio and also can parse the acceptable amount of risk (the risk budget) into risk allocations for or within asset classes. Risk budgeting does not consider expected returns, although it typically is used in asset allocation frameworks that explicitly or implicitly consider expected returns.

For example, consider an asset allocator managing the total risk of a portfolio using the portfolio's annual volatility (i.e., standard deviation of returns). The allocator may set a target aggregate risk exposure of, say, $12 \%$ for the portfolio. Furthermore, the allocator may specify the portion of that risk that each asset subclass is allowed to exhibit. In this example, the risk budgeting approach drives the allocation decision with the goal of determining an optimal portfolio with a volatility of $12 \%$. The allocator constructs a portfolio that not only satisfies other goals but also keeps total risk (and perhaps risks of asset classes) at the target level. In more advanced applications, allocations to each asset subgroup are formed to equate each group's marginal contribution to that risk.

The goals of risk budgeting are typically twofold: (1) to organize and quantify the process of allocating portfolio risk exposures and (2) to identify portfolio allocations that bear risks as efficiently as possible relative to other goals determined by the asset allocator.

Defining Risk. A key aspect that differentiates risk budgeting approaches is the specification of the risk being budgeted. Common choices include total 
risk (as illustrated previously with volatility), systematic risk, multiple beta risks, value-at-risk (VaR), and active risk. Bearing risk is generally a burden that investors perform to extract benefits, such as higher expected returns. ${ }^{47}$ In this sense, risk budgeting mirrors a household's spending budget. Instead of spending money to gain utility, a risk budget "spends" risk across asset classes to obtain the best possible combination of rewards for risk taking.

Objectives. To identify an optimal portfolio, a model must optimize some objective, which is expressed mathematically as an objective function. Risk budgeting approaches are usually paired with some type of portfolio optimization (wherein the objective function is maximized). The most familiar kind of optimization, Markowitz mean-variance optimization (after economist Harry Markowitz), maximizes the expected return of the portfolio subject to a penalty for risk. Alternatively, optimization may force the marginal contribution of each asset class to total portfolio risk to be equal, or it may maximize diversification (e.g., minimize the sum of the squared portfolio weights). Risk budgeting can be a part of the risk/return optimization process if the allocation process explicitly sets risk constraints for each type of risk. Risk budgeting typically forces the portfolio to contain the budgeted or targeted levels of each type of risk-no more and no less.

Risk Buckets. Risk bucketing is often used to describe and implement a risk budgeting approach. A risk bucket is a constraint or target level for a particular type of risk. The risk-bucketing approach typically uses multiple risk buckets, such as an equity risk bucket, an interest rate risk bucket, or a credit risk bucket. The asset allocator determines the optimal (target) exposure of the portfolio to each type of risk, the maximum permissible exposure to each type of risk, or a combination of maximums and optimums. The allocator then "fills" each bucket with an appropriate level of risk by selecting assetsnoting that each asset likely has an impact on multiple risk buckets and other important characteristics, such as taxes or liquidity.

Other classifications of risk buckets may be used alongside or in place of these risk buckets. For example, the allocator may divide investments into active versus passive management and may impose target risk levels for each bucket. Some objective must identify the preferred solution from the myriad of possible solutions. If the approach budgets risk with an objective that is

\footnotetext{
${ }^{47}$ In some cases, an investor may not perceive bearing risk as a burden, such as when an investor with little need for liquidity invests in illiquid assets or when an investor with long-term liabilities matches the duration of those liabilities with long-duration assets. Nevertheless, most portfolio optimization at the margin is well described as tolerating risk for the purpose of obtaining higher expected returns.
} 
based on expected return or risk-adjusted return optimization, then the approach is a combination of the optimization approach and risk budgeting.

Diversification Effects and Marginal Risk. In relatively sophisticated applications, the amount of risk for various potential portfolios is estimated by accounting for the covariances or correlation coefficients between asset classes to adjust for the effects of diversification on total portfolio risk. In these more quantitative applications, the return correlations among asset classes or subclasses are estimated and inserted into computer programs that generate the total risk and the marginal contribution of each eligible investment to the risk of the portfolio. The computation of marginal risks typically sets the marginal contribution of each asset to the risk of the portfolio equal to each other or equal to the budgeted values for each asset.

Expected Returns. Although asset allocation approaches that use risk budgeting often do not explicitly attempt to optimize expected returns, the expected returns of some or all of the investments may enter into the process through such variables as alpha. For example, the asset allocator may include target levels of alpha or target allocations to alpha generators within the risk budgeting approach. Furthermore, once allocations to each asset class have been determined, the process may allow allocations within each asset class to be optimized with respect to expected return while constraining the marginal risk of each asset class to remain within its budgeted amount.

\subsection{Risk Parity}

Risk parity is an asset allocation approach that identifies asset allocations based on balancing the contribution of each asset to portfolio risk. As in the case of risk budgeting, allocations are driven primarily by risk, not by expected return. As in the case of risk budgeting, risk may be defined using any metric the allocator selects, such as volatility or VaR.

Risk parity approaches allocate assets to equate each asset's contribution to portfolio risk. Thus, in a stocks-versus-bonds allocation, bonds would be overweighted relative to stocks until the risk generated by the bond allocation equaled that of the stocks. By equating the risk contribution of each asset class to the risk of the portfolio, the approach could be viewed in the context of risk budgeting as generating an efficient way to budget the total risk among various asset classes. The result of risk parity is to ensure that each asset class contributes the same amount of risk to the portfolio-hence, the name risk parity. In this sense, the portfolio may be viewed as diversifying among risks such that each risk is equally weighted. 
Let's return to the classic decision to invest in just two asset classes: equities and bonds. Bonds tend to contain less risk than equities, so the "first" dollar of bonds contributes less risk than the first dollar of equities. Thus, in a risk parity approach, bonds are initially overweighted relative to equities based on the inverse of their risk relative to the inverse of the risk of equities.

Risk parity, however, does not simply weight each asset in inverse proportion to its volatility (as in an inverse volatility approach). Diversification effects are driven by correlations among the portfolio's assets. Although low-volatility assets tend to be overweighted in risk parity, their weights are tempered by the method's recognition that, as bonds and other low-risk assets begin to dominate a portfolio, their marginal risk contribution to the portfolio rises because of reduced diversification (i.e., concentrated positions in low-risk asset classes). Eventually, the high-risk asset classes, such as equities, gain attractiveness as diversifiers. The risk parity approach balances these effects to achieve allocations such that each asset class contributes the same amount to the portfolio's total risk.

The risk parity approach tends to discourage investing in riskier assets. Applications of the risk parity approach, therefore, tend to overweight fixedincome assets and underweight equities relative to traditional asset allocations. A focus on equating the contributions of each asset class to the total risk of the portfolio through the risk parity approach tends to drive a portfolio toward being low risk. Therefore, portfolios based on risk parity approaches tend to perform relatively poorly during periods when high-risk assets, such as equities, perform well.

Modern portfolio theory suggests that assets should be allocated according to their size - with each portfolio weight equal to the weight that each asset has in the market portfolio. The primary rationale for risk parity is that it tends to create relatively low-risk portfolios. These low-risk portfolios are criticized in periods of high equity returns for their relatively poor performance.

This criticism, however, ignores the potential role of leverage. The lowrisk portfolios generated by the risk parity approach can be leveraged to generate risk comparable to that of other portfolios. In other words, leverage (through margin or financial derivatives) allows the asset allocator to reach whatever level of total portfolio risk is desired. If the low-risk portfolios suggested by risk parity offer a higher return-to-risk ratio (i.e., Sharpe ratio), then the leveraged low-risk portfolios should be preferred to unleveraged high-risk portfolios. So the standard by which risk parity approaches should be evaluated relative to other asset allocation approaches is their risk/return tradeoffs, not their total return. This assumes, however, that the investor is willing 
and able to apply leverage and is able to withstand the risks and monitoring costs specific to leveraged portfolios.

\subsection{Moment Optimization Approaches}

A large and popular category of portfolio selection is moment optimization. In statistics, moments refers to mean, variance, skew, kurtosis, and other such descriptions of probability distributions. The most well-known investment return moment optimization approach is the mean-variance optimization pioneered by Markowitz. Mean-variance asset allocation models identify the portfolios offering the most attractive combinations of expected return and risk as measured by the portfolio's volatility or variance of returns.

The exclusive use of the means and variances (or volatilities) of the returns of assets to describe their return and risk is well justified when the return distributions of the prospective investments are normal. In fact, all higher moments of a distribution are functions of the mean and variance when the distribution is normal. Also, investors tend to be unanimous in their preference for higher mean returns and lower variances. Even for somewhat non-normal return distributions, mean-variance approaches may be suitable for liquid assets over relatively short time horizons and for modeling equity portfolios.

As discussed in Chapter 14, however, returns of many assets-in particular, many alternative assets-have return distributions that differ markedly from the normal distribution. Specifically, alternative assets tend to have negative skew (tail risk), positive skew (relatively large probabilities of huge gains, such as with venture capital), or both (excess kurtosis). Because most alternative investments tend to have potentially important skew and kurtosis properties (especially in the case of illiquid assets), such properties should be considered in portfolio allocations-especially in risk management. Therefore, some asset allocation models include "higher" moments in their optimization approaches (skew or kurtosis) especially for portfolios that include alternative investments.

Using these higher moments of skew and kurtosis in portfolio optimization approaches pose three primary problems: (1) The skew and kurtosis of individual securities vary substantially through time, making them hard to estimate and even harder to predict; (2) the preferences and aversions of investors with regard to higher moments, such as skew and kurtosis, are not clear or uniform; and (3) the relationships between the higher moments of the individual assets and the higher moments of a portfolio of those assets are complex. For example, the skew or kurtosis of a portfolio can differ markedly from the average skew and kurtosis of the portfolio's constituent assets. The result is that mean-variance approaches are the most common application of moment optimization portfolio modeling. 
The mean-variance approach requires the asset allocator to provide estimates of the expected returns and variances (or volatilities) of each asset as well as the correlations between the returns of every possible pair of assets. The major problem with mean-variance optimization of a portfolio is that the optimized weights of each asset tend to take on more extreme values than most institutional investors seek. Also, portfolios based on weights from a traditional mean-variance optimization do not consistently generate higher mean returns and lower volatilities. This inconsistency is due to the large differences between the estimated inputs (means, volatilities, and correlations) and the values that subsequently occur in the markets. Worse, the extreme portfolio weights using unconstrained mean-variance optimization approaches tend to generate extreme (good or bad) subsequent returns as a result of relatively poor diversification.

Extensive work has been performed to address the problems of unconstrained mean-variance portfolio optimization models. One solution to this challenge of extreme optimized portfolio weights is to constrain each asset weight with a minimum weight (such as zero in the absence of short selling) and an arbitrary maximum weight (to prevent concentration). Similarly, constraints may be placed on combinations of assets. This solution is not completely satisfactory because the optimized weights tend to be precisely at the constraints, meaning that the person setting the constraints is, in effect, designing the portfolio.

The other major problem with unconstrained mean-variance portfolio optimization is that the model's suggested asset weights are highly sensitive to the expected returns, variances, and (to a much lesser extent) the correlation coefficients estimated and used as inputs to the model. For example, the model tends to assign very high portfolio weights to those assets with higher estimated expected returns. The resulting portfolio solutions contain extreme portfolio weights that are driven more by estimation error in the mean return than by the effects of diversification.

Improvements on Markowitz's mean-variance approach usually temper the model's tendency to generate extreme portfolio weights based on estimation errors in the means, volatilities, and correlations. The Black-Litterman model ${ }^{48}$ is a pioneering example of a financial engineering method used to reduce extreme portfolio weights. The Black-Litterman approach imposes relationships among the estimated mean returns that align more closely with modern portfolio theory (the capital asset pricing model). By tempering the extreme inputs, the portfolio allocator can generate portfolio weights that are closer to market weights without losing the entire benefit of the optimization process.

\footnotetext{
${ }^{48}$ See Fischer Black and Robert Litterman, "Global Portfolio Optimization," Financial Analysts Journal 48, no. 5 (1992): 28-43.
} 
The philosophy of optimizing portfolios by examining total portfolio mean return and volatility is attractive. Challenges remain, however, in implementing mean-variance optimization approaches as a practical asset allocation tool. Other approaches based less on theory, such as risk budgeting, often are viewed as being more practical and valuable.

\subsection{Conclusion}

This chapter discussed formal approaches to the challenge of allocating to asset classes within a portfolio of traditional and alternative assets. No one approach is clearly superior or widely used. Chapter 17 discusses the endowment modelan informal asset allocation strategy that reflects asset allocation decisions among the endowments of major academic institutions. The endowment model is an example of high allocations to alternatives and may be viewed as a reference point for other institutions seeking high returns. Many institutions may prefer to blend a traditional portfolio allocation with the potentially extreme allocations to alternatives suggested by the endowment model. This blending of the endowment model with a traditional asset-only model may be based on an institution's needs, goals, experience, and resources. 


\section{The Case for Investing in Alternatives}

Chapter 1 discussed three primary reasons to invest in alternative assets: (1) achieving reduced risk through diversification, (2) achieving increased riskadjusted returns through alpha, and (3) avoiding obsolescence and perhaps missing any potential first-mover advantages. This chapter expands that list of reasons for including alternative investments in an institutional portfolio containing traditional assets.

\subsection{Valuation Levels of Traditional Assets}

The appropriateness of alternative assets for a particular portfolio and the size of any allocation to alternative assets should be driven in part by the valuation levels of traditional assets and, therefore, the relative attractiveness of traditional and alternative assets.

Traditional equities have enjoyed astounding performance success in the United States for well over a century, and they have enjoyed similar success in most other industrial nations since the mid-20th century. Some financial economists have been puzzled by the high average return of public equities when compared with other investments (i.e., the equity risk premium puzzle). Equities have been much more rewarding than certain types of formal macroeconomic models predict. The relatively high valuation levels of public equities reached in the decade since the financial crisis of 2007-2009 suggest that market prices may have adjusted such that prospective equity returns during the coming decades will be lower.

Consider the decade since the financial crisis, when stock values reached dramatic new highs and equity valuation measures, such as $\mathrm{P} / \mathrm{E}$ ratios, neared all-time highs. During the same periods, bonds posted consistently high returns and bond yields fell to historic lows, similarly raising questions regarding their prospective returns. Alternative assets, such as hedge funds and commodities, generally posted disappointing returns, however. It is during these periods of long-term and large and persistent divergence in performance between traditional and alternative assets that both asset groups should be included in welldiversified portfolios, despite the recent pain of one asset group (in this case, alternatives) and the seemingly unending good fortune of the other.

This discussion raises questions about whether markets follow cycles or trends. Are the values of traditional assets driven in predictable ways by the supply and demand for capital and cycles of economic activity and growth? Is there a cycle to the supply and demand for capital that affects the returns on 
skill-based strategies, for example, because such returns are needed to maintain efficiently inefficient markets? Do commodity returns respond to longterm cycles generated by supply-and-demand imbalances and the length of time necessary to ramp up production?

Ultimately, decisions regarding portfolio composition should be linked to the financial needs, goals, and circumstances of the investor. Most institutions seek portfolios that meet their requirements for income and expected growth while doing so with as little downside risk as possible. To drive market prices toward efficient valuation levels, however, at least some investors must assess the relative attractiveness of alternative investments and traditional investments. These investors adjust their asset allocations in response to perceived valuation extremes. Presumably, those investors who are best able to discern these opportunities will be rewarded in the long run.

\subsection{The Endowment Model}

The endowment model generally is associated with David Swensen's recommendations as chief investment officer of Yale University, as revealed in his book Pioneering Portfolio Management. ${ }^{49}$ The asset allocations deployed by many of the largest university endowments reflect Swensen's and Yale's influence. The endowment model is an approach to asset allocation deemed by a group of thought leaders to be appropriate for major endowments and other investors with substantial wealth and long-term time horizons.

The salient features of the endowment model are that the allocations

- favor illiquid investments, such as private equity over public equity;

- favor alternative investments, such as hedge funds and natural resources;

- underweight most or all types of liquid bonds; and

- favor real assets for inflation protection against rising nominal expenditures.

The endowment model tends to be aggressive in holding positions that are illiquid and relatively high risk, based on the idea that the endowment can thereby earn higher long-term returns. Advocates contend that most major endowments are in a better position to tolerate illiquidity and short-term portfolio fluctuations than other investors, because of their reduced immediate cash flow needs and thus their ability to invest for the long term.

The goal of the endowment model is to earn large risk premiums and, in some cases, to generate alpha by exploiting pricing inefficiencies through

\footnotetext{
${ }^{49}$ David F. Swensen, Pioneering Portfolio Management: An Unconventional Approach to Institutional Investment (New York: Free Press, 2000).
} 
superior investment selection. Proponents of the endowment model tend to view liquid bonds as offering little added return while subjecting investors to huge losses in the event of a credit crisis or rise in interest rates. The case for institutional investing in alternative investments is supported by the longterm success of major university endowments in using their ability to tolerate liquidity risks to generate higher long-term returns.

The endowment model can be viewed as embracing a relatively radical asset allocation policy that differs markedly from a traditional $60 \%$ public equity $/ 40 \%$ bond mix. The largest and most risk-tolerant endowments invested $50 \%$ or more of their assets in alternatives in the years after the financial crisis, with those allocations emphasizing hedge funds and private equity.

Not all institutions share the risk tolerance of major endowments. Furthermore, it may be argued that many major endowments may have connections with alumni and successful managers who enhance their ability to generate successful returns. These special relationships usually are not available to other endowment managers.

For less risk-tolerant institutions, the endowment model can serve as the aggressive end of a spectrum regarding potential alternative asset allocations (with the conservative end formed by institutions with a traditional $60 \%$ equity $/ 40 \%$ bonds mix). Institutions seeking a middle ground can select a portfolio between the traditional and endowment models that suits their tolerance of risks and their perceived ability to identify alpha.

\subsection{Enhanced Efficient Frontiers: Broader Beta Coverage}

Traditional asset allocations are often heavily exposed to the public equity and investment-grade debt markets. Alternative assets can be used to increase exposure to a broader set of betas, including private equity, infrastructure, commodities, distressed debt, private real estate, natural resources, and intellectual property. This broader beta coverage reduces total risk because the systematic risk factors (beta) are imperfectly correlated. These diverse beta exposures should offer risk premiums that are missed by investors who concentrate their positions in traditional assets.

Factor investing is the process of selecting stocks, bonds, and other assets to diversify across the factors that drive asset returns and may offer enhanced returns. In equity markets, popular factors include value, size, momentum, and quality. In other markets, popular factors can include liquidity, credit, real rates, inflation rates, and economic growth.

Figure 17.1 illustrates the improved opportunities for lower risk by diversifying global systematic risks or factors. Reduced risk from broader beta coverage can lower overall portfolio risk while maintaining expected returns. 
Figure 17.1. Diversification through Broader Beta Coverage

Expected Return

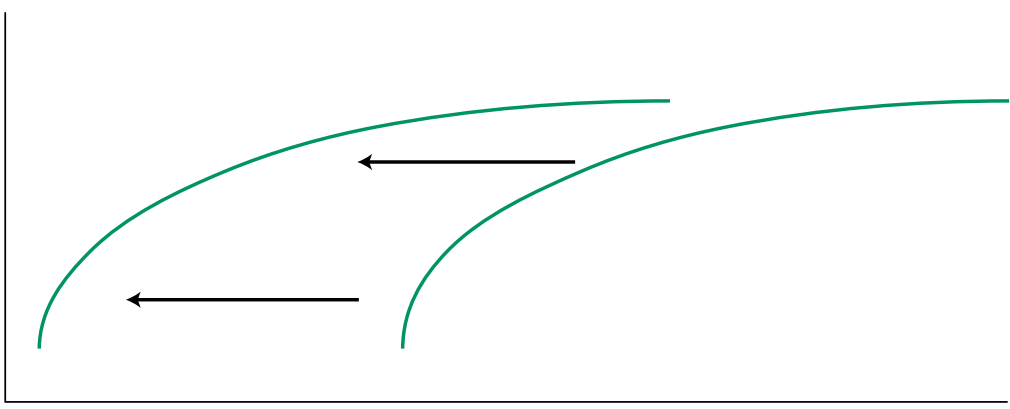

Total Portfolio Risk

More broadly diversified portfolios contain less risk and thus enable greater use of leverage than can safely be achieved with poorly diversified portfolios. Therefore, well-diversified portfolios with leverage can offer higher expected returns than poorly diversified, unlevered portfolios that contain the same risk.

\subsection{Enhanced Efficient Frontiers: Alpha, Illiquidity, and Skill-Based Premiums}

Chapter 1 briefly discussed the concept of "efficiently inefficient"-the theory that markets must offer some added return as an incentive for investors to gather, analyze, and implement skill-based strategies (as well as to bear the added idiosyncratic risk of skill-based strategies relative to passive indexers). For a market to be efficiently inefficient, there must be a supply of investment capital that actively seeks higher risk-adjusted returns through the gathering and analysis of information related to the pricing of each asset. In other words, it requires that active managers exist and be well funded. Sophisticated fund managers compete to be among the managers who consistently generate superior risk-adjusted returns. Investors who are able to identify and gain access to these managers can enhance their opportunities as illustrated in Figure 17.2.

Traditional institutional portfolios tend to have relatively modest allocations to skill-based and illiquid holdings. Therefore, these portfolios may fail to diversify across a larger set of investment opportunities.

Another potential opportunity for enhanced return is judicious selection of systematic risk exposures. As discussed in the previous section, factor investing is the process of selecting target portfolio exposures to various factors. Skill-based asset allocations exposed to a particular equity market may 
Figure 17.2. Enhanced Return through Alpha and Other Premiums

Expected Return

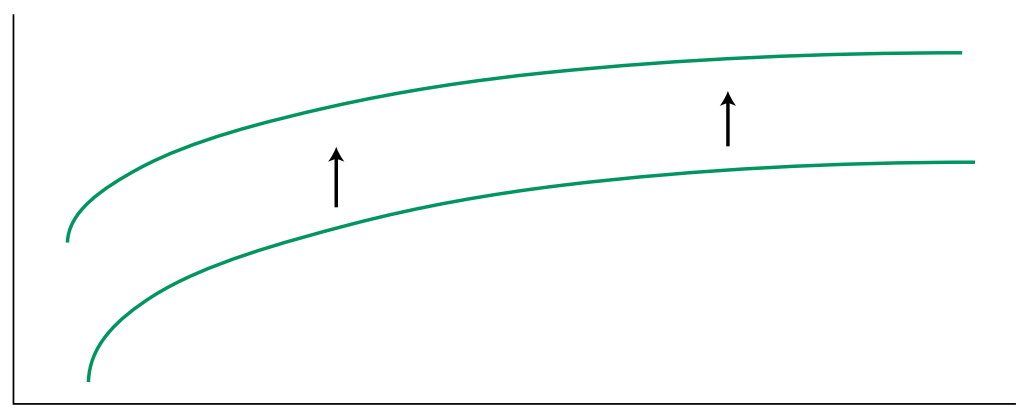

Total Portfolio Risk

seek relatively large or small exposures to the factors that drive equity returns, including value, size, momentum, quality, and low volatility. Alternative investments, such as hedge funds, can facilitate skilled management of diverse beta exposures through the ability to use short positions and leverage and, in doing so, may enhance expected return.

Illiquidity is undesirable to an investor. Investors in private equity during the recent financial crisis not only experienced huge declines in the liquidation values of some of their private equity investments but also had to contribute additional capital to those investments to meet capital calls. Investors with long investment horizons and high tolerance for short-term risk, however, should be able to earn illiquidity risk premiums in the long run by diversifying into illiquid investments, including private equity, private developed real estate, and real assets, such as land.

\subsection{Conclusion}

The proposition that institutional asset allocation should select from a static set of asset classes traditionally viewed as institutional quality-such as public equities, corporate bonds, government bonds, and cash—ignores the history of dramatic changes in institutional investing over the past 150 years. More than a century ago, investments in common stocks and corporate bonds (at least those without backing by substantial tangible collateral) were not considered to be mainstream institutional investments. A half-century ago, small stocks and below-investment-grade bonds were viewed as inappropriate for institutions seeking prudent investments. 
Alternative investing is the process of using an expanded set of investment opportunities relative to those most commonly adopted in recent years by conservative institutional investors. In recent years, alternative institutional investing has been associated with hedge funds, real assets, private equity, and structured products. Those institutions that led the innovations often enjoyed a first mover advantage of enhanced returns with reduced risk.

Figure 17.3 illustrates the two goals of an investment program that includes both traditional and alternative investments: opportunities to increase expected return while also reducing long-term risk. The inclusion of alternative assets in an institutional portfolio requires familiarity with a greatly expanded set of assets, investing tools, investment methods, and requirements for due diligence. The improved beta coverage, diversification, and extra sources of enhanced expected return offered by alternative assets, however, can make the inclusion of alternative assets into many institutional portfolios a prudent decision.

Figure 17.3. Enhanced Return and Reduced Risk Achieved by Adding Alternatives to a Traditional Portfolio

Expected Return

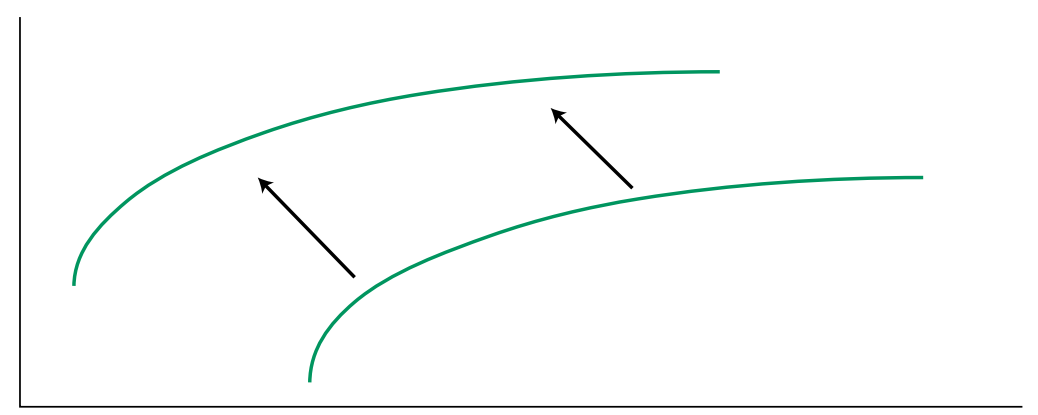

Total Portfolio Risk 



\section{The CFA Institute \\ Research Foundation \\ Board of Trustees \\ 2017-2018}

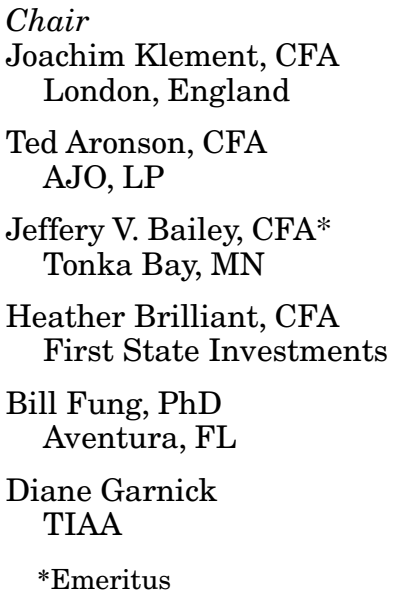
JT Grier, CFA
Virginia Retirement
System
Joanne Hill
ProShares

George R. Hoguet, CFA

Chesham Investments, LLC

\section{Jason Hsu, PhD}

Rayliant Global Advisors

Vikram Kuriyan, CFA, PhD

Indian School of

Business
Fred Lebel, CFA

HFS Hedge Fund

Selection S.A.

Mauro Miranda, CFA CFA Society Brazil

Sophie Palmer, CFA Jarislowsky Fraser

Paul Smith, CFA CFA Institute

\section{Officers and Directors}

\section{Executive Director \\ Bud Haslett, CFA \\ CFA Institute}

Gary P. Brinson Director of Research

Laurence B. Siegel

Blue Moon Communications
Secretary

Jessica Critzer

CFA Institute

Treasurer

Kim Maynard

CFA Institute

\section{CFA Institute Research Foundation Review Board}

William J. Bernstein

Efficient Frontier

Advisors

Elroy Dimson

London Business School

Stephen Figlewski

New York University

William N. Goetzmann

Yale School of

Management

Elizabeth R. Hilpman

Barlow Partners, Inc.
Paul D. Kaplan, CFA

Morningstar, Inc.

Robert E. Kiernan III Advanced Portfolio

Management

Andrew W. Lo

Massachusetts Institute of Technology

Alan Marcus

Boston College

Paul O'Connell

FDO Partners
Krishna Ramaswamy

University of

Pennsylvania

Andrew Rudd Advisor Software, Inc.

Stephen Sexauer Allianz Global Investors Solutions

Lee R. Thomas

Pacific Investment

Management Company 


\section{Named Endowments}

CFA Institute Research Foundation acknowledges with sincere gratitude the generous contributions of the Named Endowment participants listed below.

Gifts of at least US $\$ 100,000$ qualify donors for membership in the Named Endowment category, which recognizes in perpetuity the commitment toward unbiased, practitioneroriented, relevant research that these firms and individuals have expressed through their generous support of CFA Institute Research Foundation.

Ameritech

Anonymous

Robert D. Arnott

Theodore R. Aronson, CFA

Asahi Mutual Life Insurance Company

Batterymarch Financial Management

Boston Company

Boston Partners Asset Management, L.P.

Gary P. Brinson, CFA

Brinson Partners, Inc.

Capital Group International, Inc.

Concord Capital Management

Dai-Ichi Life Company

Daiwa Securities

Mr. and Mrs. Jeffrey Diermeier

Gifford Fong Associates

Investment Counsel Association of America, Inc.

Jacobs Levy Equity Management John A. Gunn, CFA

Jon L. Hagler Foundation

Long-Term Credit Bank of Japan, Ltd.

Lynch, Jones \& Ryan, LLC

Meiji Mutual Life Insurance Company
Miller Anderson \& Sherrerd, LLP

John B. Neff

Nikko Securities Co., Ltd.

Nippon Life Insurance Company of Japan

Nomura Securities Co., Ltd.

Payden \& Rygel

Provident National Bank

Frank K. Reilly, CFA

Salomon Brothers

Sassoon Holdings Pte. Ltd.

Scudder Stevens \& Clark

Security Analysts Association of Japan

Shaw Data Securities, Inc.

Sit Investment Associates, Inc.

Standish, Ayer \& Wood, Inc.

State Farm Insurance Company

Sumitomo Life America, Inc.

T. Rowe Price Associates, Inc.

Templeton Investment Counsel Inc.

Frank Trainer, CFA

Travelers Insurance Co.

USF\&G Companies

Yamaichi Securities Co., Ltd.

\section{Senior Research Fellows}

Financial Services Analyst Association

For more on upcoming CFA Institute Research Foundation

publications and webcasts, please visit

www.cfainstitute.org/learning/foundation.

CFA Institute Research Foundation monographs are online at www.cfapubs.org. 


\section{CFA INSTITUTE RESEARCH FOUNDATION CONTRIBUTION FORM}

$\square$ Yes, I want CFA Institute Research Foundation to continue to fund innovative research that advances the investment management profession. Please accept my tax-deductible contribution at the following level:

Thought Leadership Circle. US $\$ 1,000,000$ or more

Named Endowment US $\$ 100,000$ to US\$999,999

Research Fellow US $\$ 10,000$ to US\$99,999

Contributing Donor. US $\$ 1,000$ to US $\$ 9,999$

Friend Up to US\$999

I would like to donate US\$

My check is enclosed (payable to CFA Institute Research Foundation).

$\square$ I would like to donate appreciated securities (send me information).

$\square$ Please charge my donation to my credit card.

$\square$ VISA $\square$ MC $\square$ Amex $\square$ Diners

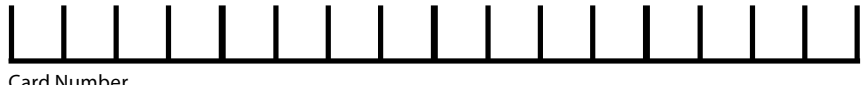

Card Number

Expiration Date

Name on card PLEASE PRINT

$\square$ Corporate Card

$\square$ Personal Card

Signature

$\square$ This is a pledge. Please bill me for my donation of US\$

I would like recognition of my donation to be:

$\square$ Individual donation $\square$ Corporate donation $\square$ Different individual

PLEASE PRINT NAME OR COMPANY NAME AS YOU WOULD LIKE IT TO APPEAR

PLEASE PRINT $\square$ Mr. $\square$ Mrs. $\square$ Ms. $\quad$ MEMBER NUMBER

\begin{tabular}{lcc}
\hline Last Name (Family Name) & First (Given Name) & Middle Initial \\
\hline Title & & \\
\end{tabular}

Address

\begin{tabular}{lll}
\hline City & State/Province & Country ZIP/Postal Code
\end{tabular}

Please mail this completed form with your contribution to:

CFA Institute Research Foundation • P.O. Box 2082

Charlottesville, VA 22902-2082 USA

For more on CFA Institute Research Foundation, please visit www.cfainstitute.org/learning/foundation/Pages/index.aspx. 
$=\mathbb{N} / 1 /$ CFA Institute

Research

Foundation

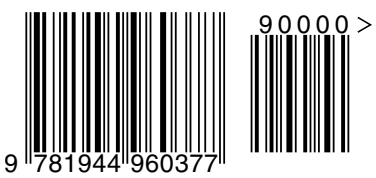

